\title{
Lanthanide-doped semiconductor nanocrystals: electronic structures and optical properties
}

\author{
Wenqin Luo ${ }^{1,2}$, Yongsheng Liu ${ }^{1}$ and Xueyuan Chen ${ }^{1 *}$
}

Trivalent lanthanide $\left(\mathrm{Ln}^{3+}\right)$ ions doped semiconductor nanomaterials have recently attracted considerable attention owing to their distinct optical properties and their important applications in diverse fields such as optoelectronic devices, flat plane displays and luminescent biolabels. This review provides a comprehensive survey of the latest advances in the synthesis, electronic structures and optical spectra of $\mathrm{Ln}^{3+}$ ions in wide band-gap semiconductor nanocrystals (SNCs). In particular, we highlight the general wet-chemical strategies to introduce $\mathrm{Ln}^{3+}$ ions into host lattices, the local environments as well as the sensitization mechanism of $\mathrm{Ln}^{3+}$ in SNCs. The energy levels and crystal-field parameters of $\mathrm{Ln}^{3+}$ in various SNCs determined from energy-level-fitting are summarized, which is of vital importance to understanding the optical properties of $\mathrm{Ln}^{3+}$ ions in SNCs. Finally, some future prospects and challenges in this rapidly growing field are also proposed.

\section{INTRODUCTION}

Trivalent lanthanide ions $\left(\mathrm{Ln}^{3+}\right)$ possess fascinating optical properties and have been utilized in solid-state lasers, luminescent lamps, optical fibers, flat displays and other photonic devices for decades [1-10]. The emissions of $\mathrm{Ln}^{3+}$ ions mostly come from their intra $4 \mathrm{f}$ electronic transitions. Among $\mathrm{Ln}^{3+}$ series from $\mathrm{La}^{3+}$ to $\mathrm{Lu}^{3+}$, each has its unique electronic structure and characteristic spectral signature, and thus multiple color outputs from visible to near infrared (NIR) can be achieved by doping with different $\mathrm{Ln}^{3+}$ ions, which is appealing for their technology applications. Moreover, because the 4 f orbitals of $\mathrm{Ln}^{3+}$ are shielded by the filled $5 s^{2} 5 p^{6}$ sub-shells and prevented from the interaction with ligands, the emission features of $\mathrm{Ln}^{3+}$ vary little at different hosts. It should be noted that the inter-configuration of $4 \mathrm{f}$ electrons are parity forbidden, thus the photoluminescence (PL) of $\mathrm{Ln}^{3+}$ ions in various hosts is usually featured by sharp lines, long luminescent lifetime, and large Stokes/ anti-Stokes shifts, which render the $\mathrm{Ln}^{3+}$ ions applicable in the fields of sensitive optical detectors and pure-color solid state lightings $[11,12]$. Nevertheless, due to the parity forbidden transition nature, the absorption cross-section of $\mathrm{f}$ - $\mathrm{f}$ transition is small and usually high power light sources such as laser are needed to excite the $\mathrm{Ln}^{3+}$ ions. The ability to excite $\mathrm{Ln}^{3+}$ ions efficiently in a broad spectral range is strongly desired for realizing their full potentials in signaling and lighting applications. To improve the excitation efficiency of $\mathrm{Ln}^{3+}$, sensitization is an efficient way to avoid the direct excitation of the $\mathrm{Ln}^{3+}$. Charge transfer, electronics transfer from ligand ground states (e.g., $\mathrm{O}$ 1s) to the $\mathrm{Ln}^{3+}$ excited states, has proved to be an efficient means to achieve intense $\mathrm{Ln}^{3+}$ emissions, due to its large band absorption cross-section. By employing this strategy, commercial phosphor $\mathrm{Y}_{2} \mathrm{O}_{3}: \mathrm{Eu}^{3+}$ has been demonstrated to be an excellent red phosphor, which can be effectively excited at Eu-O charge transfer band at $255 \mathrm{~nm}$. Another strategy for efficient sensitization of $\mathrm{Ln}^{3+}$ is via the energy transfer (ET) from semiconductor nanocrystals (SNCs), which generally possess large absorption cross-section for $\mathrm{Ln}^{3+}$ excited states. Moreover, it is known that the exciton Bohr radius of semiconductors is much larger than that of insulators [13], which could result in pronounced quantum confinement effect for small nanocrystals (NCs) (e.g., 2-10 $\mathrm{nm}$ for $\mathrm{In}_{2} \mathrm{O}_{3}, \mathrm{ZnO}$ and $\mathrm{TiO}_{2}$ ). As a result, the optical properties of $\mathrm{Ln}^{3+}$ incorporated in SNCs could be tailored via size control or bandgap engineering, which is very attractive in fabricating a nano-device for technological applications. It is anticipated that the luminescence of $\mathrm{Ln}^{3+}$ ions can be efficiently sensitized via the energy transfer from the excited host to $\mathrm{Ln}^{3+}$, which thereby overcomes the inefficient direct absorptions of the parity forbidden $4 \mathrm{f}-4 \mathrm{f}$ transitions of $\mathrm{Ln}^{3+}$ ions (Fig. 1). To realize the efficient energy transfer and intense $\mathrm{Ln}^{3+} \mathrm{PL}$, the successful incorporation of $\mathrm{Ln}^{3+}$ into the lattices of SNCs is of utmost importance, which still remains a great challenge via conventional wet-chemical methods especially for some widely used wide bandgap

\footnotetext{
Key Laboratory of Optoelectronic Materials Chemistry and Physics, Fujian Institute of Research on the Structure of Matter, Chinese Academy of Sciences, Fuzhou 350002, China

${ }^{2}$ College of Life Sciences, Huzhou University, Huzhou 313000, China

Corresponding author (email: xchen@fjirsm.ac.cn)
} 


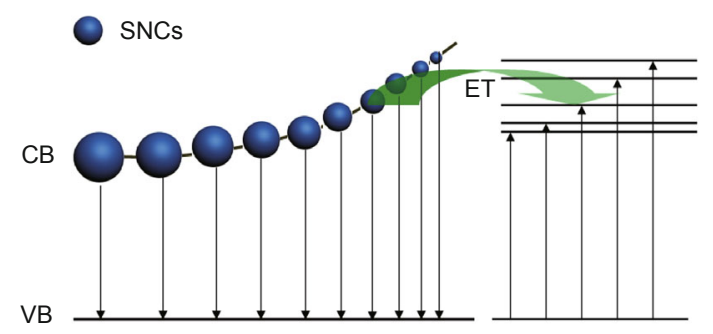

Figure 1 A schematic illustration of quantum size effect on the bandgap energy of SNCs and energy transfer mechanism from SNCs to $\mathrm{Ln}^{3+}$ ions.

SNCs with large discrepancy of ionic radius and charge between $\mathrm{Ln}^{3+}$ and the host cations such as $\mathrm{ZnO}, \mathrm{ZnS}, \mathrm{CdS}$ [14]. In spite of this, considerable efforts have been devoted to the synthesis and optical property tuning in $\mathrm{Ln}^{3+}$ ions doped SNCs in the past few years [15-34]. Although, in most cases reported in the literature [35-39], only broad emission lines of $\mathrm{Ln}^{3+}$ ions located at the surface of SNCs were obtained, it proved that $\mathrm{Ln}^{3+}$ can be incorporated into the SNC lattice site via judiciously designing the synthesis strategies. Diverse $\mathrm{Ln}^{3+}$ ions have been successfully embedded into the lattices of SNCs such as $\mathrm{ZnO}, \mathrm{TiO}_{2}, \mathrm{SnO}_{2}$, $\mathrm{In}_{2} \mathrm{O}_{3}$, and $\mathrm{Ga}_{2} \mathrm{O}_{3}$ via various wet-chemical methods. As a result, intense and sharp emission lines of $\mathrm{Ln}^{3+}$ ions ranging from visible to NIR regions were realized in most SNCs via host sensitization. Moreover, multiple sites of $\mathrm{Ln}^{3+}$ with different crystal-field (CF) surroundings could be explicitly identified in various SNCs by using site-selective and time-resolved spectroscopy. Based on the abundant experimental CF levels of multiplets of $\mathrm{Ln}^{3+}$ ions within the SNC lattice sites identified from the highly resolved and intense emission and excitation lines of $\mathrm{Ln}^{3+}$, many efforts had been devoted to the energy level fitting and thus to explore the CF surroundings experienced by the $\mathrm{Ln}^{3+}$ ions. As a consequence, the obtained CF parameters are particularly important in optimizing optical performance for further technological applications of the materials.

Previously, the optical properties of $\mathrm{Ln}^{3+}$ in SNCs were occasionally summarized in several reviews [40-43]. However, a comprehensive survey covering the preparation strategy, optical properties, and electronic structures of $\mathrm{Ln}^{3+}$ in SNCs is still lacking so far. This review mainly concentrates on the electronic structures and optical properties of $\mathrm{Ln}^{3+}$ ions doped in SNCs that were synthesized by using various methods. It is organized as follows. First, the most representative synthetic strategies to prepare SNCs with $\mathrm{Ln}^{3+}$ embedded in the host lattice site are briefly introduced. Then, the CF structures of $\mathrm{Ln}^{3+}$ ions in SNC lattice sites derived from the energy level fitting are summarized and discussed. Finally, the doping locations and the host sensitized luminescence of $\mathrm{Ln}^{3+}$ ions in SNCs are probed and revealed.

\section{SYNTHESIS TECHNIQUES}

To realize efficient energy transfer from host materials to $\mathrm{Ln}^{3+}$ ions, the distance between energy donor and acceptor should be small enough (usually less than $5 \mathrm{~nm}$ ). To meet this requirement, it is essential to incorporate $\mathrm{Ln}^{3+}$ ions into the SNCs lattice. It is well known that the dopant situation in a host is closely related to the ionic radius and charge difference between dopant ions and host cations. For III-VI SNCs, such as $\operatorname{In}_{2} \mathrm{O}_{3}$ and $\mathrm{Ga}_{2} \mathrm{O}_{3}$, the $\mathrm{Ln}^{3+}$ dopant ions and host cations have similar ionic radius and the same charge. Thus $\mathrm{In}_{2} \mathrm{O}_{3}$ SNCs with $\mathrm{Ln}^{3+}$ ions embedded in the host lattice can be easily obtained by chemical methods [44]. However, for II-VI and IV-VI SNCs, such as ZnO, ZnS, and $\mathrm{TiO}_{2}$, due to the large mismatch in ionic radius between $\mathrm{Ln}^{3+}$ and host ions (e.g., $0.086-0.103 \mathrm{~nm} v s .0 .061 \mathrm{~nm}$ for $\mathrm{Ti}^{4+}$, for coordination number VI) [45] and their charge imbalance, it is notoriously difficult to incorporate $\mathrm{Ln}^{3+}$ ions into the SNCs lattice through conventional chemical methods. To this end, diverse chemical and physical methods had been attempted to synthesize $\mathrm{Ln}^{3+}$ doped SNCs as briefly reviewed in Table 1 . In some special cases, it was found that, $\mathrm{Ln}^{3+}$ ions could be effectively incorporated into a metastable lattice site of SNCs usually accompanied with lattice distortion and charge compensation.

To effectively incorporate $\mathrm{Ln}^{3+}$ ions into SNC lattice site via wet chemical approach, it is essential to retain the dopant ions within the SNC matrix during the nanocrystal growth process. Sol-gel process has proved to be an effective way to capture the $\mathrm{Ln}^{3+}$ ions. During the hydrolysis process of the precursor molecules, $\mathrm{Ln}^{3+}$ ions can be readily bonded to the host ionic ions via oxygen bridges. With the particle growth, $\mathrm{Ln}^{3+}$ ions can be embedded into the host matrix (Fig. 2a). However, it should be noted that the as-prepared NCs by sol-gel method are usually in amorphous nature, and post heat treatment is thus needed to yield crystallized samples. In this case, lanthanide ions are thermally metastable in the glassy host matrix, and careful heat treatment should be conducted since high-temperature annealing may result in self-purification process and thus $\mathrm{Ln}^{3+}$ ions might be expelled from the crystallized lattice and form separated phase [46].

Another approach to increase the contents of $\mathrm{Ln}^{3+}$ ions in the host crystal lattice is shell overgrowth, which was successfully applied to increase doping level of transition metal and $\mathrm{Ln}^{3+}$ ions in SNCs [168-171]. By epitaxial growth of additional layers of host material, the surface dopant ions will be transferred to the lattice sites (Fig. 2b). Recently, 


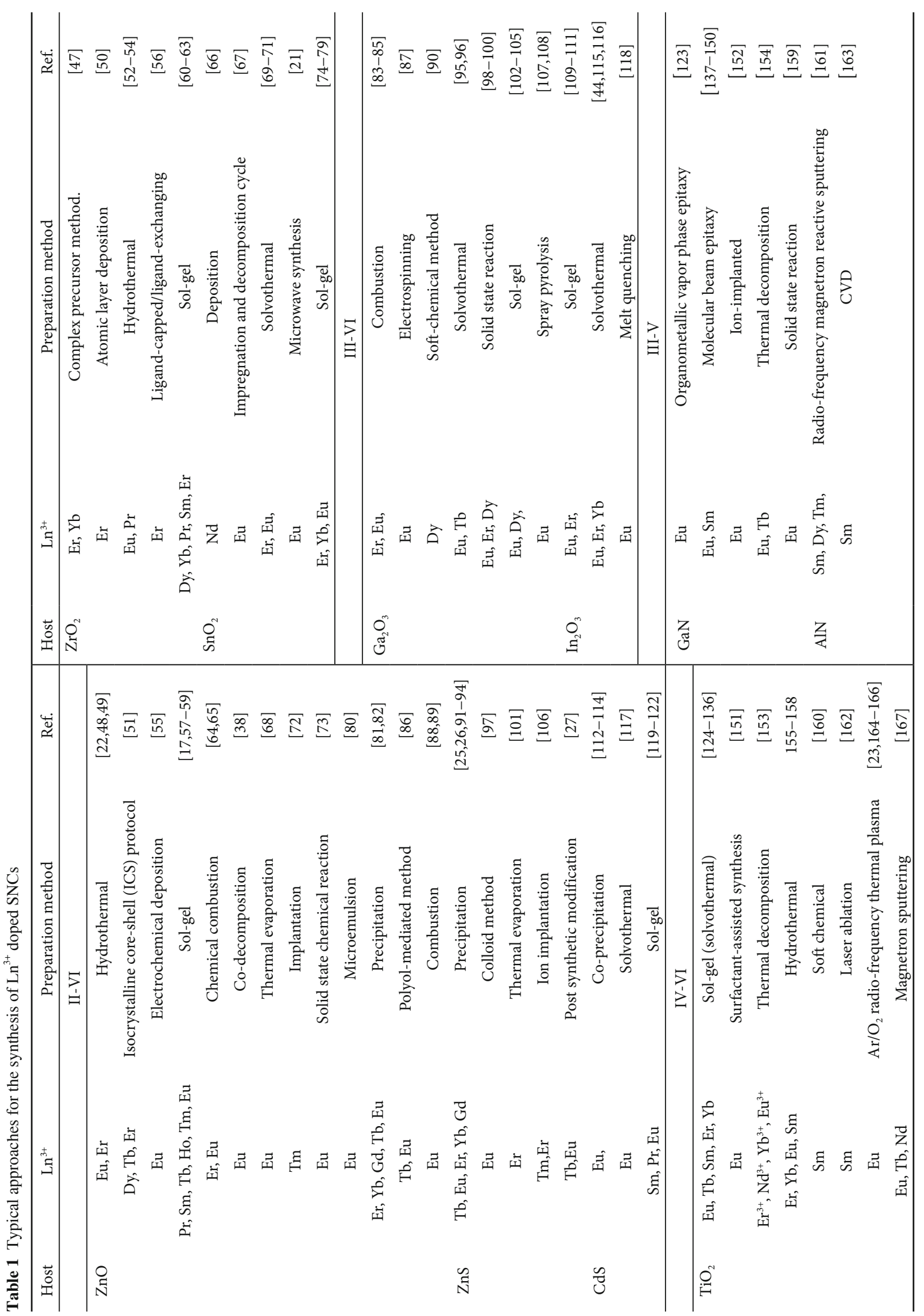



Precursors $\stackrel{\text { Hydrolysis }}{\longrightarrow}-\mathrm{M}-\mathrm{O}-\mathrm{Ln}-$ Condensation $-\mathrm{M}-\mathrm{O}-\mathrm{M}-$

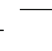

Growth
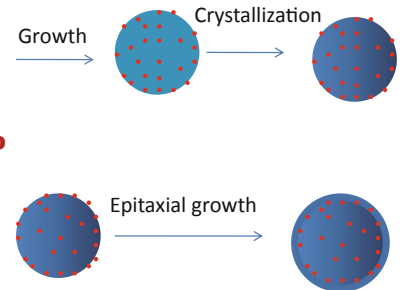

In, : Lanthanide ions

: SNCS
Figure 2 A schematic illustration of the strategies to incorporate $\mathrm{Ln}^{3+}$ ions into the SNC lattice through (a) sol-gel, and (b) epitaxial growth method.

Martin-Rodriguez and co-workers [171] presented a facile way to incorporate $\mathrm{Yb}^{3+}$ ions into the CdSe quantum dots (QDs) through epitaxial growth method, and enhanced energy transfer from CdSe host to $\mathrm{Yb}^{3+}$ ions was achieved. As shown in Fig. 3a, CdSe QDs were used as core templates, and the $\mathrm{Yb}$ and Se were then successively coated onto the CdSe QDs surface. During the shell growth process at high temperature of $265^{\circ} \mathrm{C}$, the $\mathrm{Yb}^{3+}$ ions can diffuse into the CdSe host lattice. During the doping process, the morphology and dispersity of the nanoparticles can be retained (Fig. 3b). Fig. 3c shows the PL excitation and emission spectra of CdSe: $\mathrm{Yb}^{3+} \mathrm{NCs}$. For the sample with $\mathrm{Yb}^{3+}$ physically adsorbed on the surface, energy transfer from CdSe to $\mathrm{Yb}^{3+}$ can be obtained, and thus broad emission band at around $980 \mathrm{~nm}$ attributed to the ${ }^{2} \mathrm{~F}_{5 / 2}$ to ${ }^{2} \mathrm{~F}_{7 / 2}$ transition of $\mathrm{Yb}^{3+}$ was observed (Fig. 3d). Such surface adsorbed $\mathrm{Yb}^{3+}$ ions were unstable and easily desorbed from the nanoparticle after washing, which resulted in the decrease of emission intensity of $\mathrm{Yb}^{3+}$. Followed by the coating of Se layer, the emission lines of $\mathrm{Yb}^{3+}$ ions became sharper and better resolved (Fig. 3e), indicating that the Se coating promoted the incorporation of $\mathrm{Yb}^{3+}$ in CdSe QDs. Meanwhile, the PL decay curve of CdSe: $\mathrm{Yb}^{3+} \mathrm{QDs}$ also provided additional evidence for the incorporation of $\mathrm{Yb}^{3+}$ in CdSe lattice. As shown in Fig. 3f, the PL lifetime of ${ }^{2} \mathrm{~F}_{5 / 2}$ of $\mathrm{Yb}^{3+}$ was found to be significantly prolonged after Se layer growth due to the minimization of surface quenching groups such as $\mathrm{C}-\mathrm{H}$ $\left(\sim 3000 \mathrm{~cm}^{-1}\right)$ or $\mathrm{O}-\mathrm{H}\left(\sim 3300 \mathrm{~cm}^{-1}\right)$ by doping into the CdSe lattice site.

\section{ELECTRONIC STRUCTURES OF LANTHANIDE IONS IN SNCS}

\section{Crystal-field theory of $\mathrm{Ln}^{3+}$}

The electronic structure of $\mathrm{Ln}^{3+}$ is closely related to their locations in the host [172]. A slight variation of local structure around $\mathrm{Ln}^{3+}$ ions will lead to a significant change in the CF of $\mathrm{Ln}^{3+}$. It is a general practice to perform the energy-level-fitting by the parameterization of an effective operator Hamiltonian including free-ion (FI) and CF interactions. The commonly used effective operator Hamiltonian is

$$
H=H_{\mathrm{FI}}+H_{\mathrm{CF}},
$$

where the FI Hamiltonian can be expressed as

$$
\begin{aligned}
H_{\mathrm{FI}}= & E_{\text {avg }}+\sum_{k=2,4,6} F^{k} f_{k}+\zeta_{f} A_{\mathrm{SO}}+\alpha L(L+1)+\beta G\left(R_{2}\right) \\
& +\gamma G\left(R_{7}\right)+\sum_{i=2,3,4,6,7,8} T^{i} t_{i}+\sum_{h=0,2,4} M^{h} m_{h}+\sum_{f=2,4,6} P^{f} p_{f} .
\end{aligned}
$$

There are up to $20 \mathrm{FI}$ parameters in Equation (2). The predominant terms in this Hamiltonian are the electrostatic and spin-orbit interactions represented by parameters $F^{k}$ and $\zeta_{f}$. The configuration interactions $(\alpha, \beta, \gamma)$, spin-spin and spin-other-orbit interactions $\left(M^{h}\right)$, the two-body electrostatically correlated magnetic interactions $\left(P^{f}\right)$, and the three-particle configuration interactions $\left(T^{i}\right)$ represent higher order interactions that are essential in order to accurately reproduce the energy level structure of $f$-element ions. The physical meaning of these FI parameters has been described by Crosswhite and Carnall et al. [173,174].

The single-particle CF Hamiltonian is expressed in Wybourne's notation [175],

$$
H_{\mathrm{CF}}=\sum_{k, q} \operatorname{Re} B_{q}^{k}\left[C_{q}^{k}+(-1)^{q} \cdot C_{-q}^{k}\right]+i \operatorname{Im} B_{q}^{k}\left[C_{q}^{k}-(-1)^{q} \cdot C_{-q}^{k}\right]
$$

The values of $k$ and $q$ are limited by the site symmetry of Ln ions, since the Hamiltonian must be invariant under the operations of the point group symmetry. In the low site symmetry, all the independent CF parameters except $B_{o}^{k}$ are complex, each having real and imaginary parts denoted by $\operatorname{Re} B_{q}^{k}$ and $\operatorname{Im} B_{q}^{k}$. It should be noted that the CF parameters defined in Wybourne's notation are complex conjugate to their counterparts in Morrison's definition [176].

The scalar CF strength $(S)$ that reflects the overall CF interaction in the crystal can be calculated according to Chang's definition [177]

$$
S=\left\{\frac{1}{3} \sum_{k=2,4,6} \frac{1}{2 k+1}\left[\left|B_{0}^{k}\right|^{2}+2 \sum_{q>0}\left(\left|\operatorname{Re} B_{q}^{k}\right|^{2}+\left|\operatorname{Im} B_{q}^{k}\right|^{2}\right)\right]\right\}^{1 / 2} .
$$

\section{$\mathrm{Ln}^{3+}$ doped $\mathrm{TiO}_{2} \mathrm{NCs}$}

$E u^{3+}$

The high-resolution site-selective PL excitation and emis- 

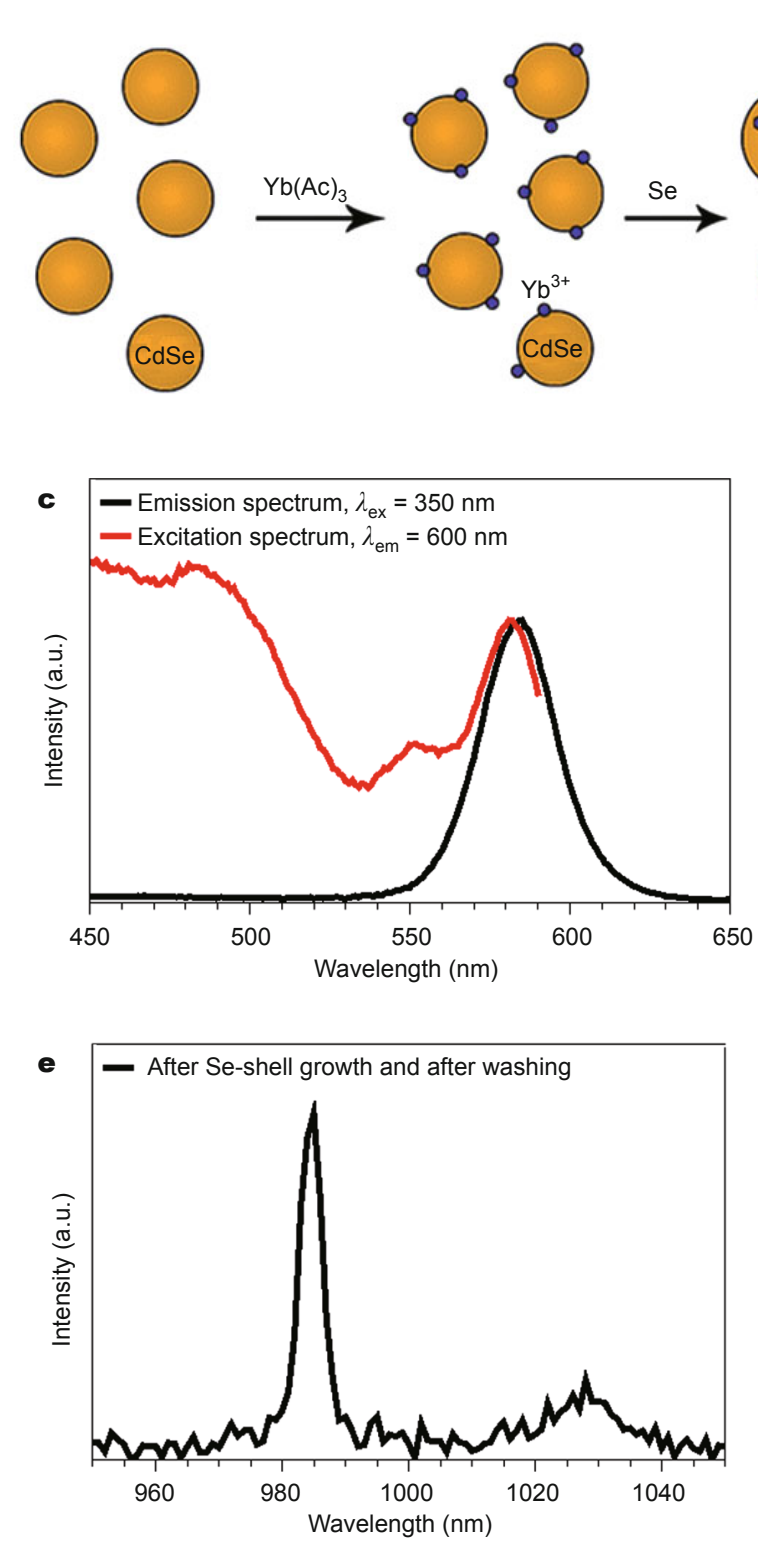

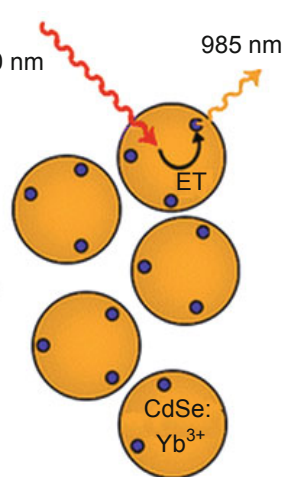

b

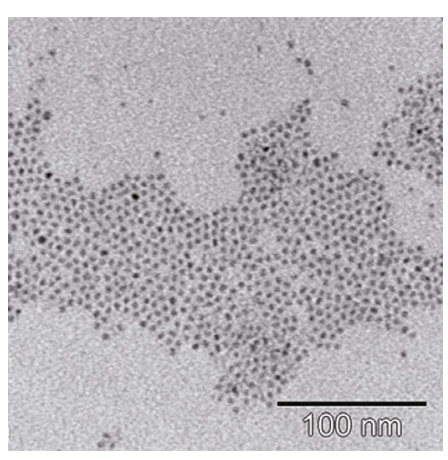

d
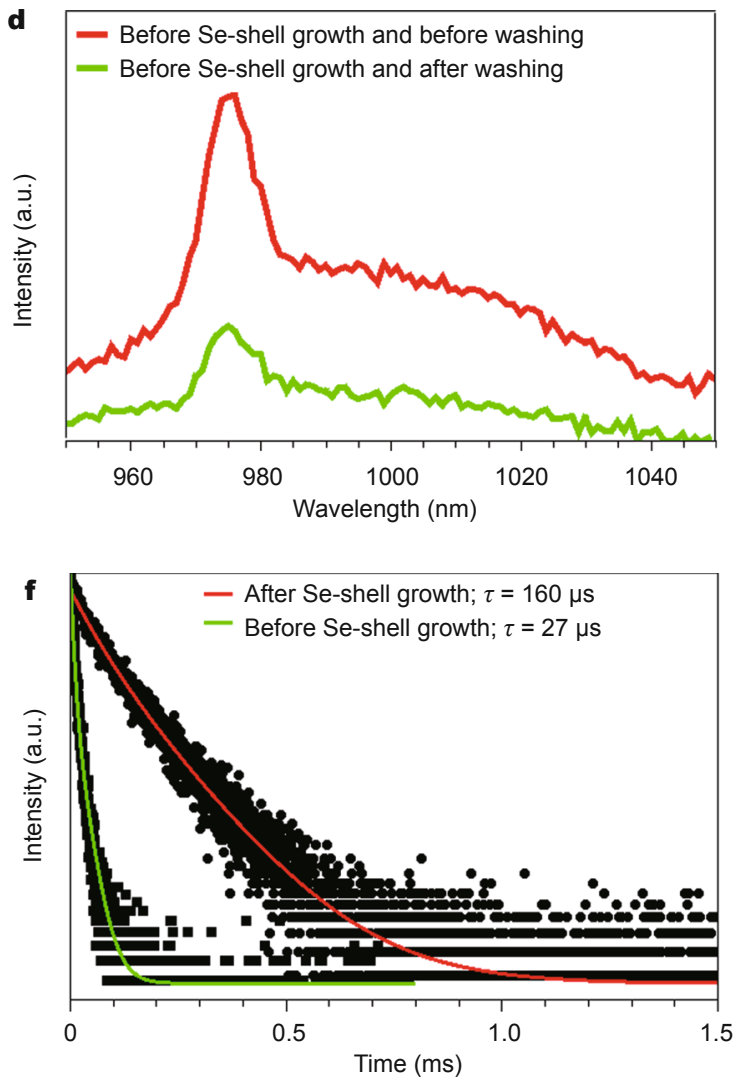

Figure 3 (a) A schematic illustration of the incorporation of $\mathrm{Yb}^{3+}$ ions into CdSe host lattice; (b) transmission electron microscopy (TEM) image of CdSe:Yb ${ }^{3+}$ QDs; (c) emission $\left(\lambda_{\mathrm{ex}}=350 \mathrm{~nm}\right)$ and excitation $\left(\lambda_{\mathrm{em}}=600 \mathrm{~nm}\right)$ spectra of CdSe:Yb ${ }^{3+}$; (d) NIR emission spectra of unshelled CdSe:Yb ${ }^{3+}$ before (red line) and after (green line) washing; (e) PL emission spectrum of CdSe:Yb ${ }^{3+}$ after Se-shell growth upon excitation at 585 nm; (f) PL decay curves of $\mathrm{Yb}^{3+}$ in CdSe QDs by monitoring the emission at $980 \mathrm{~nm}$ upon pulsed excitation at $580 \mathrm{~nm}$ before (green) and after (red) Se-shell overgrowth. (Adapted with permision from Ref. [171]. Copyright 2013, American Chemical Society).

sion spectra of $\mathrm{TiO}_{2}: \mathrm{Eu}^{3+}$ at $10 \mathrm{~K}, 47 \mathrm{CF}$ levels at $C_{2 v}$ site and $42 \mathrm{CF}$ levels at $\mathrm{D}_{2}$ site were experimentally determined as listed in Table 2 [178]. Thereafter, the energy level fitting was performed by Ma et al. [179] by allowing the variation of both 9 CF parameters and FI parameters such as Slater integrals and spin-orbit coupling constant. The fitted energy levels are compared with the experimental values in Table 2. The root mean square (rms) deviation of the final fit is as small as $31.8 \mathrm{~cm}^{-1}$ and $33.7 \mathrm{~cm}^{-1}$ for $C_{2 v}$ and $\mathrm{D}_{2}$ sites, respectively, which indicates a good agreement between the observed and the calculated sets. However, it should be pointed out that there are some large discrepancies between the experimental and fitted results as marked by star symbol in Table 2 , which may be caused by the un- 
Table 2 Energy levels of $\mathrm{Eu}^{3+}$ ions situated at the sites of $C_{2 v}$ and $D_{2}$ symmetries in anatase $\mathrm{TiO}_{2} \mathrm{NCs}\left(\right.$ unit: $\mathrm{cm}^{-1}$ ). Reprinted with permission from Ref. [179]. Copyright 2011, Elsevier B.V.

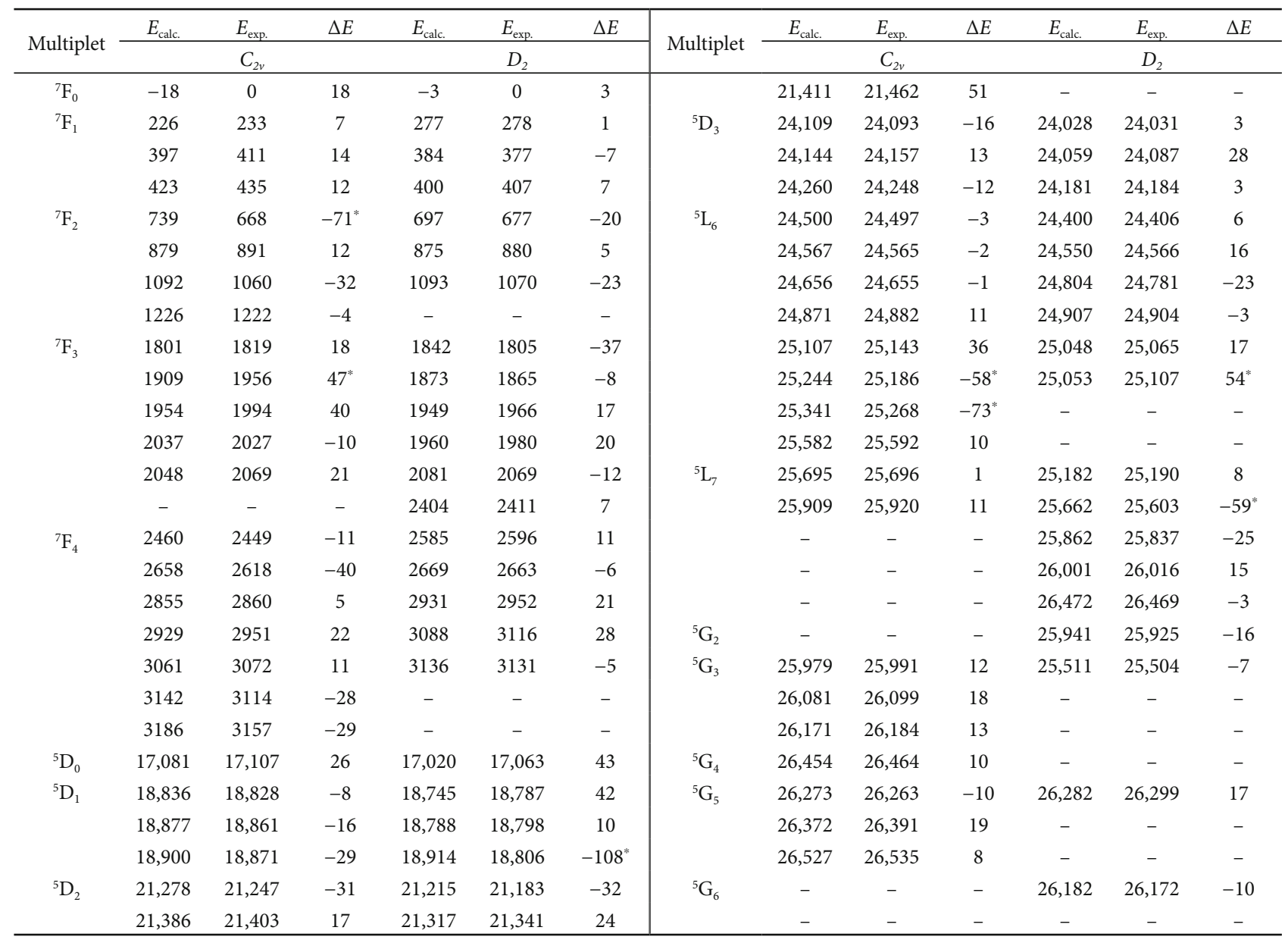

certainty in the location of some energy levels due to the spectral overlap of three site emissions in some wavelength region under the current experimental conditions. Table 3 lists the final FI and CF parameters of the fit. By adopting the CF parameters in Table 3, the value of $S$ is determined to be 751 and $1095 \mathrm{~cm}^{-1}$ for $\mathrm{Eu}^{3+}$ ions at the $C_{2 v}$ and $D_{2}$ site in anatase $\mathrm{TiO}_{2} \mathrm{NCs}$, respectively, which are slightly larger than that at the $C_{2}$ site of $\mathrm{Gd}_{2} \mathrm{O}_{3}$ and double of that at the $C_{2 v}$ site of $\mathrm{LaF}_{3}$ [182], indicating the large CF experienced by $\mathrm{Eu}^{3+}$ in $\mathrm{TiO}_{2}$. The relatively large $\mathrm{CF}$ strength may be due to the great lattice distortion and site symmetry descending at $\mathrm{Ln}^{3+}$ sites since a lower point-group symmetry occupied by $\mathrm{Ln}^{3+}$ ions in the host usually results in a larger CF strength [183].

\section{$\mathrm{Er}^{3+}$}

Fine CF splittings experienced by $\mathrm{Er}^{3+}$ in anatase $\mathrm{TiO}_{2} \mathrm{NCs}$ were observed in high-resolution PL excitation and emis- sion spectra at $10 \mathrm{~K}$ (Fig. 4). Fig. 4a exhibits the $10 \mathrm{~K}$ excitation spectrum for $\mathrm{Er}^{3+}$ doped $\mathrm{TiO}_{2} \mathrm{NCs}$ when monitoring the ${ }^{4} \mathrm{~S}_{3 / 2} \rightarrow{ }^{4} \mathrm{I}_{15 / 2}$ emission at $566.5 \mathrm{~nm}$. Abundant sharp excitation lines of $\mathrm{Er}^{3+}$ centered at 380.8, 407.8, 445.6, 454.6, $489.5,523.5$, and $550.5 \mathrm{~nm}$ are attributed to the transitions from the ground state of ${ }^{4} \mathrm{I}_{15 / 2}$ to the excited states of ${ }^{4} \mathrm{G}_{11 / 2}$, ${ }^{2} \mathrm{H}_{9 / 2},{ }^{4} \mathrm{~F}_{7 / 2},{ }^{2} \mathrm{H}_{11 / 2},{ }^{4} \mathrm{~S}_{3 / 2}$ and ${ }^{4} \mathrm{~F}_{9 / 2}$, respectively. Eight CF levels of ${ }^{4} \mathrm{I}_{15 / 2}$ were determined to be $0,15,95,166,210,378$, 454, and $504 \mathrm{~cm}^{-1}$ according to the ${ }^{4} \mathrm{~S}_{3 / 2} \rightarrow{ }^{4} \mathrm{I}_{15 / 2}$ emission at $10 \mathrm{~K}$ (Fig. 4b). Theoretically, the multiplets of $\mathrm{Er}^{3+}$ at $D_{2 d}$ or lower symmetry sites should present $J+1 / 2$ lines due to the Kramers degeneracy for $4 f^{11}$ configuration of $\mathrm{Er}^{3+}$ [184]. The enlarged excitation spectra at different spectral regions at $10 \mathrm{~K}$ (Figs $4 \mathrm{c}-\mathrm{h}$ ) reveal that the excitation lines of different multiplets agree well with the expected degeneracy, thus further verifying the single lattice site of $\mathrm{Er}^{3+}$ ions in $\mathrm{TiO}_{2}$ NCs. Moreover, in addition to the excitation lines from the lowest CF level of ${ }^{4} \mathrm{I}_{15 / 2}$, a number of hot bands 
Table 3 FI and CF parameters of $\mathrm{Ln}^{3+}$ in $\mathrm{SNCs}$ of $\mathrm{TiO}_{2}, \mathrm{In}_{2} \mathrm{O}_{3}$, and $\mathrm{Ga}_{2} \mathrm{O}_{3}\left(\right.$ unit: $\mathrm{cm}^{-1}$ )

\begin{tabular}{|c|c|c|c|c|c|c|c|c|c|}
\hline \multirow{2}{*}{ Parameter } & \multicolumn{5}{|c|}{ Anatase $\mathrm{TiO}_{2}$} & \multicolumn{2}{|c|}{ Rutile $\mathrm{TiO}_{2}$} & \multirow{2}{*}{$\begin{array}{c}\mathrm{In}_{2} \mathrm{O}_{3} \\
C_{2}^{\mathrm{d}}\left(\mathrm{Eu}^{3+}\right) \\
\end{array}$} & \multirow{2}{*}{$\begin{array}{c}\mathrm{Ga}_{2} \mathrm{O}_{3} \\
C_{2 / m}{ }^{\mathrm{e}}\left(\mathrm{Eu}^{3+}\right) \\
\end{array}$} \\
\hline & $C_{2 v}{ }^{a}\left(\mathrm{Eu}^{3+}\right)$ & $D_{2}^{\mathrm{a}}\left(\mathrm{Eu}^{3+}\right)$ & $C_{2 v}{ }^{\mathrm{b}}\left(\mathrm{Er}^{3+}\right)$ & $D_{2 d}{ }^{\mathrm{b}}\left(\mathrm{Er}^{3+}\right)$ & $D_{2 d}{ }^{c}\left(\mathrm{Sm}^{3+}\right)$ & $D_{2 d}{ }^{c}\left(\mathrm{Sm}^{3+}\right)$ & $D_{2 h}{ }^{c}\left(\mathrm{Sm}^{3+}\right)$ & & \\
\hline$E_{\text {avg }}$ & 63,614 & 64,718 & $35,567(17)$ & $35,567(29)$ & - & - & - & $6,2791(56)$ & $63,304(15)$ \\
\hline$F^{2}$ & 82,256 & 84,685 & $96,528(130)$ & $96,509(229)$ & {$[79,805]^{g}$} & {$[79,805]$} & {$[79,805]$} & $80,206(108)$ & $81,280(57)$ \\
\hline$F^{4}$ & 61,248 & 60,381 & $64,835(187)$ & $64,902(278)$ & {$[57,175]$} & {$[57,175]$} & {$[57,175]$} & $59,968(774)$ & $61,647(93)$ \\
\hline$F^{6}$ & 40,411 & 41,288 & $57,754(243)$ & $57,740(403)$ & {$[40,250]$} & {$[40,250]$} & {$[40,250]$} & $41,068(465)$ & $40,535(53)$ \\
\hline$\zeta$ & 1324 & 1349 & $2365(4)$ & $2364(6)$ & {$[176]$} & [176] & [176] & 1313(3) & $1319(1)$ \\
\hline$\alpha$ & - & - & 17.79 & 17.79 & [20.16] & [20.16] & [20.16] & 21.4 & 20.16 \\
\hline$\beta$ & - & - & -580 & -580 & {$[-566.9]$} & {$[-566.9]$} & {$[-566.9]$} & -567 & -567 \\
\hline$\gamma$ & - & - & 1800 & 1800 & [1500] & [1500] & [1500] & 1500 & 1500 \\
\hline$T^{2}$ & - & - & 620 & 620 & [300] & [300] & [300] & 300 & 300 \\
\hline$T^{3}$ & - & - & 48 & 48 & [36] & [36] & [36] & 40 & 40 \\
\hline$T^{4}$ & - & - & 100 & 100 & [56] & [56] & [56] & 60 & 60 \\
\hline$T^{6}$ & - & - & -475 & -475 & {$[-347]$} & {$[-347]$} & {$[-347]$} & -300 & -300 \\
\hline$T^{7}$ & - & - & 380 & 380 & [373] & [373] & [373] & 370 & 370 \\
\hline$T^{8}$ & - & - & 163 & 163 & [348] & [348] & [348] & 320 & 320 \\
\hline$M^{0}$ & - & - & 2.95 & 2.95 & {$[2.6]$} & {$[2.6]$} & {$[2.6]$} & 2.1 & 2.1 \\
\hline$P^{2}$ & - & - & 627 & 627 & [357] & [357] & [357] & 360 & 360 \\
\hline$B_{0}^{2}$ & 99 & -24 & $45(147)$ & 121(105) & -452 & -886 & 546 & $-168(47)$ & $41(46)$ \\
\hline$B_{2}^{2}$ & -721 & 446 & $152(105)$ & - & - & - & 615 & $-806(27)$ & $-625(31)$ \\
\hline$B_{0}^{4}$ & 1079 & -3733 & $2483(164)$ & $3035(132)$ & 2276 & 4870 & -4806 & $-1206(21)$ & $-988(48)$ \\
\hline$B_{2}^{4}$ & -707 & -1945 & $-1050(156)$ & - & - & - & -759 & $\begin{array}{l}\text { Re: }-1951(57) \\
\text { Im: -221(162) }\end{array}$ & $\begin{array}{l}\text { Re: }-397(89) \\
\text { Im: }-1243(42)\end{array}$ \\
\hline$B_{4}^{4}$ & -2414 & 1125 & $-481(176)$ & $-423(215)$ & 2030 & 1745 & 1417 & $\begin{array}{c}\text { Re: 1133(62) } \\
\text { Im: }-271(243)\end{array}$ & $\begin{array}{l}\text { Re: }-165(71) \\
\text { Im: 223(48) }\end{array}$ \\
\hline$B_{0}^{6}$ & 2092 & -3916 & $-143(144)$ & $-170(86)$ & 674 & 960 & -117 & $143(96)$ & $-1096(84)$ \\
\hline$B_{2}^{6}$ & -1697 & -1853 & $248(126)$ & - & - & - & - & $\begin{array}{l}\text { Re: 452(68) } \\
\text { Im: 465(101) }\end{array}$ & $\begin{array}{l}\text { Re: }-177(78) \\
\text { Im: -201(59) }\end{array}$ \\
\hline$B_{4}^{6}$ & 1182 & 171 & $395(76)$ & $314(82)$ & -211 & -133 & 752 & $\begin{array}{c}\text { Re: } 1124(68) \\
\text { Im: }-313(219)\end{array}$ & $\begin{array}{l}\text { Re: 73(93) } \\
\text { Im: 553(58) }\end{array}$ \\
\hline$B_{6}^{6}$ & 1073 & 121 & 124(105) & - & - & - & -1086 & $\begin{array}{l}\text { Re: }-30(90) \\
\text { Im: }-253(93)\end{array}$ & $\begin{array}{l}\text { Re: 720(53) } \\
\text { Im: 151(166) }\end{array}$ \\
\hline$r m s^{\mathrm{f}}$ & 31.8 & 33.7 & 25.1 & 31.7 & 16.6 & 37.5 & 3.1 & 13.8 & 12.9 \\
\hline $\mathrm{S} / \mathrm{cm}^{-1}$ & 751 & 1095 & 549 & 609 & - & - & - & 790 & 546 \\
\hline
\end{tabular}

a) Ref. [179]; b) Ref. [180]; c) Ref. [181]; d) Ref. [115]; e) Ref. [83]; the values in parentheses are errors in the indicated parameters which were freely varied in the fit. f) The rms deviation between the experimental and calculated energies was used as a figure of merit to describe the quality of a fit, with

$$
r m s=\sqrt{\sum\left(E_{\text {exp }}-E_{\text {calc }}\right)^{2} /(N-P)}
$$

where $N$ is the number of levels fit, and $P$ is the number of parameters freely varied. g) The FI parameters in brackets were adopted from $\mathrm{Sm}^{3+} \mathrm{in} \mathrm{LaF}_{3}$ crystals in Ref. [174] and fixed during the energy level fitting. 

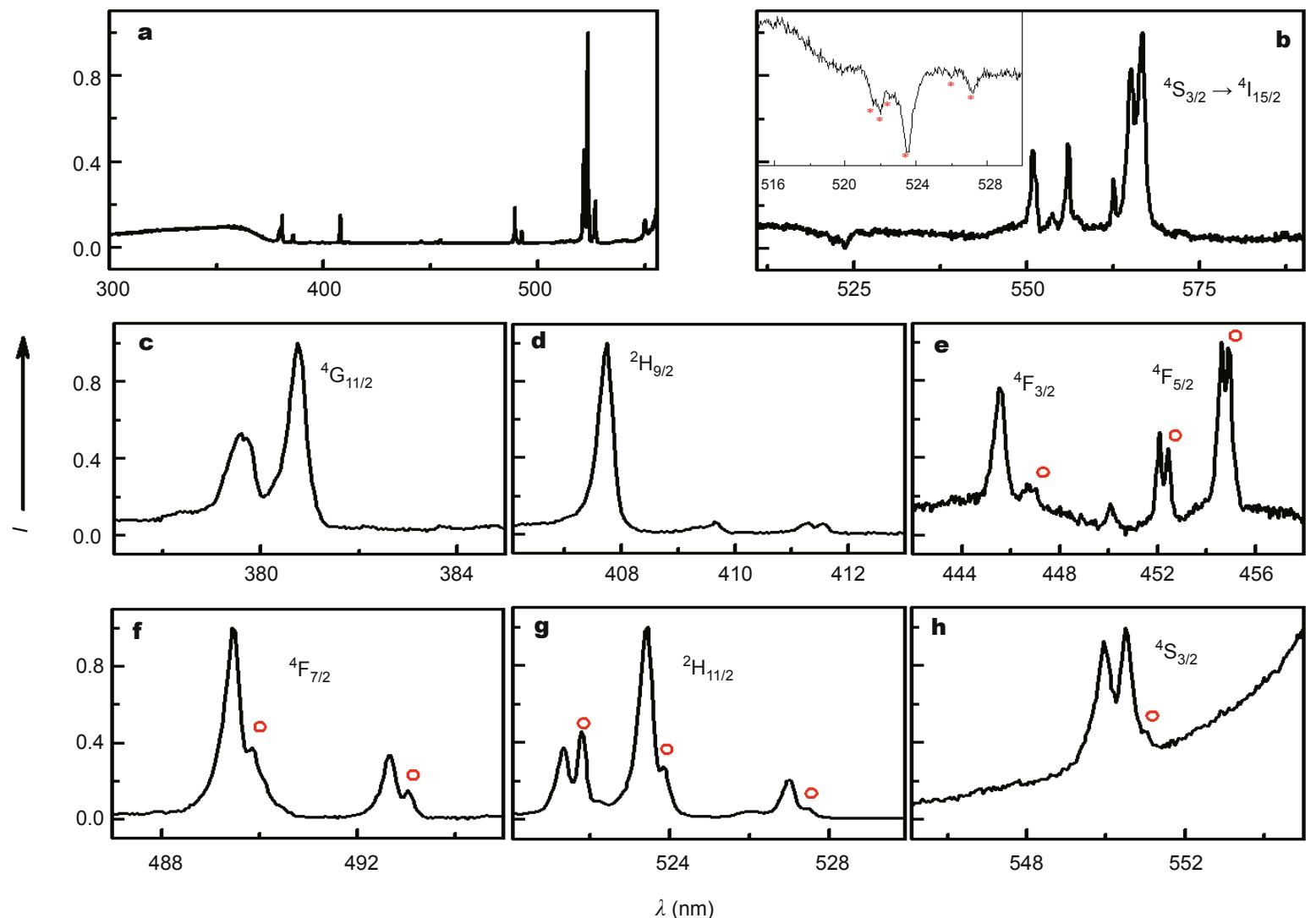

Figure 4 (a) $10 \mathrm{~K}$ PL excitation spectrum by monitoring the ${ }^{4} \mathrm{~S}_{3 / 2} \rightarrow{ }^{4} \mathrm{I}_{15 / 2}$ emission at $566.5 \mathrm{~nm}$; (b) PL emission spectra upon excitation at $407.8 \mathrm{~nm}$ for $\mathrm{TiO}_{2}: \mathrm{Er}^{3+} \mathrm{NCs}$; (c-h) enlarged high-resolution excitation peaks in different spectral regions. Peaks marked by circles are hot bands from the second lowest level of the ground state. Reprinted with permission from Ref. [180]. Copyright 2011, Wiley-VCH Verlag GmbH \& Co. KGaA.

marked by the circle symbols with an energy gap of $15 \mathrm{~cm}^{-1}$ appear in lower energy side, which are ascribed to the transitions from the second lowest $\mathrm{CF}$ level of ${ }^{4} \mathrm{H}_{15 / 2}$. From the viewpoint of spectroscopy, we infer that most of $\mathrm{Er}^{3+}$ ions are very likely located at the substitutional $\mathrm{Ti}^{4+}$ lattice site with a site symmetry descending from $D_{2 d}$ to $C_{2 v}$ or $D_{2}$, as previously revealed in $\mathrm{Eu}^{3+}$ doped $\mathrm{TiO}_{2} \mathrm{NCs}$ [178].

According to the high-resolution PL excitation and emission spectra at $10 \mathrm{~K}, 45 \mathrm{CF}$ levels belonging to 12 different SLJ multiplets of $4 f^{11}$ configuration of $\mathrm{Er}^{3+}$ were experimentally determined (Table 4) and subjected to energy level fitting [180]. The energy-level-fitting was performed using the $f$-shell empirical programs of Prof. Reid, which enabled a complete diagonalization without truncation of the $4 f^{11}$ wave functions [185]. In the least-square fitting of CF energy level structure, five FI parameters $\left(E_{\text {avg }}, F^{k}\right.$, $\zeta_{f}$ ) were allowed to vary freely whereas the others of $M^{2}$, $M^{4}, P^{4}$, and $P^{6}$ were constrained by the Hartree-Fock-determined ratios $M^{2} / M^{0}=0.56, M^{4} / M^{0}=0.38 ; P^{4} / P^{2}=0.75, P^{6} /$ $P^{2}=0.5$ [173]. The FI and CF parameters of $\mathrm{LaF}_{3}: \mathrm{Er}^{3+}[174]$ were used as starting values. Some strategies were employed to fulfill the fit repeatedly: firstly, those most reliable CF levels were fitted by freely varying both the FI parameters $\left(E_{\text {avg }}, F^{k}, \zeta_{f}\right)$ and the CF parameters. The other FI parameters were fixed at the parameters of $\mathrm{LaF}_{3}: \mathrm{Er}^{3+}$; secondly, finely tuning the above fit by introducing the remaining FI parameters, or adding more CF levels of other multiplets such as those congested levels, or both; thirdly, relocating or reassigning those uncertain CF levels that would result in anomalously large $r m s$ deviation of the fit, and finally simultaneously varying the free parameters to fit the $45 \mathrm{CF}$ levels. An rms deviation of $25.1 \mathrm{~cm}^{-1}$ based on the $C_{2 v}$ symmetry was obtained in the final fit, which is smaller than that based on the $D_{2 d}$ symmetry $\left(31.7 \mathrm{~cm}^{-1}\right)$, indicating that the fitting based on $C_{2 v}$ is more reasonable in energy. The fitted energy levels for the $D_{2 d}$ and $C_{2 v}$ site symmetries are compared with experimental values in Table 4 . The optimal FI and CF parameters are listed in Table 3. By adopting the CF parameters in Table 3, the value of $S$ was determined to be $549 \mathrm{~cm}^{-1}$ for $\mathrm{Er}^{3+}$ ions at the $C_{2 v}$ site in anatase $\mathrm{TiO}_{2} \mathrm{NCs}$, 
Table 4 Energy levels of $\mathrm{Er}^{3+}$ at the $D_{2 d}$ and $C_{2 v}$ sites of $\mathrm{TiO}_{2} \mathrm{NCs}$ (unit: $\mathrm{cm}^{-1}$ ). Reprinted with permission from Ref. [180]. Copyright 2011, Wiley$\mathrm{VCH}$ Verlag $\mathrm{GmbH} \& \mathrm{Co} . \mathrm{KGaA}$

\begin{tabular}{|c|c|c|c|c|c|c|c|c|c|c|c|}
\hline \multirow{2}{*}{ Multiplet } & \multicolumn{3}{|c|}{ Energy } & \multirow{2}{*}{$\Delta E\left(D_{2 d}\right)$} & \multirow{2}{*}{$\Delta E\left(C_{2 v}\right)$} & \multirow{2}{*}{ Multiplet } & \multicolumn{3}{|c|}{ Energy } & \multirow{2}{*}{$\Delta E\left(D_{2 d}\right)$} & \multirow{2}{*}{$\Delta E\left(C_{2 v}\right)$} \\
\hline & Exp. & Fit $\left(D_{2 d}\right)$ & Fit $\left(C_{2 v}\right)$ & & & & Exp. & Fit $\left(D_{2 d}\right)$ & Fit $\left(C_{2 v}\right)$ & & \\
\hline \multirow[t]{8}{*}{${ }^{4} I_{15 / 2}$} & 0 & -1 & -19 & -1 & -19 & \multirow{3}{*}{${ }^{4} S_{3 / 2}$} & 15,404 & 15,374 & 15,383 & -30 & -21 \\
\hline & 15 & 19 & 7 & 4 & -8 & & 18,165 & 18,140 & 18,152 & -25 & -13 \\
\hline & 95 & 74 & 81 & -21 & -14 & & 18,183 & 18,184 & 18,195 & 1 & 12 \\
\hline & 166 & 148 & 166 & -18 & 0 & \multirow[t]{5}{*}{${ }^{2} \mathrm{H}_{11 / 2}$} & 18,975 & 18,997 & 18,972 & 22 & -3 \\
\hline & 210 & 223 & 219 & 13 & 9 & & 19,010 & $19,089^{*}$ & 19,025 & 79 & 15 \\
\hline & 378 & 401 & 392 & 23 & 14 & & 19,104 & 19,112 & 19,086 & 8 & -18 \\
\hline & 454 & 446 & 469 & -8 & 15 & & 19,148 & 19,114 & 19,152 & -34 & 4 \\
\hline & 504 & 523 & 506 & 19 & 2 & & 19,181 & 19,185 & 19,201 & 4 & 20 \\
\hline \multirow[t]{7}{*}{${ }^{4} I_{13 / 2}$} & 6525 & 6510 & 6525 & -15 & 0 & \multirow{5}{*}{${ }^{4} \mathrm{~F}_{7 / 2}$} & 19,226 & 19,195 & 19,215 & -31 & -11 \\
\hline & 6533 & 6542 & 6543 & 9 & -10 & & 20,298 & $20,342^{*}$ & 20,320 & 44 & 22 \\
\hline & 6585 & 6599 & 6594 & 14 & 9 & & 20,392 & 20,390 & 20,400 & -2 & 8 \\
\hline & - & 6620 & 6649 & - & - & & 20,430 & 20,398 & 20,418 & -32 & -12 \\
\hline & - & 6766 & 6745 & - & - & & 20,466 & 20,459 & 20,453 & -7 & -13 \\
\hline & - & 6820 & 6851 & - & - & \multirow[t]{2}{*}{${ }^{4} \mathrm{~F}_{5 / 2}$} & 21,997 & $22,049^{*}$ & $22,049^{*}$ & 52 & 52 \\
\hline & - & 6890 & 6859 & - & - & & 22,119 & 22,109 & 22,117 & -10 & -2 \\
\hline \multirow[t]{6}{*}{${ }^{4} \mathrm{I}_{11 / 2}$} & - & 10,155 & 10,166 & - & - & \multirow{3}{*}{${ }^{4} \mathrm{~F}_{3 / 2}$} & 22,217 & 22,178 & $22,161^{*}$ & -39 & -56 \\
\hline & - & 10,189 & 10,184 & - & - & & 22,386 & 22,384 & 22,381 & -2 & -5 \\
\hline & 10,205 & 10,195 & 10,206 & -10 & 1 & & 22,444 & 22,440 & 22,452 & -4 & 8 \\
\hline & - & 10,276 & 10,268 & - & - & \multirow[t]{3}{*}{${ }^{2} \mathrm{H}_{9 / 2}$} & 24,298 & 24,274 & 24,283 & -24 & -15 \\
\hline & - & 10,305 & 10,328 & - & - & & 24,313 & 24,286 & 24,295 & -27 & -18 \\
\hline & - & 10,354 & 10,330 & - & - & & 24,411 & 24,414 & 24,406 & 3 & -5 \\
\hline \multirow[t]{5}{*}{${ }^{4} \mathrm{I}_{9 / 2}$} & - & 12,254 & 12,252 & - & - & \multirow{9}{*}{${ }^{4} \mathrm{G}_{11 / 2}$} & 24,426 & 24,464 & 24,442 & 38 & 16 \\
\hline & - & 12,288 & 12,287 & - & - & & 24,525 & 24,547 & 24,546 & 22 & 21 \\
\hline & - & 12,409 & 12,401 & - & - & & 25,920 & $25,993^{*}$ & $25,991^{*}$ & 73 & 71 \\
\hline & - & 12,472 & 12,453 & - & - & & 26,062 & 26,049 & 26,031 & -13 & -31 \\
\hline & 12,588 & 12,562 & 12,584 & -26 & -4 & & 26,170 & 26,137 & 26,160 & -33 & -10 \\
\hline \multirow[t]{4}{*}{${ }^{4} \mathrm{~F}_{9 / 2}$} & - & 15,110 & 15,122 & - & - & & 26,264 & 26,267 & 26,244 & 3 & -20 \\
\hline & 15,140 & 15,129 & 15,133 & -11 & -7 & & 26,344 & 26,322 & 26,359 & -22 & 15 \\
\hline & 15,242 & 15,278 & 15,263 & 36 & 21 & & 26,427 & 26,407 & 26,397 & -20 & -30 \\
\hline & 15,291 & 15,316 & 15,303 & 25 & 12 & & - & - & - & - & - \\
\hline
\end{tabular}

which was close to that at the $C_{2}$ site in $\mathrm{Y}_{2} \mathrm{O}_{3}\left(S=569 \mathrm{~cm}^{-1}\right)$ [177], but about two times that at the $C_{2 v}$ site in $\operatorname{LaF}_{3}(S=$ $257 \mathrm{~cm}^{-1}$ ) [186], indicative of a strong CF interaction experienced by $\mathrm{Er}^{3+}$.

\section{$\mathrm{Sm}^{3+}$}

Different from the multiple sites of $\mathrm{Sm}^{3+}$ in anatase $\mathrm{TiO}_{2}$ NCs in our previous work [187], single lattice site of $\mathrm{Sm}^{3+}$ was detected in anatase $\mathrm{TiO}_{2} \mathrm{NCs}$ by Kiisk and co-workers [181], which enabled the precise assignment of experimental electronic state of $\mathrm{Sm}^{3+}$ in $\mathrm{TiO}_{2}$ crystals. As shown in Fig. $5 \mathrm{a}$, the shape and position of the emission lines are alike to that selected out under the excitation at $416.2 \mathrm{~nm}$ of $\mathrm{Sm}^{3+}$ in anatase $\mathrm{TiO}_{2}$ prepared by sol-gel solvothermal method [187], indicative of the essentially same CF environment around $\mathrm{Sm}^{3+}$ in these two sites. Besides, well resolved emission lines of $\mathrm{Sm}^{3+}$ were also observed in rutile $\mathrm{TiO}_{2}$ crystals (Fig. 5b), which exhibits significantly different emissive behavior from that of $\mathrm{Sm}^{3+}$ in anatase phase, indicative of the totally different local symmetry of $\mathrm{Sm}^{3+}$ in these two crystal phase.

In all, 16 energy levels belonging to ${ }^{6} \mathrm{H}_{J}(J=J=5 / 2,7 / 2$, $9 / 2,11 / 2$ ) multiplets of $\mathrm{Sm}^{3+}$ in anatase or rutile $\mathrm{TiO}_{2} \mathrm{NCs}$ were located and assigned as listed in Table 5. Due to the 

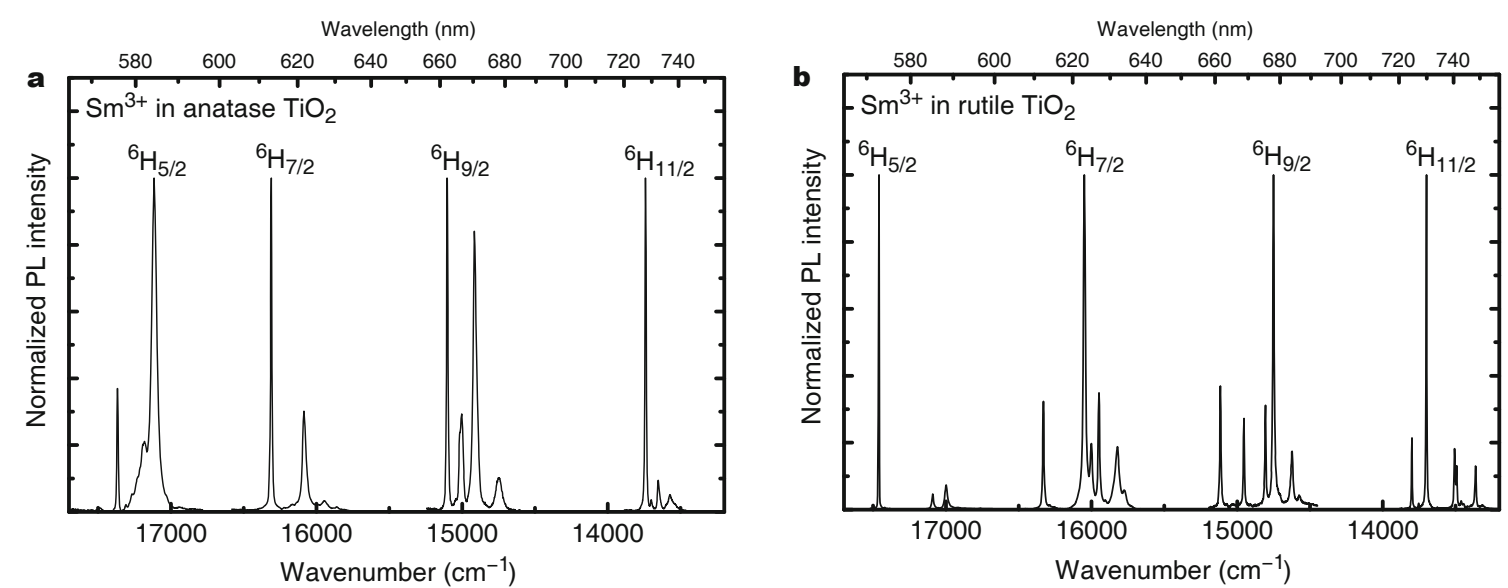

Figure $510 \mathrm{~K}$ high-resolution PL emission spectra of $\mathrm{Sm}^{3+}$ in (a) anatase and (b) rutile phase of $\mathrm{TiO}_{2}$ under the excitation at $355 \mathrm{~nm}$. The intensities of the bands corresponding to different multiplets were normalized at the most intense emission line. Reprinted with permission from Ref. [181]. Copyright 2009, IOP publishing Ltd.

Table 5 Calculated and observed energy levels of $\mathrm{Sm}^{3+}$ in anatase and rutile phases of $\mathrm{TiO}_{2}$ (unit: $\mathrm{cm}^{-1}$ ). Reprinted with permission from Ref. [181]. Copyright 2009, IOP publishing Ltd.

\begin{tabular}{|c|c|c|c|c|c|c|c|c|c|}
\hline \multirow{2}{*}{ Multiplet } & \multicolumn{3}{|c|}{ Anatase $D_{2 d}$} & \multicolumn{3}{|c|}{ Rutile $D_{2 d}$} & \multicolumn{3}{|c|}{ Rutile $D_{2 h}$} \\
\hline & $E_{\text {exp. }}$ & $E_{\text {calc. }}$ & $\Delta E$ & $E_{\text {exp. }}$ & $E_{\text {calc. }}$ & $\Delta E$ & $E_{\text {exp. }}$ & $E_{\text {calc. }}$ & $\Delta E$ \\
\hline \multirow[t]{3}{*}{${ }^{6} \mathrm{H}_{5 / 2}$} & 0 & -24 & 24 & 0 & 71 & -71 & 0 & 1 & -1 \\
\hline & 181 & 199 & -18 & 376 & 312 & 64 & 376 & 375 & 1 \\
\hline & 251 & 258 & -7 & 469 & 458 & 11 & 469 & 469 & 0 \\
\hline \multirow[t]{4}{*}{${ }^{6} \mathrm{H}_{7 / 2}$} & 1055 & 1067 & -12 & 1135 & 1111 & 24 & 1135 & 1138 & -3 \\
\hline & 1204 & 1196 & 8 & 1415 & 1429 & -14 & 1415 & 1415 & 0 \\
\hline & 1280 & 1279 & 1 & 1514 & 1507 & 7 & 1514 & 1511 & 3 \\
\hline & 1418 & 1415 & 3 & 1638 & 1659 & -21 & 1638 & 1635 & 3 \\
\hline \multirow[t]{5}{*}{${ }^{6} \mathrm{H}_{9 / 2}$} & 2265 & 2262 & 3 & 2348 & 2343 & 5 & 2348 & 2343 & 5 \\
\hline & 2348 & 2330 & 18 & 2509 & 2503 & 6 & 2509 & 2509 & 0 \\
\hline & 2364 & 2385 & -21 & 2656 & 2656 & 0 & 2656 & 2656 & 0 \\
\hline & 2451 & 2471 & -20 & 2712 & 2691 & 21 & 2712 & 2716 & -4 \\
\hline & 2619 & 2598 & 21 & 2837 & 2870 & -33 & 2837 & 2839 & -2 \\
\hline \multirow[t]{6}{*}{${ }^{6} \mathrm{H}_{11 / 2}$} & 3626 & 3635 & -9 & 3663 & 3665 & -2 & 3663 & 3664 & -1 \\
\hline & 3666 & 3657 & 9 & 3763 & 3806 & -43 & 3763 & 3762 & -1 \\
\hline & - & 3698 & - & - & 3919 & - & 3964 & 3960 & 4 \\
\hline & 3713 & 3706 & 7 & 3964 & 3927 & 37 & - & 4010 & - \\
\hline & 3812 & 3818 & -6 & - & 4083 & - & 4101 & 4105 & -4 \\
\hline & - & 3855 & - & 4101 & 4090 & 11 & - & 4228 & - \\
\hline
\end{tabular}

small number of experimentally detected energy levels, the FI parameters were fixed at values provided in $\mathrm{LaF}_{3}$ [174] during the energy-level-fitting. The fitted energy levels based on $D_{2 d}$ for anatase phase and $D_{2 d}$ or $D_{2 h}$ for rutile phase are compared in Table 5. The optimal CF parameters are listed in Table 3. By adopting the CF parameters in
Table 3, the value of $S$ was determined to be 609,1033 , and $1020 \mathrm{~cm}^{-1}$ for $\mathrm{Sm}^{3+}$ ions at the $D_{2 d}$ site of anatase, $D_{2 d}$ and $D_{2 h}$ sites of rutile $\mathrm{TiO}_{2} \mathrm{NCs}$, respectively. It should be noted that the lattice distortion induced by the replacement of $\mathrm{Ti}^{4+}$ with larger $\mathrm{Sm}^{3+}$ and the charge compensation process was not taken into account in the energy level fitting, which 
may be to some extent influence the final fitting results.

\section{$\mathrm{Ln}^{3+}$ doped $\mathrm{In}_{2} \mathrm{O}_{3} \mathrm{NCs}$}

Indium sesquioxide $\left(\operatorname{In}_{2} \mathrm{O}_{3}\right)$ is a wide bandgap III-VI semiconductor (direct bandgap energy of $\sim 2.9-3.2 \mathrm{eV}$ ) [188-190] with a large exciton Bohr radius of $2.14 \mathrm{~nm}$ [191]. Due to the similarity of ions radius and charge between $\mathrm{In}^{3+}$ and $\mathrm{Ln}^{3+}$ ions, $\mathrm{Ln}^{3+}$ ions can be easily incorporated into the $\operatorname{In}_{2} \mathrm{O}_{3}$ nanocrystal lattice by replacing $\mathrm{In}^{3+}$. According to the crystal structure of $\mathrm{In}_{2} \mathrm{O}_{3}$ which crystallizes with the C-type $\mathrm{Y}_{2} \mathrm{O}_{3}$ structure, two distinct sites are expected for $\mathrm{Ln}^{3+}$ in the In-lattice, namely a low symmetry site of $C_{2}$ and a centrosymmetric site of $S_{6}$.

The optical properties of $\mathrm{Ln}^{3+}$ in $\mathrm{In}_{2} \mathrm{O}_{3}$ NCs have been sporadically reported in recent years [29,192-195]. Kim et al. [193] and Choi et al. [194] observed the $\mathrm{Er}^{3+}$ emission around $1.54 \mu \mathrm{m}$ in $\mathrm{In}_{2} \mathrm{O}_{3}: \mathrm{Er}^{3+}$ under direct excitation of $\mathrm{Er}^{3+}$ ions. The $\mathrm{Eu}^{3+}$ luminescence was observed in $\mathrm{In}_{2} \mathrm{O}_{3}$ : $\mathrm{Eu}^{3+} \mathrm{QDs}$ upon indirect excitation above $350 \mathrm{~nm}$ at room temperature [29], due possibly to the host sensitization. Antic-Fidancev and co-workers [195] performed the energy-level-fitting of $\mathrm{Eu}^{3+}$ in C-type $\mathrm{In}_{2} \mathrm{O}_{3}$ polycrystals. 21 energy levels belonging to ${ }^{7} \mathrm{~F}_{J}(J=0,1,2,3,4)$ multiplets of $\mathrm{Eu}^{3+}$ at the $C_{2}$ site of $\operatorname{In}_{2} \mathrm{O}_{3}$ were subjected to the fitting, yielding small $\mathrm{rms}$ deviation of $3.9 \mathrm{~cm}^{-1}$. Recently, more elaborate spectroscopy and electronic structure analysis of $\mathrm{Eu}^{3+}$ in $\mathrm{In}_{2} \mathrm{O}_{3}$ NCs prepared by a solvothermal method were carried out in our group [115]. $48 \mathrm{CF}$ levels below 25,500 $\mathrm{cm}^{-1}$ of $\mathrm{Eu}^{3+}$ at the $\mathrm{C}_{2}$ site of $\operatorname{In}_{2} \mathrm{O}_{3}$ were located and assigned based on the $10 \mathrm{~K}$ high-resolution PL excitation and emission spectra. Fig. 6 presents the emission and excitation spectra of $\mathrm{Eu}^{3+}$ in $\mathrm{In}_{2} \mathrm{O}_{3}$ NCs. As shown in Fig. 6a, upon di- rect excitation from the ground state ${ }^{7} \mathrm{~F}_{0}$ to ${ }^{5} \mathrm{D}_{2}$ of $\mathrm{Eu}^{3+}\left(C_{2}\right)$ at $465.1 \mathrm{~nm}$, sharp emission lines corresponding to ${ }^{5} \mathrm{D}_{1} \rightarrow{ }^{7} \mathrm{~F}_{1}$ and ${ }^{5} \mathrm{D}_{0} \rightarrow{ }^{7} \mathrm{~F}_{J}(J=0,1,2,3,4,5,6)$ transitions of $\mathrm{Eu}^{3+}$ were observed at 533.0, 580.4, 586.3, 611.0, 648.4, 709.4, 741.4 and $804.4 \mathrm{~nm}$, respectively. Sharp excitation peaks centered at $467.4,528.2$ and $580.4 \mathrm{~nm}$ attributing to the direct excitation of $\mathrm{Eu}^{3+}$ from the ground state ${ }^{7} \mathrm{~F}_{0}$ to different ${ }^{5} \mathrm{D}_{J}(J=$ $2,1,0)$ multiplets can be well assigned as illustrated in Fig. 6b. Furthermore, besides the direct excitation lines of $\mathrm{Eu}^{3+}$, an intense broad UV band centered at $350 \mathrm{~nm}$ that originates from the bandgap absorption of $\operatorname{In}_{2} \mathrm{O}_{3} \mathrm{NCs}$ is also presented in Fig. 6b, indicating that the $\mathrm{Eu}^{3+}$ emissions can be achieved via an efficient nonradiative energy transfer process from the $\mathrm{In}_{2} \mathrm{O}_{3}$ host to $\mathrm{Eu}^{3+}$.

The energy-level-fitting was performed and the procedure is similar to that of $\mathrm{TiO}_{2}: \mathrm{Er}^{3+}$. The rms deviation of the final fit is only $13.8 \mathrm{~cm}^{-1}$, indicative of excellent agreement between the experimental and fitted CF levels. The fitted energy levels are compared with experimental values in Table 6. The FI and CF parameters are listed in Table 3. The CF parameters of $B_{0}^{2}, \operatorname{Im} B_{0}^{2}, B_{0}^{6}, \operatorname{Im} B_{2}^{6}, \operatorname{Im} B_{4}^{6}$ and $\operatorname{Im} B_{6}^{6}$ are significantly different from that reported by Antic-Fidancev et al. [195], which is most probably due to much less experimental data (only 21 CF levels) included in their energy-level-fitting and thus the less reliability of the sixthrank parameters than that of the second- and fourth-rank parameters. The obtained CF parameters are also compared with that of cubic $\mathrm{Y}_{2} \mathrm{O}_{3}: \mathrm{Eu}^{3+}$ [196]. The FI and second-rank $\mathrm{CF}$ parameters of fitting results are close to that at $\mathrm{C}_{2}$ site in $\mathrm{Y}_{2} \mathrm{O}_{3}: \mathrm{Eu}^{3+}$, but the other $\mathrm{CF}$ parameters differ appreciably in magnitude. Particularly, the $\operatorname{Im} B_{4}^{4}, \operatorname{Im} B_{4}^{6}$, $\operatorname{Im} B_{6}^{6}$ and $\mathrm{Re}_{6}^{6}$ values of $\mathrm{Eu}^{3+}$ in $\operatorname{In}_{2} \mathrm{O}_{3}$ have opposite signs,
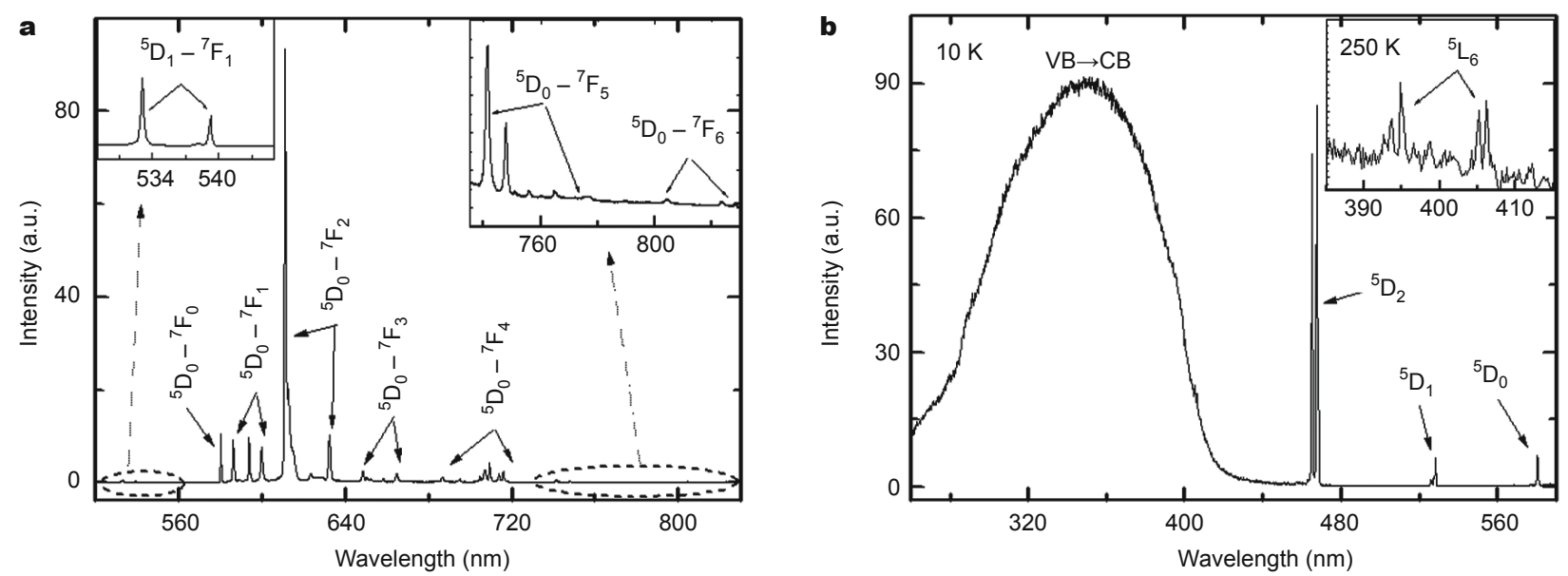

Figure 6 Optical spectra of $\mathrm{Eu}^{3+}$ at the $C_{2}$ site in $\mathrm{In}_{2} \mathrm{O}_{3}$ NCs. (a) $10 \mathrm{~K}$ emission spectrum upon excitation at $465.1 \mathrm{~nm}$; (b) $10 \mathrm{~K}$ excitation spectra by monitoring the ${ }^{5} \mathrm{D}_{0} \rightarrow{ }^{7} \mathrm{~F}_{2}$ transition at $611.0 \mathrm{~nm}$; the inset in (b) shows the $250 \mathrm{~K}$ excitation spectrum in the region of ${ }^{5} \mathrm{~L}_{6}$. Reprinted with permission from Ref. [115]. Copyright 2010, American Chemical Society. 
Table 6 Energy levels of $\mathrm{Eu}^{3+}$ at the $C_{2}$ site of $\mathrm{In}_{2} \mathrm{O}_{3} \mathrm{NCs}$ (unit: $\mathrm{cm}^{-1}$ ). Reprinted with permission from Ref. [115]. Copyright 2010, American Chemical Society

\begin{tabular}{|c|c|c|c|c|c|c|c|}
\hline \multirow{2}{*}{ Multiplet } & \multicolumn{2}{|c|}{ Energy } & \multirow{2}{*}{$\Delta E$} & \multirow{2}{*}{ Multiplet } & \multicolumn{2}{|c|}{ Energy } & \multirow{2}{*}{$\Delta E$} \\
\hline & Exp. & Fit & & & Exp. & Fit & \\
\hline${ }^{7} \mathrm{~F}_{0}$ & 0 & 2 & -2 & & - & 5128 & - \\
\hline \multirow[t]{3}{*}{${ }^{7} \mathrm{~F}_{1}$} & 173 & 184 & -11 & & - & 5141 & - \\
\hline & 389 & 396 & -7 & & 5159 & 5143 & 16 \\
\hline & 566 & 582 & -16 & & - & 5405 & - \\
\hline \multirow{5}{*}{${ }^{7} \mathrm{~F}_{2}$} & 866 & 852 & 14 & & - & 5412 & - \\
\hline & 900 & 879 & 21 & & - & 5434 & - \\
\hline & 975 & 961 & 14 & & - & 5529 & - \\
\hline & 1191 & 1172 & 19 & & - & 5533 & - \\
\hline & 1422 & 1415 & 7 & & - & 5696 & - \\
\hline \multirow[t]{7}{*}{${ }^{7} \mathrm{~F}_{3}$} & 1797 & 1803 & -6 & & - & 5696 & - \\
\hline & 1854 & 1867 & -13 & ${ }^{5} \mathrm{D}_{0}$ & 17,229 & 17,229 & 0 \\
\hline & 1898 & 1908 & -10 & ${ }^{5} \mathrm{D}_{1}$ & 18,932 & 18,910 & 22 \\
\hline & 1961 & 1963 & -2 & & 18,968 & 18,964 & 4 \\
\hline & 2026 & 2037 & -11 & & 19,020 & 19,048 & -28 \\
\hline & 2176 & 2178 & -2 & ${ }^{5} \mathrm{D}_{2}$ & 21,365 & 21,372 & -7 \\
\hline & - & 2234 & - & & - & 21,378 & - \\
\hline \multirow[t]{9}{*}{${ }^{7} \mathrm{~F}_{4}$} & 2663 & 2665 & -2 & & 21,395 & 21,392 & 3 \\
\hline & 2812 & 2798 & 14 & & - & 21,463 & - \\
\hline & 2841 & 2851 & -10 & & 21,501 & 21,490 & 11 \\
\hline & 3040 & 3039 & 1 & & - & 24,153 & - \\
\hline & 3085 & 3070 & 15 & & - & 24,201 & - \\
\hline & 3130 & 3128 & 2 & & - & 24,227 & - \\
\hline & 3219 & 3216 & 3 & & - & 24,235 & - \\
\hline & 3260 & 3252 & 8 & & - & 24,261 & - \\
\hline & 3283 & 3287 & -4 & & - & 24,282 & - \\
\hline \multirow[t]{11}{*}{${ }^{7} \mathrm{~F}_{5}$} & 3742 & 3739 & 3 & & - & 24,291 & - \\
\hline & 3856 & 3853 & 3 & ${ }^{5} \mathrm{~L}_{6}$ & - & 24,557 & - \\
\hline & 3912 & 3903 & 9 & & - & 24,595 & - \\
\hline & 3933 & 3924 & 9 & & 24,618 & 24,632 & -14 \\
\hline & 3999 & 3994 & 5 & & 24,704 & 24,697 & 7 \\
\hline & 4076 & 4078 & -2 & & - & 24,703 & - \\
\hline & - & 4089 & - & & - & 24,779 & - \\
\hline & 4149 & 4157 & -8 & & - & 24,829 & - \\
\hline & 4337 & 4342 & -5 & & - & 25,018 & - \\
\hline & 4356 & 4358 & -2 & & - & 25,239 & - \\
\hline & - & 4421 & - & & - & 25,310 & - \\
\hline \multirow[t]{3}{*}{${ }^{7} \mathrm{~F}_{6}$} & 4798 & 4812 & -14 & & 25,329 & 25,330 & -1 \\
\hline & - & 4819 & - & & 25,406 & 25,400 & 6 \\
\hline & 5086 & 5104 & -18 & & 25,471 & 25,466 & 5 \\
\hline
\end{tabular}


indicating a different $\mathrm{CF}$ environment experienced by $\mathrm{Eu}^{3+}$ in $\mathrm{In}_{2} \mathrm{O}_{3}$ host. The value of $S$ for $\mathrm{Eu}^{3+}$ at the $C_{2}$ site of $\operatorname{In}_{2} \mathrm{O}_{3}$ was calculated to be $790 \mathrm{~cm}^{-1}$.

\section{$\mathrm{Ln}^{3+}$ doped $\mathrm{Ga}_{2} \mathrm{O}_{3} \mathrm{NCs}$}

Gallium oxide $\left(\mathrm{Ga}_{2} \mathrm{O}_{3}\right)$ has five crystal structures and $\beta-\mathrm{Ga}_{2} \mathrm{O}_{3}$ is the most stable phase, which is a semiconductor with a wide bandgap of $\sim 4.8 \mathrm{eV}[197,198]$. The structure of $\beta-\mathrm{Ga}_{2} \mathrm{O}_{3}$ is monoclinic with a space group of $C_{2 / m}$, and $\mathrm{Ga}^{3+}$ ions occupy two crystallographic sites, namely tetrahedral and octahedral, respectively [199]. $\beta-\mathrm{Ga}_{2} \mathrm{O}_{3}$ is a good host for $\mathrm{Ln}^{3+}$ ions due to its high thermal and chemical stability and wide range of optical transparency. To date, the visible to infrared luminescence of $\mathrm{Ln}^{3+}$ in $\mathrm{Ga}_{2} \mathrm{O}_{3}$ have been achieved under either photon or electron excitation [59,90,98,99,104,105,200-205]. However, the $\mathrm{Ln}^{3+}$ emission and excitation spectra previously reported show a broadband pattern rather than sharp transition lines that are typical of $\mathrm{Ln}^{3+}$ in a crystalline environment, indicating that $\mathrm{Eu}^{3+}$ ions might be located at the surface or close to the surface sites instead of entering the crystal lattice of $\beta-\mathrm{Ga}_{2} \mathrm{O}_{3}$. In our recent work, sharp emission lines of $\mathrm{Eu}^{3+}$ in $\beta-\mathrm{Ga}_{2} \mathrm{O}_{3}$ NCs prepared via a simple combustion method were observed (Fig. 7), suggesting that $\mathrm{Eu}^{3+}$ ions were embedded in $\beta-\mathrm{Ga}_{2} \mathrm{O}_{3}$ nano-lattice. Interestingly, it was observed that the substitution of $\mathrm{Eu}^{3+}$ for $\mathrm{Ga}^{3+}$ occurred at merely single site, in spite of two crystallographically nonequivalent sites of $\mathrm{Ga}^{3+}$ in $\beta-\mathrm{Ga}_{2} \mathrm{O}_{3}$. Spectroscopic evidence validated the local site symmetry of $C_{s}$ for $\mathrm{Eu}^{3+}$ at this single site [83]. From the $10 \mathrm{~K}$ high-resolution excitation and emission spectra of $\mathrm{Eu}^{3+}$ in $\beta-\mathrm{Ga}_{2} \mathrm{O}_{3}, 71 \mathrm{CF}$ levels of $\mathrm{Eu}^{3+}$ were identified and listed in Table 7. The CF levels of $\mathrm{Eu}^{3+}$

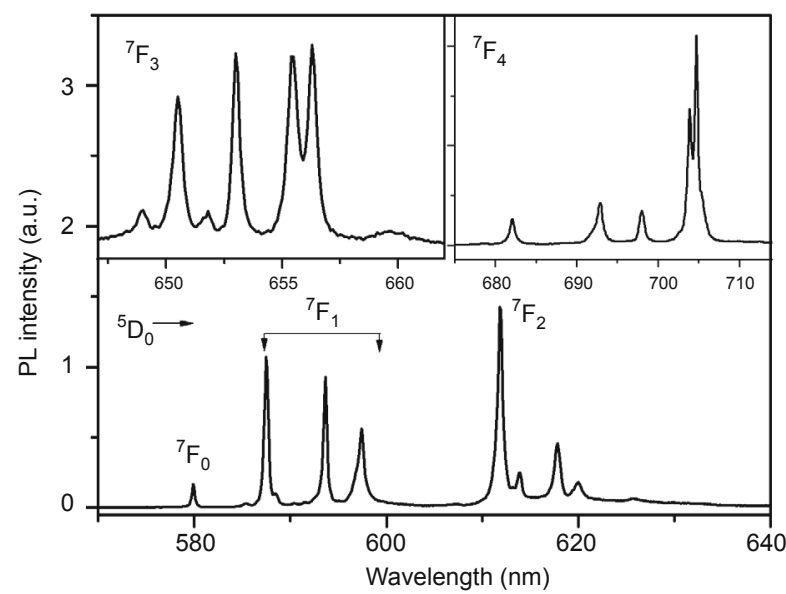

Figure 7 High-resolution PL spectra of $\mathrm{Eu}^{3+}$ in $\beta-\mathrm{Ga}_{2} \mathrm{O}_{3} \mathrm{NCs}$ upon bandgap excitation at $10 \mathrm{~K}$. Reproduced from Ref. [83] with permission from the PCCP Owner Societies. were fitted at $C_{s}$ symmetry using the $f$-shell empirical programs from Reid [185]. The detailed fitting procedure is similar to that in $\mathrm{TiO}_{2}: \mathrm{Er}^{3+}$. The FI parameters of $\mathrm{LaF}_{3}: \mathrm{Eu}^{3+}$ [48] and CF parameters of $\mathrm{Gd}_{2} \mathrm{O}_{3}: \mathrm{Eu}^{3+}$ [182] were used as initial values in the fitting. The standard $r m s$ deviation of the final fit is $12.9 \mathrm{~cm}^{-1}$, showing an excellent agreement between experimental and calculated values. The experimental and fitted CF levels below $34,000 \mathrm{~cm}^{-1}$ are compared in Table 7. The obtained FI and CF parameters are listed in Table 3. The calculated value of $S$ is $546 \mathrm{~cm}^{-1}$ for $\beta-\mathrm{Ga}_{2} \mathrm{O}_{3}: \mathrm{Eu}^{3+}$, which is much smaller than $\mathrm{In}_{2} \mathrm{O}_{3}: \mathrm{Eu}^{3+}(790$ $\mathrm{cm}^{-1}$ ) [115] with $C_{2}$ symmetry.

\section{DOPING LOCATION OF LANTHANIDE IONS IN SNCs}

It is well known that the electronic structures of $\mathrm{Ln}^{3+}$ are closely related to their locations in the host materials [172]. Because of charge imbalance and lattice distortion, multiple sites of $\mathrm{Ln}^{3+}$ with distinct CF surroundings are prone to be formed by introducing $\mathrm{Ln}^{3+}$ ions into the lattices of SNCs. In view of the diverse CF surroundings, such multiple sites of $\mathrm{Ln}^{3+}$ are usually characterized by different PL patterns and decays, which will facilitate the survey of the local structures of $\mathrm{Ln}^{3+}$ ions in SNCs by means of the site-selective or time-resolved spectroscopic techniques.

\section{Surface location of $\mathrm{Ln}^{3+}$ in SNCs}

Due to the charge imbalance and the large discrepancy of ionic radius between $\mathrm{Ln}^{3+}$ and some of semiconductor cations, $\mathrm{Ln}^{3+}$ ions can hardly be incorporated into such kinds of SNCs lattice via common wet chemical method. Instead, in most cases, the dopant ions are prone to accumulate on the loosely-structured surface sites of the NCs. Because of the continuous distributions of $\mathrm{Ln}^{3+}$ in various surface sites, the luminescence spectra usually feature broad and unresolved bands.

As an example, the emission spectra of $\mathrm{Eu}^{3+}$ ions on the surface of $\mathrm{TiO}_{2}$ and $\mathrm{ZnO}$ NCs are showcased in Fig. 8. For $\mathrm{Eu}^{3+}$ in both samples, the PL emission spectra exhibited broad bands originating from the ${ }^{5} \mathrm{D}_{0}$ to ${ }^{7} \mathrm{~F}_{J}$ transitions, and the emission intensity of ${ }^{5} \mathrm{D}_{0} \rightarrow{ }^{7} \mathrm{~F}_{2}$ is much stronger than that of ${ }^{5} \mathrm{D}_{0} \rightarrow{ }^{7} \mathrm{~F}_{1}$, indicating that $\mathrm{Eu}^{3+}$ occupied in highly distorted non-centrosymmetric locations in the surface of SNCs. Thanks to the ease of the compensation for lattice distortion and charge imbalance on the surface, the maximal doping concentration of $\mathrm{Ln}^{3+}$ on the outer surface sites are usually much larger than that in the inner lattices of SNCs. As shown in Fig. 8a, the PL concentration quenching did not occur even when the $\mathrm{Eu}^{3+}$ concentration reached 16 mol.\% in $\mathrm{TiO}_{2}$ NCs. In addition to the Eu-re- 
Table $7 \mathrm{CF}$ levels of $\mathrm{Eu}^{3+}$ at the $C_{s}$ site of $\beta-\mathrm{Ga}_{2} \mathrm{O}_{3}\left(\right.$ unit: $\left.\mathrm{cm}^{-1}\right)$. Reproduced from Ref. [83] with permission from the PCCP Owner Societies

\begin{tabular}{|c|c|c|c|c|c|c|c|c|c|c|c|c|c|c|}
\hline \multirow{2}{*}{ Multiplet } & \multicolumn{2}{|c|}{ Energy $\left(\mathrm{cm}^{-1}\right)$} & \multirow{2}{*}{ Multiplet } & \multicolumn{2}{|c|}{ Energy $\left(\mathrm{cm}^{-1}\right)$} & \multirow{2}{*}{ Multiplet } & \multicolumn{2}{|c|}{ Energy $\left(\mathrm{cm}^{-1}\right)$} & \multirow{2}{*}{ Multiplet } & \multicolumn{2}{|c|}{ Energy $\left(\mathrm{cm}^{-1}\right)$} & \multirow{2}{*}{ Multiplet } & \multicolumn{2}{|c|}{ Energy $\left(\mathrm{cm}^{-1}\right)$} \\
\hline & Exp. & Fit & & Exp. & Fit & & Exp. & Fit & & Exp. & Fit & & Exp. & Fit \\
\hline${ }^{7} \mathrm{~F}_{0}$ & 0 & 4 & & 21,510 & 21,498 & & 26,483 & 26,471 & & - & 27,744 & & - & 31,290 \\
\hline \multirow[t]{3}{*}{${ }^{7} \mathrm{~F}_{1}$} & 223 & 242 & & - & 21,526 & & - & 26,484 & & - & 27,751 & & 31,299 & 31,301 \\
\hline & 401 & 402 & ${ }^{5} \mathrm{D}_{3}$ & 24,284 & 24,273 & & - & 26,495 & & - & 27,834 & & - & 31,313 \\
\hline & 505 & 515 & & - & 24,293 & & 26,511 & 26,505 & & - & 27,838 & & - & 31,330 \\
\hline \multirow[t]{5}{*}{${ }^{7} \mathrm{~F}_{2}$} & 899 & 887 & & 24,325 & 24,314 & & - & 26,521 & & - & 27,880 & & - & 31,349 \\
\hline & 955 & 943 & & - & 24,335 & & - & 26,529 & & - & 27,883 & & - & 31,355 \\
\hline & 1058 & 1061 & & - & 24,345 & & - & 26,546 & & - & 27,931 & & - & 31,368 \\
\hline & 1115 & 1103 & & - & 24,356 & & - & 26,548 & & - & 27,964 & & 31,377 & 31,389 \\
\hline & 1265 & 1264 & & - & 24,372 & & - & 26,563 & & - & 27,988 & & - & 31,391 \\
\hline \multirow[t]{7}{*}{${ }^{7} \mathrm{~F}_{3}$} & 1836 & 1845 & ${ }^{5} \mathrm{~L}_{6}$ & - & 24,758 & & - & 26,572 & & - & 28,038 & & - & 31,408 \\
\hline & 1872 & 1858 & & - & 24,772 & & - & 26,573 & & - & 28,044 & & - & 31,421 \\
\hline & 1902 & 1893 & & - & 24,833 & & - & 26,587 & & - & 28,080 & & - & 31,444 \\
\hline & 1930 & 1933 & & 24,876 & 24,878 & & 26,617 & 26,612 & & - & 28,087 & & - & 31,469 \\
\hline & 1986 & 1983 & & - & 24,921 & & - & 26,620 & & - & 28,101 & & - & 31,472 \\
\hline & 2007 & 1990 & & 24,963 & 24,934 & & - & 26,668 & & - & 28,107 & & - & 31,473 \\
\hline & 2086 & 2089 & & - & 24,978 & & - & 26,677 & & - & 28,120 & & - & 31,491 \\
\hline${ }^{7} \mathrm{~F}_{4}$ & 2584 & 2599 & & 25,107 & 25,106 & & - & 26,713 & & - & 28,127 & & - & 31,494 \\
\hline & - & 2792 & & 25,195 & 25,209 & & - & 26,721 & & - & 28,174 & & - & 31,504 \\
\hline & 2812 & 2814 & & 25,253 & 25,257 & & - & 26,724 & & - & 28,186 & & - & 31,539 \\
\hline & 2918 & 2913 & & - & 25,289 & & - & 26,741 & & - & 28,193 & & - & 31,567 \\
\hline & - & 2952 & & 25,323 & 25,349 & & - & 26,744 & & - & 28,213 & & - & 31,570 \\
\hline & 3038 & 3033 & & 25,400 & 25,370 & & - & 26,745 & & - & 28,317 & & - & 31,570 \\
\hline & 3054 & 3057 & ${ }^{5} \mathrm{G}_{2,3}$ & - & 25,800 & & - & 26,776 & & - & 28,327 & & 31,596 & 31,586 \\
\hline & - & 3130 & ${ }^{5} \mathrm{G}_{4,5}$ & - & 25,869 & & - & 26,788 & & - & 28,388 & & - & 31,621 \\
\hline & - & 3204 & ${ }^{5} G_{6}$ & - & 25,871 & & - & 26,799 & & - & 28,431 & & - & 31,649 \\
\hline${ }^{7} \mathrm{~F}_{5}$ & - & 3741 & ${ }^{5} \mathrm{~L}_{7}$ & - & 25,892 & & 26,817 & 26,805 & & - & 28,455 & & 31,676 & 31,679 \\
\hline & - & 3745 & & 25,900 & 25,893 & ${ }^{5} \mathrm{~L}_{8}$ & - & 26,933 & & - & 28,541 & & - & 31,690 \\
\hline & - & 3881 & & - & 25,927 & & - & 26,949 & & - & 28,566 & & - & 31,696 \\
\hline & - & 3957 & & 25,947 & 25,947 & & - & 26,972 & & - & 28,575 & & - & 31,722 \\
\hline & - & 3991 & & 25,974 & 25,970 & & - & 26,974 & & - & 28,594 & & - & 31,731 \\
\hline & - & 3994 & & 25,994 & 26,000 & & 27,020 & 27,033 & & - & 28,680 & & - & 31,761 \\
\hline & - & 4024 & & - & 26,035 & & - & 27,054 & & - & 28,696 & & - & 31,792 \\
\hline & - & 4106 & & - & 26,055 & & - & 27,089 & & - & 28,778 & & - & 31,809 \\
\hline & - & 4147 & & - & 26,078 & & - & 27,094 & & - & 28,778 & & - & 31,834 \\
\hline & - & 4203 & & 26,123 & 26,118 & & - & 27,166 & & - & 28,791 & & - & 31,834 \\
\hline & - & 4271 & & - & 26,150 & & - & 27,188 & & - & 28,793 & ${ }^{3} \mathrm{P}_{0}$ & - & 32,366 \\
\hline${ }^{7} \mathrm{~F}_{6}$ & - & 4846 & & - & 26,170 & & 27,218 & 27,199 & ${ }^{5} \mathrm{H}_{3,4}$ & - & 30,869 & ${ }^{5} \mathrm{~F}_{2,3}$ & - & 32,854 \\
\hline & - & 4858 & & 26,199 & 26,207 & & 27,278 & 27,269 & ${ }^{5} \mathrm{H}_{5,6}$ & - & 30,881 & & - & 32,879 \\
\hline & - & 4933 & & - & 26,220 & & - & 27,290 & ${ }^{5} \mathrm{H}_{7}$ & - & 30,909 & & - & 32,895 \\
\hline & - & 4941 & & - & 26,236 & & - & 27,316 & & - & 30,936 & & - & 32,948 \\
\hline & - & 5037 & & 26247 & 26,242 & & 27,322 & 27,332 & & - & 30,949 & & 32,960 & 32,954 \\
\hline & - & 5060 & & - & 26,258 & & - & 27,337 & & - & 30,959 & & - & 32,967 \\
\hline & - & 5221 & & 26,288 & 26,281 & & - & 27,349 & & 30,979 & 30,962 & & 33,014 & 33,015 \\
\hline & - & 5235 & & - & 26,295 & & - & 27,472 & & - & 30,978 & & - & 33,031 \\
\hline & - & 5286 & & - & 26,295 & ${ }^{2} \mathrm{D}_{4}$ & - & 27,499 & & - & 31,034 & & - & 33,050 \\
\hline & - & 5316 & & - & 26,349 & ${ }^{5} \mathrm{~L}_{9,10}$ & 27,533 & 27,528 & & - & 31,037 & & 33,102 & 33,104 \\
\hline & - & 5327 & & - & 26,355 & & - & 27,548 & & 31,075 & 31,075 & & - & 33,162 \\
\hline & - & 5462 & & - & 26,359 & & - & 27,564 & & - & 31,099 & & - & 33,194 \\
\hline & - & 5463 & & - & 26,367 & & - & 27,574 & & - & 31,131 & ${ }^{5} \mathrm{~F}_{1}$ & - & 33,324 \\
\hline${ }^{5} \mathrm{D}_{0}$ & 17,244 & 17,232 & & 26,385 & 26,397 & & 27,586 & 27,590 & & - & 31,162 & & - & 33,343 \\
\hline${ }^{5} \mathrm{D}_{1}$ & 18,975 & 18,959 & & - & 26,402 & & - & 27,609 & & - & 31,186 & & - & 33,356 \\
\hline & 19,008 & 19,012 & & - & 26,422 & & 27,617 & 27,629 & & - & 31,205 & ${ }^{5} \mathrm{~F}_{4}$ & - & 33,373 \\
\hline & 19,033 & 19,053 & & - & 26,434 & & 27,647 & 27,643 & & - & 31,213 & & - & 33,397 \\
\hline${ }^{5} \mathrm{D}_{2}$ & 21,436 & 21,445 & & - & 26,436 & & - & 27,644 & & - & 31,229 & & - & 33,402 \\
\hline & 21,450 & 21,464 & & 26,455 & 26,450 & & - & 27,696 & & - & 31,256 & & 33,445 & 33,462 \\
\hline & 21,468 & 21,478 & & - & 26,468 & & 27,693 & 27,702 & & - & 31,285 & & & \\
\hline
\end{tabular}



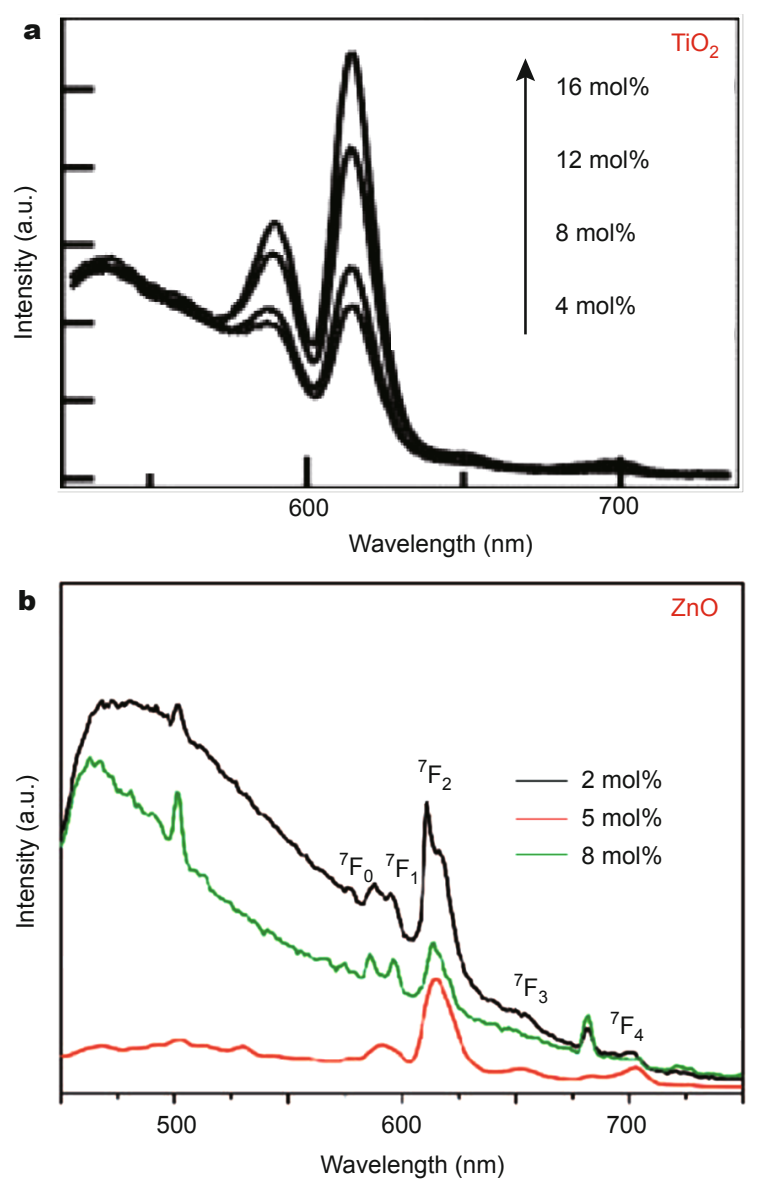

Figure 8 PL emission spectra of $\mathrm{Eu}^{3+}$ doped (a) $\mathrm{TiO}_{2}$ (b) $\mathrm{ZnO}$ NCs upon excitation above the bandgap of $\mathrm{TiO}_{2}(325 \mathrm{~nm})$ and $\mathrm{ZnO}(380 \mathrm{~nm})$, respectively. Adapted with permission from Refs. [37,38]. Copyright 2008, Wiley-VCH Verlag GmbH \& Co. KGaA and American Chemical Society.

lated emission, the PL emission of surface defects typical of broad bands in the visible region was often observed to superpose on the emission spectra of $\mathrm{Ln}^{3+}$. As shown in Fig. 8, the broad defect emission bands centered at around $525 \mathrm{~nm}$ were observed in both $\mathrm{TiO}_{2}$ and $\mathrm{ZnO}$ samples. It should be noted that the energy transfer from the hosts to surface $\mathrm{Ln}^{3+}$ ions becomes easier with the aid of the surface defect states, as will be discussed later.

\section{Multiple-site structure of $\mathrm{Ln}^{3+}$ ions}

\section{Site-selective spectroscopy}

Due to the discrepancy of surroundings of $\mathrm{Ln}^{3+}$ ions in multiple sites of SNCs, both the PL emission and excitation spectra at each site usually exhibit distinctive optical characteristics in the line position and relative intensities. Site-selective spectroscopy is an effective technique to ac- quire the separated PL spectra of $\mathrm{Ln}^{3+}$ at multiple sites. To successfully separate the PL spectra of $\mathrm{Ln}^{3+}$ at each site, the primary condition is the insignificant spectral overlap between PL spectra of different sites at wavelengths selected as excitation or monitoring lines. Moreover, a low experimental temperature is commonly set to eliminate the influence of phonon broadening on the PL lines.

In our previous work, by using $\mathrm{Eu}^{3+}$ as a sensitive structural probe, we showed unambiguously the presence of multiple sites of $\mathrm{Eu}^{3+}$ in 9-nm hexagonal wurtzite $\mathrm{ZnO}$ NCs that were synthesized via a facile sol-gel method [59,206]. As compared in Fig. 9, two types of luminescence sites of $\mathrm{Eu}^{3+}$ were clearly identified by means of site-selective spectroscopy at low temperature $(10 \mathrm{~K})$. One site (denoted as
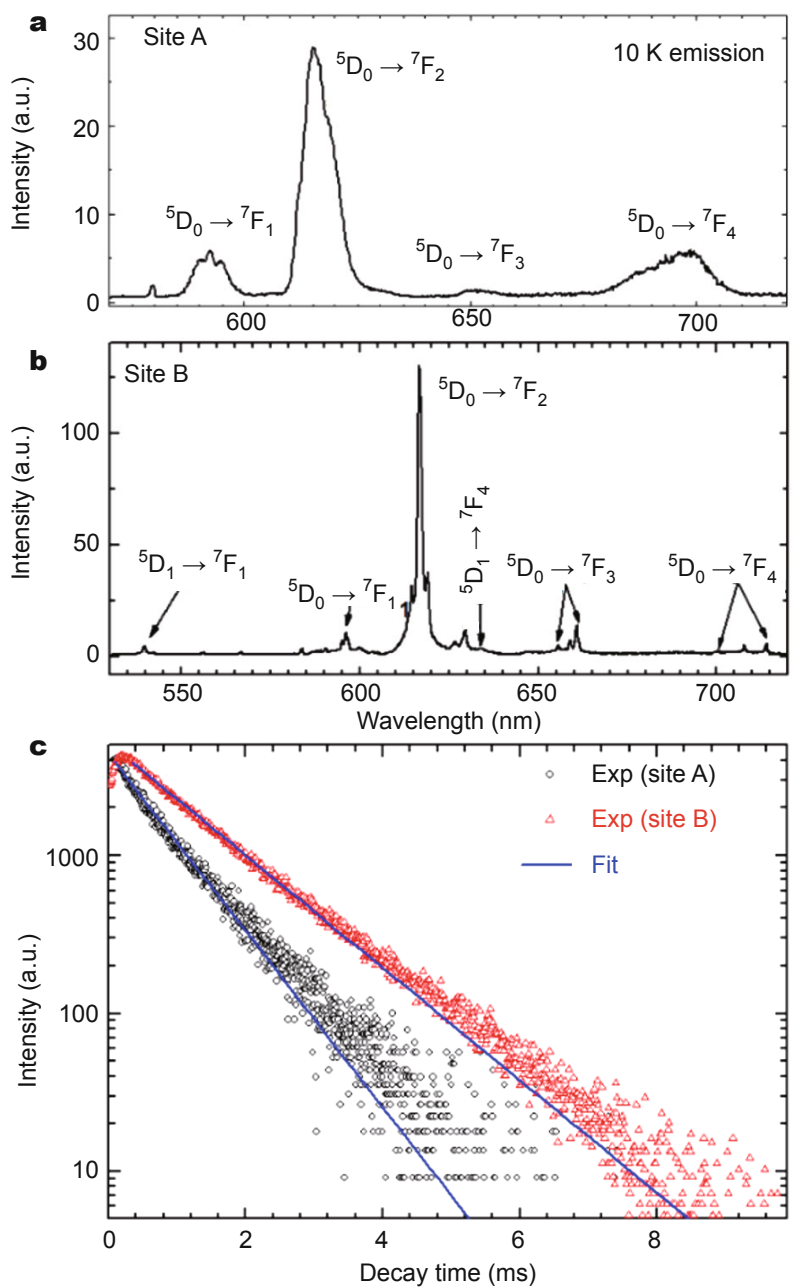

Figure $910 \mathrm{~K}$ site-selective $\mathrm{PL}$ emission spectra of $\mathrm{ZnO}: \mathrm{Eu}^{3+} \mathrm{NCs}$ under the (a) $465 \mathrm{~nm}$ excitation for $\mathrm{Eu}^{3+}$ at site $\mathrm{A}$ and (b) $467.8 \mathrm{~nm}$ excitation for $\mathrm{Eu}^{3+}$ at site B; (c) $10 \mathrm{~K}$ PL decays from ${ }^{5} \mathrm{D}_{0}$ of $\mathrm{Eu}^{3+}$ at sites $\mathrm{A}$ and $\mathrm{B}$ in $\mathrm{ZnO}: \mathrm{Eu}^{3+} \mathrm{NCs}$ under the site-selective excitation at 464.8 and $467.8 \mathrm{~nm}$, respectively. Adapted with permission from Ref. [206]. Copyright 2007, Optical Society of America. 
site A) exhibited broadened PL excitation and emission peaks with the most intense emission at $615 \mathrm{~nm}$ similar to that of $\mathrm{Eu}^{3+}$ ion in glasslike phase, which is associated with the distorted lattice sites near the surface. These broad emission lines centered at 580, 592, 615, 650 and $698 \mathrm{~nm}$ can be readily ascribed to the ${ }^{5} \mathrm{D}_{0} \rightarrow{ }^{7} \mathrm{~F}_{0},{ }^{5} \mathrm{D}_{0} \rightarrow{ }^{7} \mathrm{~F}_{1},{ }^{5} \mathrm{D}_{0} \rightarrow{ }^{7} \mathrm{~F}_{2}$, ${ }^{5} \mathrm{D}_{0} \rightarrow{ }^{7} \mathrm{~F}_{3}$, and ${ }^{5} \mathrm{D}_{0} \rightarrow{ }^{7} \mathrm{~F}_{4}$ transitions of $\mathrm{Eu}^{3+}$, respectively (Fig. 9a). Unlike site A, sharp PL excitation and emission lines of $\mathrm{Eu}^{3+}$ with the most intense emission lines at $616.6 \mathrm{~nm}$ were observed (Fig. 9b), which are originated from the $\mathrm{Eu}^{3+}$ ions located at a lattice site with ordered crystalline environment (denoted as site B). The value of full width at half-maximum height (FWHM) of site B is much smaller than that of site A, decreasing from $\sim 8.0 \mathrm{~nm}$ (the $615-\mathrm{nm}$ peak) to $0.9 \mathrm{~nm}$ (the 616.6-nm peak). In addition to these very sharp emission lines of the ${ }^{5} \mathrm{D}_{0} \rightarrow^{7} \mathrm{~F}_{J}(J=0,1,2,3,4)$ transitions, weak emission lines of the ${ }^{5} \mathrm{D}_{1} \rightarrow{ }^{7} \mathrm{~F}_{J}(J=1,2,3,4)$ transitions of $\mathrm{Eu}^{3+}$ were also detected at $10 \mathrm{~K}$ (Fig. 9b), further revealing the much better crystalline surroundings for $\mathrm{Eu}^{3+}$ at site $\mathrm{B}$ relative to that at site $\mathrm{A}$.

The PL lifetime $(\tau)$ depends significantly upon radiative and nonradiative decay rates of the excited state, which are bound up with the crystalline environment around the dopants [172]. Because of the existence of multiple sites of $\mathrm{Ln}^{3+}$ ions in SNCs, different luminescence decays of $\mathrm{Ln}^{3+}$ ions are expected in $\mathrm{Ln}^{3+}$ doped SNCs. For this reason, we detected two types of PL decays of $\mathrm{Eu}^{3+}$ in $\mathrm{ZnO}: \mathrm{Eu}^{3+} \mathrm{NCs}$ when monitoring the site-selective emissions of $\mathrm{Eu}^{3+}$ at the surface and lattice sites (Fig. 9c) [59]. For $\mathrm{Eu}^{3+}$ at the surface site (site A), the PL decay exhibits a single exponential behavior, and the ${ }^{5} \mathrm{D}_{0}$ lifetime was determined to be 0.75 ms by fitting with single exponential function. Unlike $\mathrm{Eu}^{3+}$ ions at site $\mathrm{A}$, the $\mathrm{PL}$ decay from ${ }^{5} \mathrm{D}_{0}$ of $\mathrm{Eu}^{3+}$ at the lattice site (site $\mathrm{B}$ ) features a noticeable rising edge at the initial stage and a single exponential decay in the tail when excited to the ${ }^{5} \mathrm{D}_{2}$ state. The intrinsic lifetime of ${ }^{5} \mathrm{D}_{0}$ was estimated to be $1.25 \mathrm{~ms}$ from the tail at $10 \mathrm{~K}$. Moreover, the luminescence lifetime of ${ }^{5} \mathrm{D}_{0}$ of $\mathrm{Eu}^{3+}$ in $\mathrm{ZnO} \mathrm{NCs}$ was observed to be weakly dependent on the temperature due to the large energy gap between ${ }^{5} \mathrm{D}_{0}$ and its next low-lying ${ }^{7} \mathrm{~F}_{6}(\sim 12,000$ $\left.\mathrm{cm}^{-1}\right)$. The ${ }^{5} \mathrm{D}_{0}$ lifetime of sites $\mathrm{A}$ and $\mathrm{B}$ were determined to be 0.69 and $1.05 \mathrm{~ms}$ by monitoring the site-selective emission $\left({ }^{5} \mathrm{D}_{0} \rightarrow{ }^{7} \mathrm{~F}_{2}\right)$ at room temperature, respectively.

Another typical example for multiple-site structures of $\mathrm{Eu}^{3+}$ was exemplified in anatase $\mathrm{TiO}_{2}$ aggregates assembled from the 10-12 nm $\mathrm{TiO}_{2} \mathrm{NCs}$ (Fig. 10a) [178]. As illustrated in Fig. 10, the PL excitation and emission patterns of $\mathrm{Eu}^{3+}$ ions at three sites differ obviously from each other in line positions, shapes and intensities, indicative of a totally different $\mathrm{CF}$ environment experienced by $\mathrm{Eu}^{3+}$ ions in $\mathrm{TiO}_{2}: \mathrm{Eu}^{3+} \mathrm{NCs}$. When excited at $464.6 \mathrm{~nm}$, the $\mathrm{TiO}_{2}: \mathrm{Eu}^{3+}$ NCs exhibit broadened emission lines with the most intense peak centered at $613.3 \mathrm{~nm}$ similar to that of $\mathrm{Eu}^{3+}$ in glasslike phase (Fig. 10b), which is ascribed to the distorted lattice site near the surface (marked as site I). In stark contrast, upon selective excitations at 470.7 and $472.1 \mathrm{~nm}$, much sharper emission lines with the most intense peaks at 616.7 and $618.1 \mathrm{~nm}$ are observed relative to that of site I (Figs $10 \mathrm{c}$ and $\mathrm{d}$ ), which are originated from the lattice sites with ordered crystalline environment in anatase $\mathrm{TiO}_{2}$ (marked as sites II and III, respectively). It should be noted that, due to the spectral overlap between the monitored

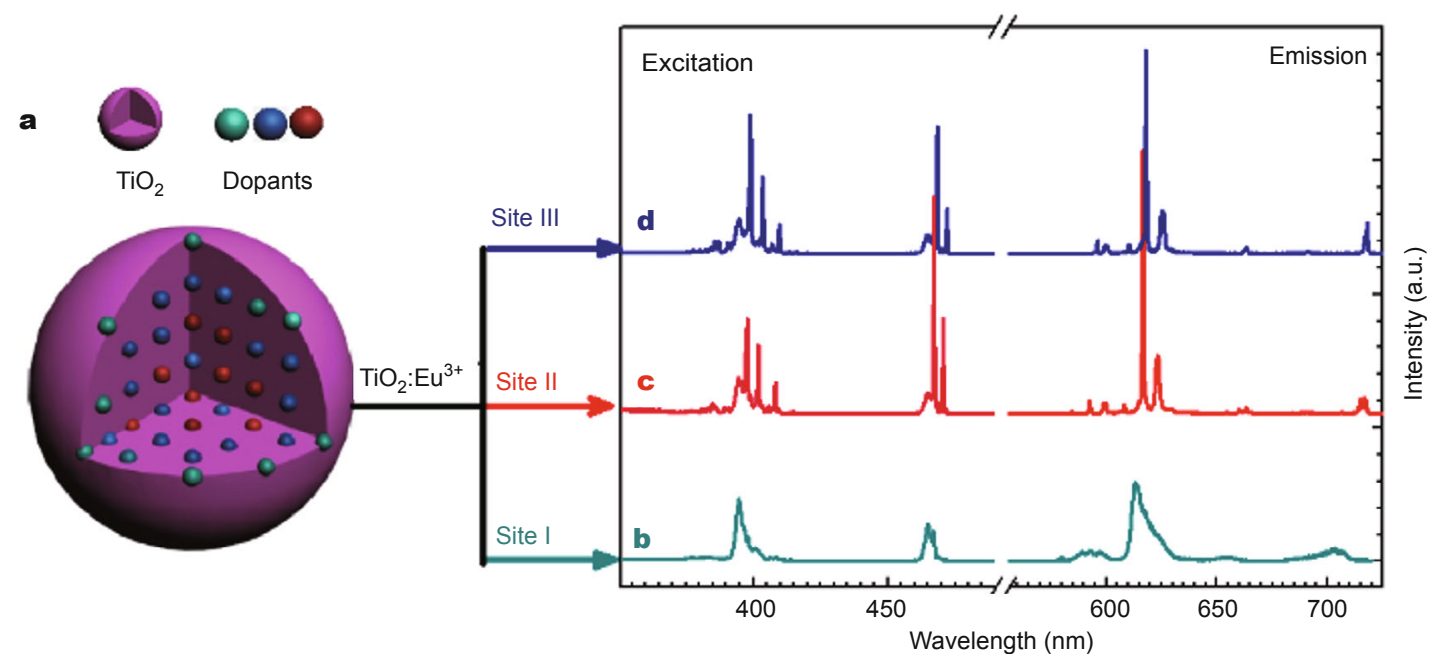

Figure 10 (a) A schematic illustration showing $\mathrm{Eu}^{3+}$ ions doped $\mathrm{TiO}_{2} \mathrm{NCs}$ with multiple luminescence centers of Eu ${ }^{3+}$; $10 \mathrm{~K}$ excitation spectra (left) of $\mathrm{TiO}_{2}: \mathrm{Eu}^{3+} \mathrm{NCs}$ annealed at $400^{\circ} \mathrm{C}$ by monitoring the ${ }^{5} \mathrm{D}_{0} \rightarrow{ }^{7} \mathrm{~F}_{2}$ emissions at (b) $613.3 \mathrm{~nm}$, (c) $616.7 \mathrm{~nm}$, and (d) $618.1 \mathrm{~nm}$ for sites I, II and III, respectively; and $10 \mathrm{~K}$ emission spectra (right) of $\mathrm{TiO}_{2}: \mathrm{Eu}^{3+}$ annealed at $400^{\circ} \mathrm{C}$, with (b) $\lambda_{\mathrm{ex}}=464.6 \mathrm{~nm}$ for site I, (c) $\lambda_{\mathrm{em}}=470.7 \mathrm{~nm}$ for site II, and (d) $\lambda_{\mathrm{ex}}=472.1$ nm for site III. Adapted with permission from Ref. [178]. Copyright 2008, American Chemical Society. 
emission lines at $616.7 \mathrm{~nm}$ for site II (or at $618.1 \mathrm{~nm}$ for site III) and broad emission at $613 \mathrm{~nm}$ for site I, the excitation lines of site I were found to mingle into the site-selective excitation spectra of site II and III.

\section{Time-resolved PL spectroscopy}

In addition to the site-selective spectroscopy aforementioned, time-resolved PL (TRPL) technique is another useful means to identify multiple $\mathrm{Ln}^{3+}$ sites in SNCs. For example, we were unable to pick out the PL from single $\mathrm{Nd}^{3+}$ site by the site-selective spectroscopy, owing to the very close $\mathrm{CF}$ levels $\left(\sim 13 \mathrm{~cm}^{-1}\right)$ of ${ }^{4} \mathrm{~F}_{3 / 2}$ for various $\mathrm{Nd}^{3+}$ ions in $\mathrm{ZnO}$ NCs [207]. As shown in Fig. 11a, upon direct excitation from the ground state ${ }^{4} \mathrm{I}_{9 / 2}$ to the ${ }^{4} \mathrm{~F}_{5 / 2}$ state of $\mathrm{Nd}^{3+}$ at $811 \mathrm{~nm}$, three broad emission bands centered at 898,1082 and $1373 \mathrm{~nm}$ can be observed at room temperature, which are attributed to the radiative relaxations from ${ }^{4} \mathrm{~F}_{3 / 2}$ to its low-lying multiplets of ${ }^{4} \mathrm{I}_{9 / 2},{ }^{4} \mathrm{I}_{11 / 2}$ and ${ }^{4} \mathrm{I}_{13 / 2}$, respectively. Meanwhile, much sharper and better resolved emission lines originating from CF levels of ${ }^{4} \mathrm{~F}_{3 / 2}$ to that of ${ }^{4} \mathrm{I}_{9 / 2},{ }^{4} \mathrm{I}_{11 / 2}$ and ${ }^{4} \mathrm{I}_{13 / 2}$ were also detected at low temperature (4.2 K) (Fig. 11b). Owing to the time-reversal (Kramers) degeneracy for the $4 f^{3}$ configuration $\left(\mathrm{Nd}^{3+}\right)$, theoretically, five emission peaks for the transition from ${ }^{4} \mathrm{~F}_{3 / 2}$ to ${ }^{4} \mathrm{I}_{9 / 2}$ are expected for single $\mathrm{Nd}^{3+}$ site in $\mathrm{ZnO} \mathrm{NCs}$ at $4.2 \mathrm{~K}$. However, as depicted in the inset of Fig. 11b, ten moderately resolved transition lines assigned to ${ }^{4} \mathrm{~F}_{3 / 2} \rightarrow{ }^{4} \mathrm{I}_{9 / 2}$ were identified upon direct excitation at $811 \mathrm{~nm}$, which thus corroborated that the emission lines in Fig. $11 \mathrm{~b}$ derived from the PL superimposition of at least two $\mathrm{Nd}^{3+}$ sites in $\mathrm{ZnO}$ lattices.

As opposed to the high-resolution site-selective spectra in Fig. 11 b, such multiple $\mathrm{Nd}^{3+}$ sites in $\mathrm{ZnO}$ NCs were easily distinguishable from each other in the time domain despite of the low spectral resolution $(10 \mathrm{~nm})$ in the frequency domain. Fig. 11c shows the TRPL spectra of $\mathrm{ZnO}: \mathrm{Nd}^{3+} \mathrm{NCs}$ collected at different delay time ranging from 0 to $85 \mu \mathrm{s}$. The intensity of emission peak centered at $1066 \mathrm{~nm}$ (peak A) was observed to increase dramatically with increasing delay time, reaching the maximum at $\sim 10 \mu$ s, and then became undetectable after a delay time of $\sim 30 \mu$ s. Nevertheless, a much slower time evolution process was observed for emission peak at $1082 \mathrm{~nm}$ (peak B). This noticeable difference in the evolution of peaks $\mathrm{A}$ and $\mathrm{B}$ was mainly caused by the multiple luminescence centers of $\mathrm{Nd}^{3+}$ ions in the lattice sites of $\mathrm{ZnO}$ NCs that possess various CF surroundings and therefore different decay behaviors [207].

\section{Single lattice site of $\mathrm{Ln}^{3+}$ ions}

Distinct from that observed in $\mathrm{Eu}^{3+}$ ions doped $\mathrm{TiO}_{2} \mathrm{NCs}$, only one single lattice site of $\mathrm{Er}^{3+}$ was observed in anatase $\mathrm{TiO}_{2}: \mathrm{Er}^{3+} \mathrm{NCs}$, which was unusual in view of the large mismatch of ionic radius and charge imbalance between $\mathrm{Er}^{3+}$ and $\mathrm{Ti}^{4+}$ [136]. To probe the CF surroundings experienced by $\mathrm{Er}^{3+}$ ions in $\mathrm{TiO}_{2}$ NCs, the NIR PL spectra of $\mathrm{Er}^{3+}$ were measured upon bandgap excitation at $358 \mathrm{~nm}$ and direct excitation at $523.4 \mathrm{~nm}$. As shown in Fig. 12a, almost the same NIR PL pattern attributed to the ${ }^{4} \mathrm{I}_{13 / 2} \rightarrow{ }^{4} \mathrm{I}_{15 / 2}$ transition of $\mathrm{Er}^{3+}$ was detected despite the different excitation paths, which thereby revealed the single lattice site for the doped $\mathrm{Er}^{3+}$ ions in $\mathrm{TiO}_{2}$ NCs. Fig. $12 \mathrm{~b}$ exhibits the $10 \mathrm{~K}$ excitation spectrum for $\mathrm{Er}^{3+}$ doped $\mathrm{TiO}_{2}$ NCs when monitoring the NIR ${ }^{4} \mathrm{I}_{13 / 2} \rightarrow{ }^{4} \mathrm{I}_{15 / 2}$ emission at $1532.6 \mathrm{~nm}$. Abundant sharp excitation lines of $\mathrm{Er}^{3+}$ centered at 380.6, 407.6, 489.4, 523.4, 550.5 , and $654.0 \mathrm{~nm}$ can be detected, which come from
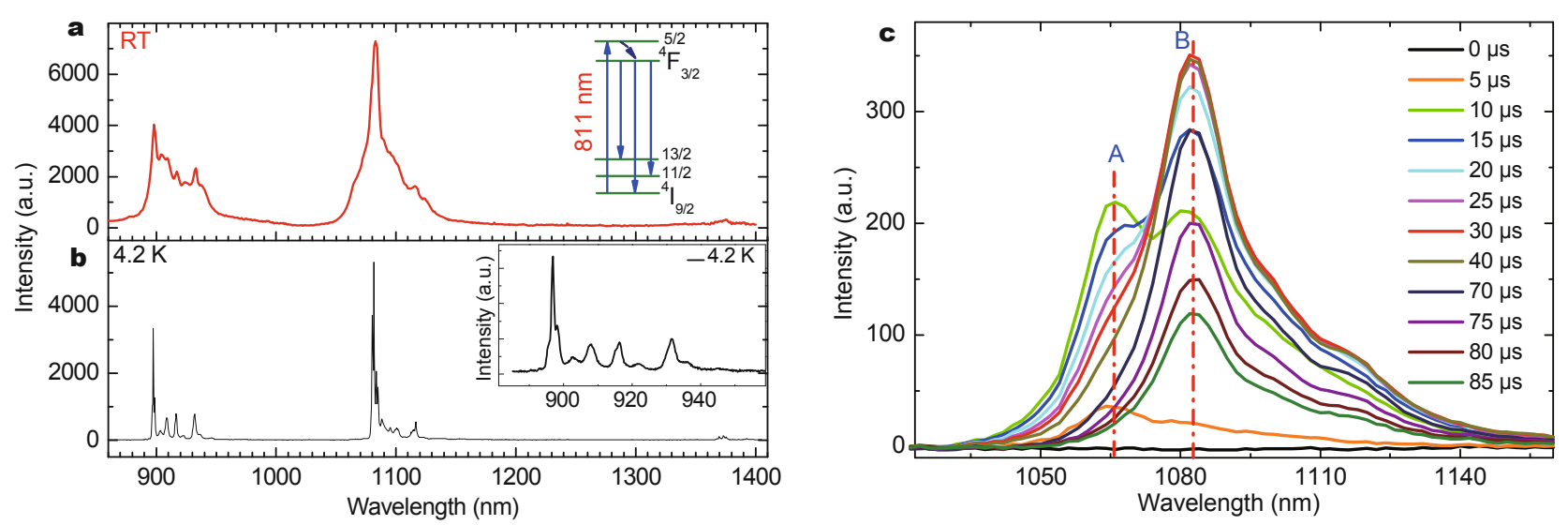

Figure 11 Room-temperature (a) and $4.2 \mathrm{~K}$ (b) NIR luminescence of $\mathrm{Nd}^{3+}$ ions doped ZnO NCs (the insets show the schematic diagram of excitation and emission levels of $\mathrm{Nd}^{3+}$ and the enlarged $4.2 \mathrm{~K}$ emission lines in the spectral region from 890 to $950 \mathrm{~nm}$ ), and (c) TRPL spectra of Nd ${ }^{3+}$ ions in $\mathrm{ZnO}$ NCs. All the spectra were measured under the laser excitation at $811 \mathrm{~nm}$. Adapted with permission from Ref. [207]. Copyright 2009, Optical Society of America. 

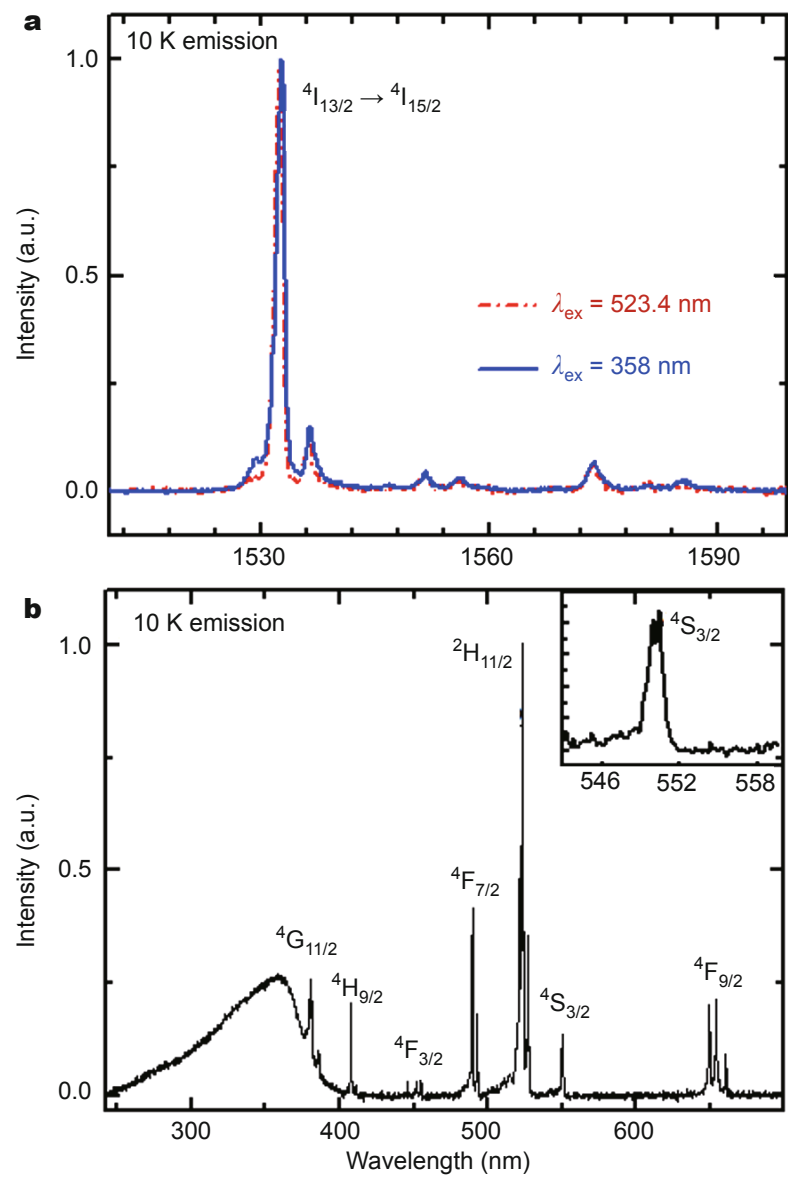

Figure 12 (a) $10 \mathrm{~K}$ NIR PL spectra for $\mathrm{TiO}_{2}: \mathrm{Er}^{3+} \mathrm{NCs}$ when directly and indirectly excited at 523.4 and $358 \mathrm{~nm}$, respectively; and (b) $10 \mathrm{~K} \mathrm{PL}$ excitation spectrum of $\mathrm{TiO}_{2}: \mathrm{Er}^{3+} \mathrm{NCs}$ (the inset enlarged the excitation lines for the transition of ${ }^{4} \mathrm{I}_{15 / 2} \rightarrow{ }^{4} \mathrm{~S}_{3 / 2}$ ). Adapted with permission from Ref. [136], Copyright 2008, Optical Society of America.

the direct excitation from the ground state of ${ }^{4} \mathrm{I}_{15 / 2}$ to the upper excited states of ${ }^{4} \mathrm{G}_{11 / 2},{ }^{2} \mathrm{H}_{9 / 2},{ }^{4} \mathrm{~F}_{7 / 2},{ }^{2} \mathrm{H}_{11 / 2},{ }^{4} \mathrm{~S}_{3 / 2}$ and ${ }^{4} \mathrm{~F}_{9 / 2}$, respectively. Fine CF splitting of the excited states of $\mathrm{Er}^{3+}$ is distinguishable, suggesting that $\mathrm{Er}^{3+}$ ions are situated at a lattice site rather than on the surface of $\mathrm{TiO}_{2} \mathrm{NCs}$.

According to the crystal structure of anatase $\mathrm{TiO}_{2}, \mathrm{Er}^{3+}$ ions occupying the Ti-lattice site should possess a $D_{2 d}$ site symmetry. Nevertheless, the actual site symmetry of $\mathrm{Er}^{3+}$ in $\mathrm{TiO}_{2}$ lattice site may be reduced from $D_{2 d}$ to lower symmetries due to the remarkable lattice distortion induced by the significant difference in chemical properties for $\mathrm{Ti}^{4+}$ and $\mathrm{Er}^{3+}$ ions. Theoretically, the multiplets of $\mathrm{Er}^{3+}$ at $D_{2 d}$ or lower symmetry sites should present $J+1 / 2$ lines due to the Kramers degeneracy of $4 f^{1}$ configuration for $\mathrm{Er}^{3+}$. As clearly presented in the inset of Fig. 12b, only two excitation lines assigned to the excited state of ${ }^{4} S_{3 / 2}$ and no trace of
CF splitting due to another site can be detected. The CF splittings of other excited states in Fig. 12b also agree well with the theoretical analysis, further verifying the single lattice site of $\mathrm{Er}^{3+}$ ions in $\mathrm{TiO}_{2} \mathrm{NCs}$. Based on these spectroscopic evidence, we infer that most of $\mathrm{Er}^{3+}$ ions are very likely located at the substitutional $\mathrm{Ti}^{4+}$ lattice site with a site symmetry descending from $D_{2 d}$ to $C_{2 v}$, as revealed in $\mathrm{Eu}^{3+}$ doped $\mathrm{TiO}_{2}$ NCs [178].

Similarly, such single lattice site of $\mathrm{Er}^{3+}$ was observed in $\mathrm{Er}^{3+}$ doped $\mathrm{SnO}_{2}$ NCs. By using a solvothermal approach followed by annealing in oxygen atmosphere at $800-1100^{\circ} \mathrm{C}, \mathrm{Er}^{3+}$ ions were successfully incorporated into the lattices of rutile $\mathrm{SnO}_{2} \mathrm{NCs}$, which gave rise to typical NIR $1.54 \mu \mathrm{m}$ emissions of $\mathrm{Er}^{3+}$ upon excitation above the $\mathrm{SnO}_{2}$ bandgap at $300 \mathrm{~nm}$ [69]. As shown in Fig. 13a, the $\mathrm{PL}$ excitation spectrum of $\mathrm{Er}^{3+}$ in $\mathrm{SnO}_{2} \mathrm{NCs}$ is dominated by a strong UV broadband centered at $\sim 300 \mathrm{~nm}$ that corresponds to the bandgap absorption peak of $\mathrm{SnO}_{2} \mathrm{NCs}$ (Fig. 13a, left), while the emission spectrum displays the fingerprint of $\mathrm{Er}^{3+}$ ions (Fig. 13a, right) when indirectly excited at $\sim 300 \mathrm{~nm}$, verifying the occurrence of energy transfer from $\mathrm{SnO}_{2} \mathrm{NCs}$ to emitters $\left(\mathrm{Er}^{3+}\right)$. These sharp and well-resolved NIR emission lines centered at $\sim 1551 \mathrm{~nm}$ are attributed to the ${ }^{4} \mathrm{I}_{13 / 2} \rightarrow{ }^{4} \mathrm{I}_{15 / 2}$ transition of $\mathrm{Er}^{3+}$ in the lattices of rutile $\mathrm{SnO}_{2}$ NCs. More importantly, it was found that these emission lines of $\mathrm{Er}^{3+}$ kept unchanged in terms of line positions and splittings for the samples annealed at temperatures of $800-1100^{\circ} \mathrm{C}$, indicating the identical site occupation of $\mathrm{Er}^{3+}$ in $\mathrm{SnO}_{2} \mathrm{NCs}$. Most likely, $\mathrm{Er}^{3+}$ ions were located at a lattice site with $\mathrm{D}_{2 h}$ centrosymmetric site symmetry after the replacement for $\mathrm{Sn}^{4+}$ in $\mathrm{SnO}_{2} \mathrm{NCs}$. This hypothesis was consistently supported by the absence of direct $4 \mathrm{f}-4 \mathrm{f}$ excitation lines of $\mathrm{Er}^{3+}$ in the PL excitation spectrum (Fig. $13 \mathrm{a}$, left). According to the selection rule for the $4 \mathrm{f}-4 \mathrm{f}$ transitions of $\mathrm{Ln}^{3+}$ ions, electric-dipole (ED) transitions are strictly forbidden for a site with a center of inversion. As a consequence, the direct $4 \mathrm{f}-4 \mathrm{f}$ excitation lines, which correspond to the transitions from the ground multiplet ${ }^{4} \mathrm{I}_{15 / 2}$ to the excited states of $\mathrm{Er}^{3+}$ in the visible and NIR spectral regions $(380 \sim 1000 \mathrm{~nm})$, are forbidden due to their ED nature. To further identify the emission lines in Fig. 13a, high-resolution temperature-dependent emission spectra were measured from 10 to $300 \mathrm{~K}$ based on the Boltzmann distribution nature of electrons in those sublevels of ${ }^{4} \mathrm{I}_{13 / 2}$ and ${ }^{4} \mathrm{I}_{15 / 2}$. As recorded in Figs $13 \mathrm{~b}$ and $\mathrm{c}$, all emission lines can be well assigned and total 20 energy levels including 4 ${ }^{4} \mathrm{I}_{13 / 2}$ sublevels and $5{ }^{4} \mathrm{I}_{15 / 2}$ sublevels can be identified according to the variation of the emission line intensity with the change of experimental temperatures, further confirming the single lattice site occupation of $\mathrm{Er}^{3+}$ in $\mathrm{SnO}_{2} \mathrm{NCs}$. 

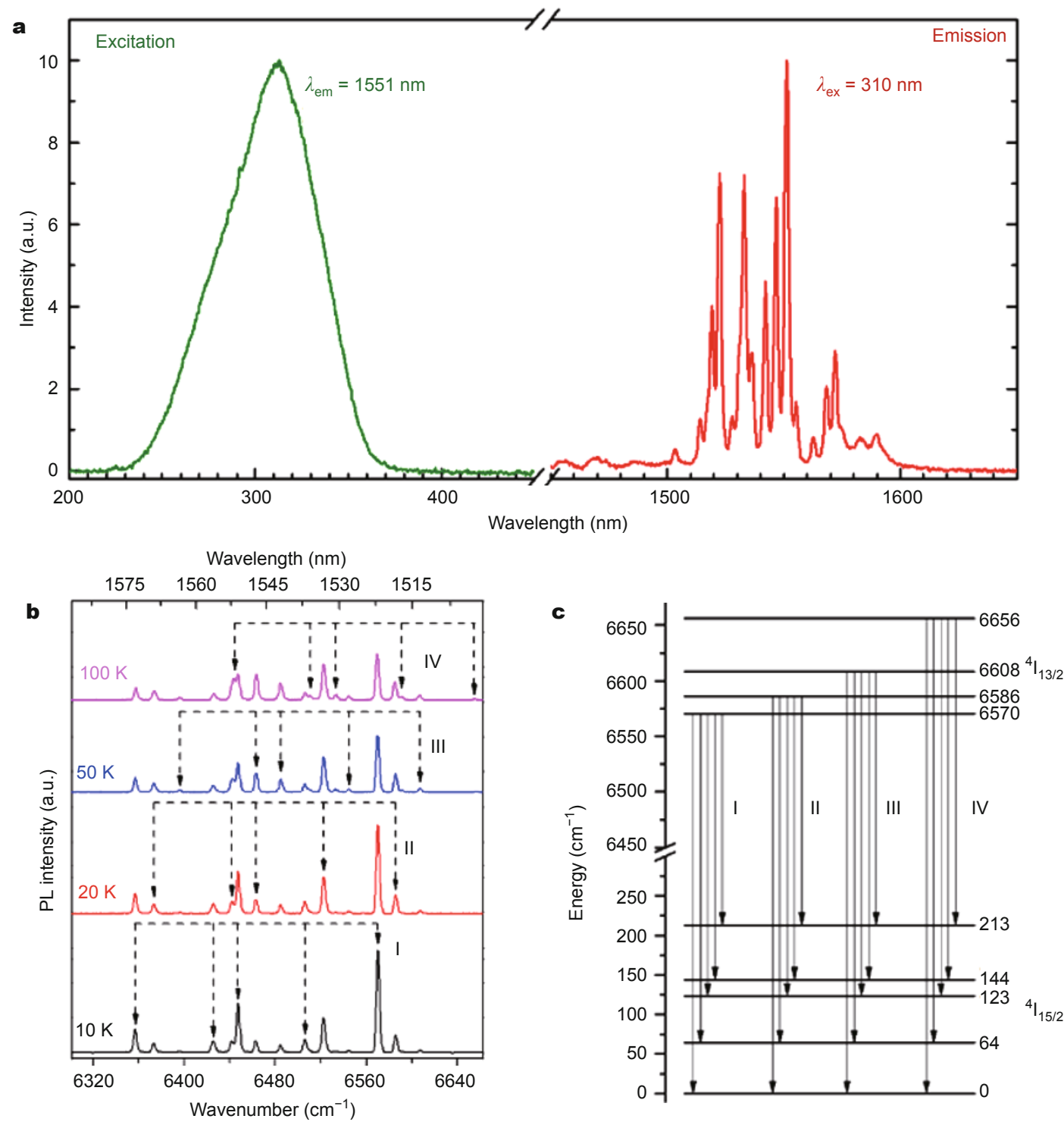

Figure 13 (a) PL excitation and emission spectra for $\mathrm{SnO}_{2}: \mathrm{Er}^{3+} \mathrm{NCs}$ at room temperature. (b) High-resolution emission spectra at 10, 20, 50, and $100 \mathrm{~K}$ upon excitation at $300 \mathrm{~nm}$. (c) Illustration on energy levels and the transition from ${ }^{4} \mathrm{I}_{13 / 2}$ to ${ }^{4} \mathrm{I}_{15 / 2}$, I, II, III, and IV represent the transitions from the lowest four sublevels of ${ }^{4} \mathrm{I}_{13 / 2}$ to the sublevels of ${ }^{4} \mathrm{I}_{15 / 2}$, respectively. Adapted with permission from Ref. [69]. Copyright 2009, Optical Society of America.

\section{HOST SENSITIZED LUMINESCENCE}

Host sensitization via the energy transfer from the excited semiconductor host to $\mathrm{Ln}^{3+}$ is considered to be an effective way to realize highly efficient luminescence of $\operatorname{Ln}^{3+}$ for practical applications such as optoelectronic devices and flat panel displays $[51,127,187]$. In general, energy transfer involves the nonradiative energy transfer from a donor (sensitizer) to an acceptor separated in a solid by distances greater than the inter-atomic separations. The transfer is resonant if the energy matches the difference in electronic energy between levels of both the donor and acceptor systems. More often, nonresonant energy transfer involves the creation of phonons at the donor and/or acceptor sites. In case of $\mathrm{Ln}^{3+}$ doped semiconductor crystals, the energy transfer proceeds via a quite different way, i.e., via exciton recombination. As illustrated in Fig. 14a, by absorption of an excitation photon, the electron in the valence band (VB) is excited into the conduction band (CB) with a hole left in the VB. The electron and positively charged hole form an exciton pair, which can transport through the crystal lattice. Such an exciton pair can be trapped at defect sites in the lattice such as $\operatorname{Ln}^{3+}$ substitution. Followed by exciton 

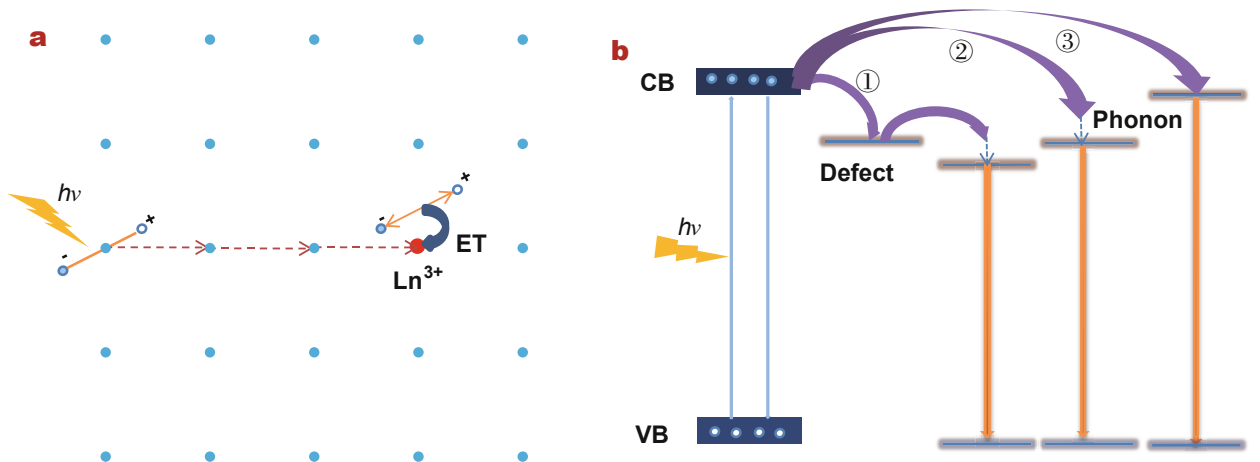

Figure 14 Proposed energy transfer (ET) mechanism in $\mathrm{Ln}^{3+}$ doped SNCs.

recombination, if spectrally matched, the energy can be transferred from the SNC host to $\mathrm{Ln}^{3+}$.

It's worthy of mentioning that, to achieve efficient energy transfer from host to dopant, the excited-state levels of $\mathrm{Ln}^{3+}$ should be equal (resonant condition) or slightly lower (nonresonant condition) than the bandgap energy of SNCs. In the latter, the energy transfer occurs via phonon assistance or defect mediated way, which is commonly observed in $\mathrm{Ln}^{3+}$ doped SNCs (Fig. 14b). For instance, efficient energy transfer is observed in $\mathrm{Nd}^{3+}$ or $\mathrm{Sm}^{3+}$ doped $\mathrm{TiO}_{2} \mathrm{NCs}$ due to the small energy discrepancy between $\mathrm{TiO}_{2}$ bandgap and excited states of $\mathrm{Nd}^{3+}$ or $\mathrm{Sm}^{3+}$ [187]. Fig. 15 shows the room-temperature excitation and emission spectra of $\mathrm{Nd}^{3+}$ and $\mathrm{Sm}^{3+}$ ions embedded in anatase $\mathrm{TiO}_{2}$ NCs synthesized via a facile sol-gel solvothermal method [187]. Intense NIR PL of $\mathrm{Nd}^{3+}$ is observed upon excitation above the $\mathrm{TiO}_{2}$ bandgap at $345 \mathrm{~nm}$. Typical emission lines of $\mathrm{Nd}^{3+}$ centered at 915, 1094 and $1384 \mathrm{~nm}$ are explicitly assigned to the transitions from ${ }^{4} \mathrm{~F}_{3 / 2}$ to ${ }^{4} \mathrm{I}_{9 / 2},{ }^{4} \mathrm{I}_{11 / 2}$ and ${ }^{4} \mathrm{I}_{13 / 2}$, respectively (Fig. 15b). Meanwhile, sharp emission lines from $\mathrm{Sm}^{3+}$ in the region of 560-750 $\mathrm{nm}$ are also observed when excited with the same excitation light. The emission lines centered at 584.1, 612.8, 664.1 and 727.0 nm are attributed to the de-excitation from ${ }^{4} \mathrm{G}_{5 / 2}$ to its lower multiplets of ${ }^{6} \mathrm{H}_{5 / 2},{ }^{6} \mathrm{H}_{7 / 2},{ }^{6} \mathrm{H}_{9 / 2}$ and ${ }^{6} \mathrm{H}_{11 / 2}$ of $\mathrm{Sm}^{3+}$, respectively (Fig. 15c). Taken together, these results strongly imply that the $\mathrm{Nd}^{3+}$ and $\mathrm{Sm}^{3+}$ emissions can be achieved via an efficient nonradiative energy transfer process from $\mathrm{TiO}_{2}$ to the dopants, which is further evidenced by the presence of the intense bandgap absorption peak of anatase $\mathrm{TiO}_{2}$ in the excitation spectra of $\mathrm{TiO}_{2}: \mathrm{Nd}^{3+}$ and $\mathrm{TiO}_{2}: \mathrm{Sm}^{3+} \mathrm{NCs}$ (Fig. 15a). Moreover, it should be noted that the excitation lines arising from $4 \mathrm{f}-4 \mathrm{f}$ transitions of $\mathrm{Nd}^{3+}\left(\right.$ or $\left.\mathrm{Sm}^{3+}\right)$ itself in the room-temperature excitation spectrum were hardly detectable, thus revealing that the sensitized emission was a much more efficient pathway than the direct excitation of
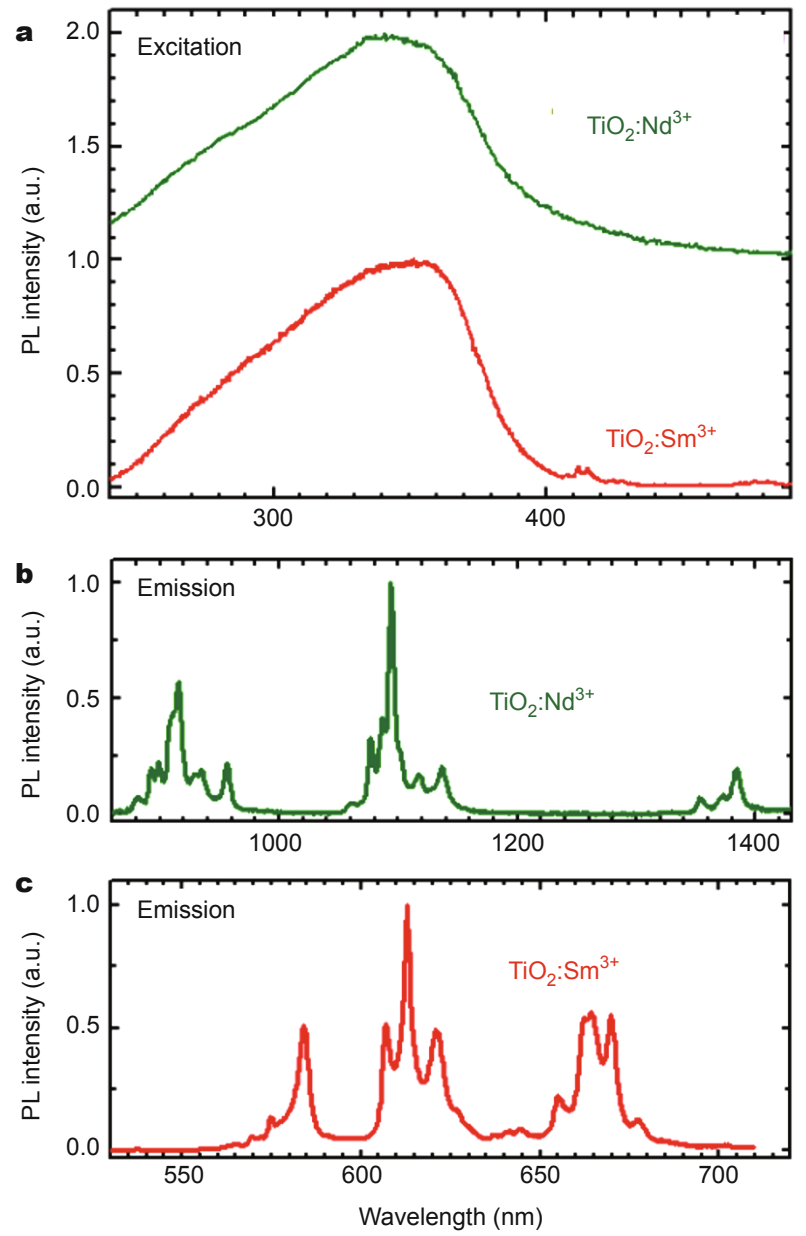

Figure 15 PL excitation (a) and emission (b, c) spectra for $\mathrm{TiO}_{2}: \mathrm{Nd}^{3+}$ and $\mathrm{TiO}_{2}: \mathrm{Sm}^{3+} \mathrm{NCs}$ at room temperature, Adapted with permission from Ref. [187]. Copyright 2009, American Chemical Society.

\section{$\mathrm{Nd}^{3+}$ or $\mathrm{Sm}^{3+}$ ions.}

Unlike $\mathrm{Nd}^{3+}$ (or $\mathrm{Sm}^{3+}$ ) doped $\mathrm{TiO}_{2} \mathrm{NCs}, \mathrm{TiO}_{2}: \mathrm{Eu}^{3+} \mathrm{NCs}$ prepared by similar method exhibited only weak energy 
transfer from $\mathrm{TiO}_{2}$ host to $\mathrm{Eu}^{3+}$ ions at low temperature (10 $\mathrm{K})$ due to the mismatch of energy between the $\mathrm{TiO}_{2}$ bandgap and $\mathrm{Eu}^{3+}$ excited states [178]. To bridge the energy gap between the $\mathrm{TiO}_{2}$ and $\mathrm{Eu}^{3+}$ excited states, a feasible alternative way is co-doping another $\mathrm{Ln}^{3+}$ ion as a mediated level. $\mathrm{Ln}^{3+}$ ions with rich ladder-like electronic structures prove to be effective energy bridges in tailoring the light output of phosphors. For this purpose, $\mathrm{Sm}^{3+}$ was introduced as an energy bridge, taking into account the fact that efficient energy transfer from the $\mathrm{TiO}_{2}$ to $\mathrm{Sm}^{3+}$ [187] and the ${ }^{4} \mathrm{G}_{5 / 2}$ state of $\mathrm{Sm}^{3+}$ to the ${ }^{5} \mathrm{D}_{0}$ state of $\mathrm{Eu}^{3+}$ [210] were achieved. As expected, the energy transfer efficiency from $\mathrm{TiO}_{2}$ to $\mathrm{Eu}^{3+}$ was greatly enhanced by co-doping 0.5 at. $\% \mathrm{Sm}^{3+}$ ions into $\mathrm{TiO}_{2}: \mathrm{Eu}^{3+} \mathrm{NCs}$ [208]. Fig. 16a compares the excitation spectra of $\mathrm{Eu}^{3+}$ singly doped and $\mathrm{Sm}^{3+} / \mathrm{Eu}^{3+}$ co-doped $\mathrm{TiO}_{2}$ NCs by monitoring the ${ }^{5} \mathrm{D}_{0} \rightarrow{ }^{7} \mathrm{~F}_{2}$ transition of $\mathrm{Eu}^{3+}$ at 617.8 $\mathrm{nm}$. Sharp emission lines centered at 394, 468.2, and 539.4 $\mathrm{nm}$, which correspond to intra- $4 \mathrm{f}$ transitions from ${ }^{7} \mathrm{~F}_{0}$ ground state to the excitation multiplets of ${ }^{5} \mathrm{~L}_{6},{ }^{5} \mathrm{D}_{2}$, and ${ }^{5} \mathrm{D}_{1}$, dominated the excitation spectrum of $\mathrm{Eu}^{3+}$ singly doped $\mathrm{TiO}_{2}$ NCs. In stark contrast, a broad band centered at 330 nm due to the $\mathrm{TiO}_{2}$ bandgap absorption emerged in the excitation spectrum of $\mathrm{Sm}^{3+} / \mathrm{Eu}^{3+}$ co-doped counterparts, indicating the existence of efficient energy transfer from the $\mathrm{TiO}_{2}$ host to the $\mathrm{Eu}^{3+}$ ions with the aid of $\mathrm{Sm}^{3+}$ ions. The underlying energy transfer mechanism was schematically illustrated in Fig. 16b. The energy absorbed by $\mathrm{TiO}_{2}$ host was first nonradiatively transferred to the excited state of $\mathrm{Sm}^{3+}$, followed by the nonradiative relaxation to the long- lived ${ }^{4} \mathrm{G}_{5 / 2}$ of $\mathrm{Sm}^{3+}$. The excited $\mathrm{Sm}^{3+}$ ions can then partially transfer their energy from ${ }^{4} \mathrm{G}_{5 / 2}$ to the ${ }^{5} \mathrm{D}_{0}$ level of $\mathrm{Eu}^{3+}$ and resulted in the intense red emission of $\mathrm{Eu}^{3+}$.

Another strategy for the energy bridge in the host-to$\mathrm{Ln}^{3+}$ energy transfer process is through defect states in NCs. In $\mathrm{Ln}^{3+}$ doped SNC systems, various defects are often generated as a result of lattice distortion and/or charge compensation due to the substitution of host cations with larger $\mathrm{Ln}^{3+}$ ions. Particularly, in nanomaterials, large specific surface area results in plenty of diverse surface defects. All these defects may play important roles in the optical performance of $\mathrm{Ln}^{3+}$ doped SNCs, for instance, being luminescent quenching centers, activators or energy transfer bridges.

In a nonresonant energy transfer process, phonons play a key role in bridging the energy mismatch between the bandgap of SNCs and the excited state of $\mathrm{Ln}^{3+}$. However, the energy transfer efficiency decreases gradually with the increase of the number of phonons involved in the energy transfer process when the phonons are more than five. To this end, an effective way to assist the nonresonant energy transfer process is using defects as intermediate states. Such defect-mediated energy transfer from SNCs to $\mathrm{Ln}^{3+}$ ions was documented in the literature $[49,127]$. In particular, Wang and co-workers [209] demonstrated a defect-mediated energy transfer pathway from the $\mathrm{ZnO}$ host to the $\mathrm{Eu}^{3+}$ ions evidenced by temperature-dependent and time-resolved PL experiments. Upon excitation above the $\mathrm{ZnO}$ bandgap at $325 \mathrm{~nm}$, emission lines at 375, 520 and $615 \mathrm{~nm}$,
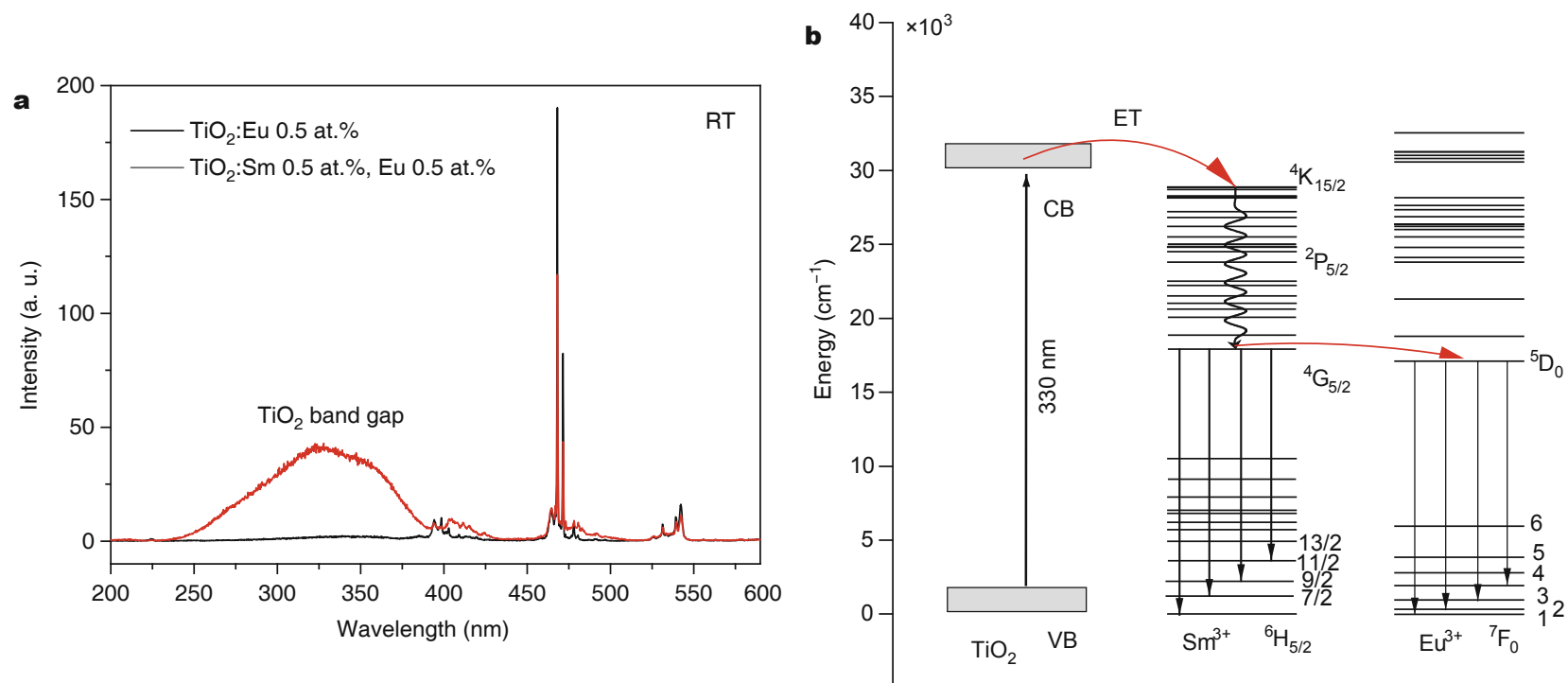

Figure 16 (a) Room-temperature excitation spectra of $\mathrm{TiO}_{2}: \mathrm{Sm}^{3+}(0.5$ at. $\%), \mathrm{Eu}^{3+}(0.5$ at. $\%)$ and $\mathrm{TiO}_{2}: \mathrm{Eu}^{3+}(0.5$ at. $\%) \mathrm{NCs}^{3}$ by monitoring the ${ }^{5} \mathrm{D}_{0} \rightarrow{ }^{7} \mathrm{~F}_{2}$ emission of $\mathrm{Eu}^{3+}$ ions at $617.8 \mathrm{~nm}$. (b) A schematic illustration of the energy transfer mechanism from the $\mathrm{TiO}_{2}$ bandgap to $\mathrm{Sm}^{3+}$ and $\mathrm{Eu}^{3+}$ ions. Adapted with permission from Ref. [208]. Copyright 2010, American Scientific Publishers. 
which are ascribed to the near-band edge (NBE) exciton recombination, defect states (oxygen vacancies) luminescence (DSL), and the ${ }^{5} \mathrm{D}_{0} \rightarrow{ }^{7} \mathrm{~F}_{2}$ transition of $\mathrm{Eu}^{3+}$ were found to dominate the emission spectra at different temperatures ranging from 5 to $300 \mathrm{~K}$, indicating an energy transfer process from the host to $\mathrm{Eu}^{3+}$. Moreover, temperature-dependent $\mathrm{Eu}^{3+}$ emission exhibited similar features to that of defect related emission, suggesting that the defect state may act as an energy reservoir in mediating the energy transfer from $\mathrm{ZnO}$ host to $\mathrm{Eu}^{3+}$ (Fig. 17a). To further establish this relationship, the PL emission spectra and excited state dynamics of the as-prepared sample (EZO-1) and the counterpart annealed at $600^{\circ} \mathrm{C}$ in air (EZO-2) were compared in Figs $17 \mathrm{~b}$ and $\mathrm{c}$. Note that the content of oxygen vacancies in EZO-2 was remarkably reduced after annealing. Consistently, with the decrease of defects in the sample (namely, a decrease of oxygen deficiency from $\sim 26 \%$ in EZO- 1 to $\sim 8.4 \%$ in EZO-2), the $\mathrm{Eu}^{3+}$ related emission decreased, thus confirming that oxygen vacancy defects acted as the intermediate state in the energy transfer process (Fig. 17d).
Another interesting example of defect mediated energy transfer was reported by Tachikawa et al. [166], who employed single-molecule (single-particle) fluorescence spectroscopy to investigate the $\mathrm{PL}$ dynamics of $\mathrm{Eu}^{3+}$ doped $\mathrm{TiO}_{2}$ NCs. During the PL measurements upon 405-nm laser excitation, the concentration of defects (oxygen vacancies) in $\mathrm{TiO}_{2}$ nanoparticles could be tuned by altering the experimental atmosphere, which enables the in situ exploration of the impact of defects on the PL properties of $\mathrm{TiO}_{2}: \mathrm{Eu}^{3+}$ nanoparticles at single particle level. As demonstrated in Fig. 18a, with the stimulation at 405-nm laser in Ar atmosphere which resulted in the increase of light induced surface defects in $\mathrm{TiO}_{2}$ nanoparticles, the brightness of $\mathrm{PL}$ containing both the defect-related and $\mathrm{Eu}^{3+}$ emissions increased dramatically. Moreover, it was found that the PL bands in the region of 500-750 nm relative to surface defect emission appeared and increased with the continuous 405-nm laser stimulation in Ar atmosphere (Figs 18b and $d)$. Meanwhile, the PL intensity of ${ }^{5} \mathrm{D}_{0} \rightarrow{ }^{7} \mathrm{~F}_{1}(590 \mathrm{~nm})$ increased with increasing irradiation time, whereas the
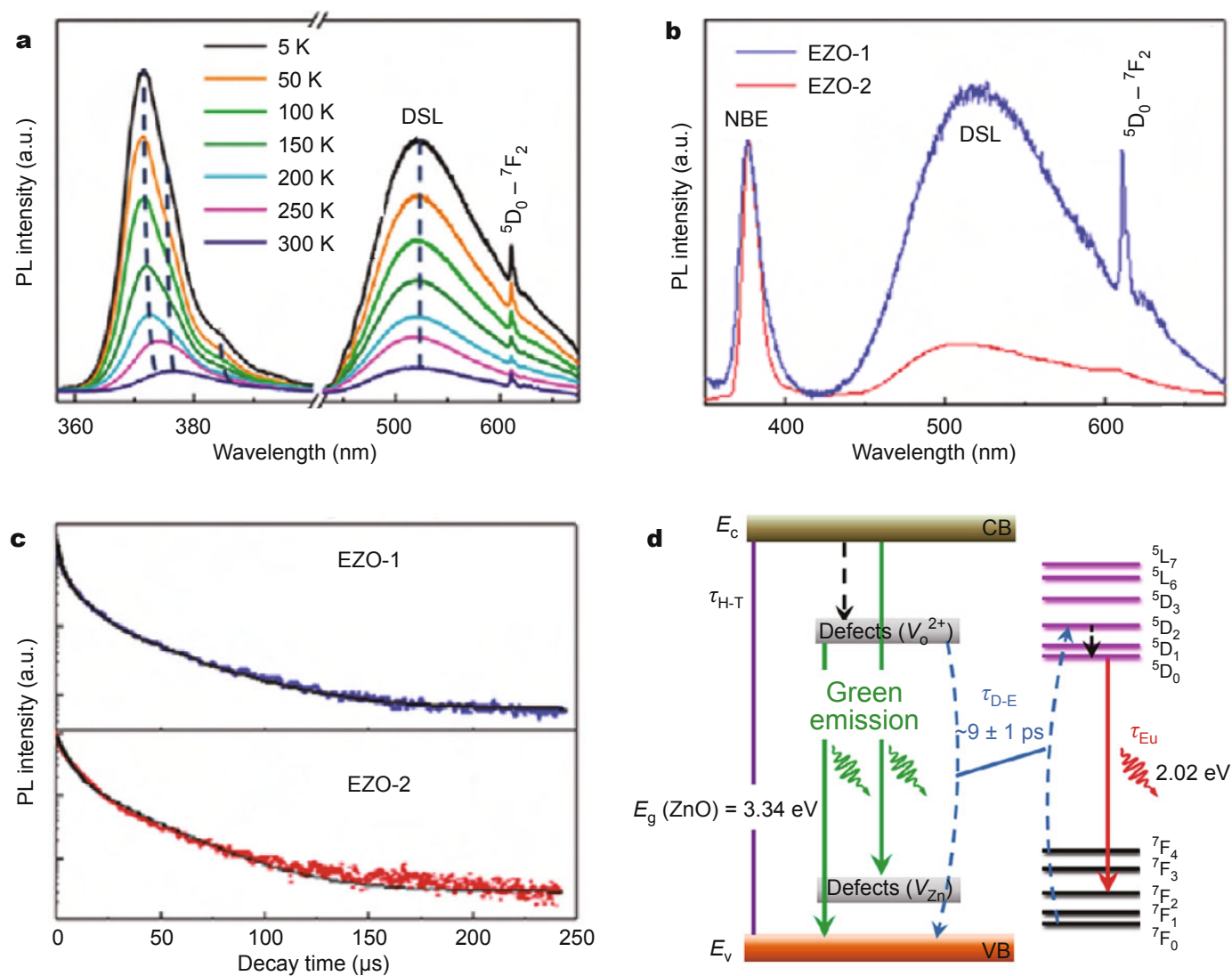

Figure 17 (a) Temperature-dependent PL spectra of as-prepared Eu ${ }^{3+}$ doped $\mathrm{ZnO}$ nanowires (EZO-1) upon excitation at $325 \mathrm{~nm}$; (b) room-temperature emission spectra of EZO-1 and the annealed sample (EZO-2) upon excitation at $325 \mathrm{~nm}$. (c) PL decays of Eu ${ }^{3+}$ in EZO-1 and EZO-2 by monitoring the $615 \mathrm{~nm}$ emission upon excitation at $325 \mathrm{~nm}$. (d) A schematic illustration of the proposed mechanism of energy transfer from the $\mathrm{ZnO}$ host to the Eu ${ }^{3+}$ ions. Adapted with permission from Ref. [209]. Copyright 2011, American Chemical Society. 
a
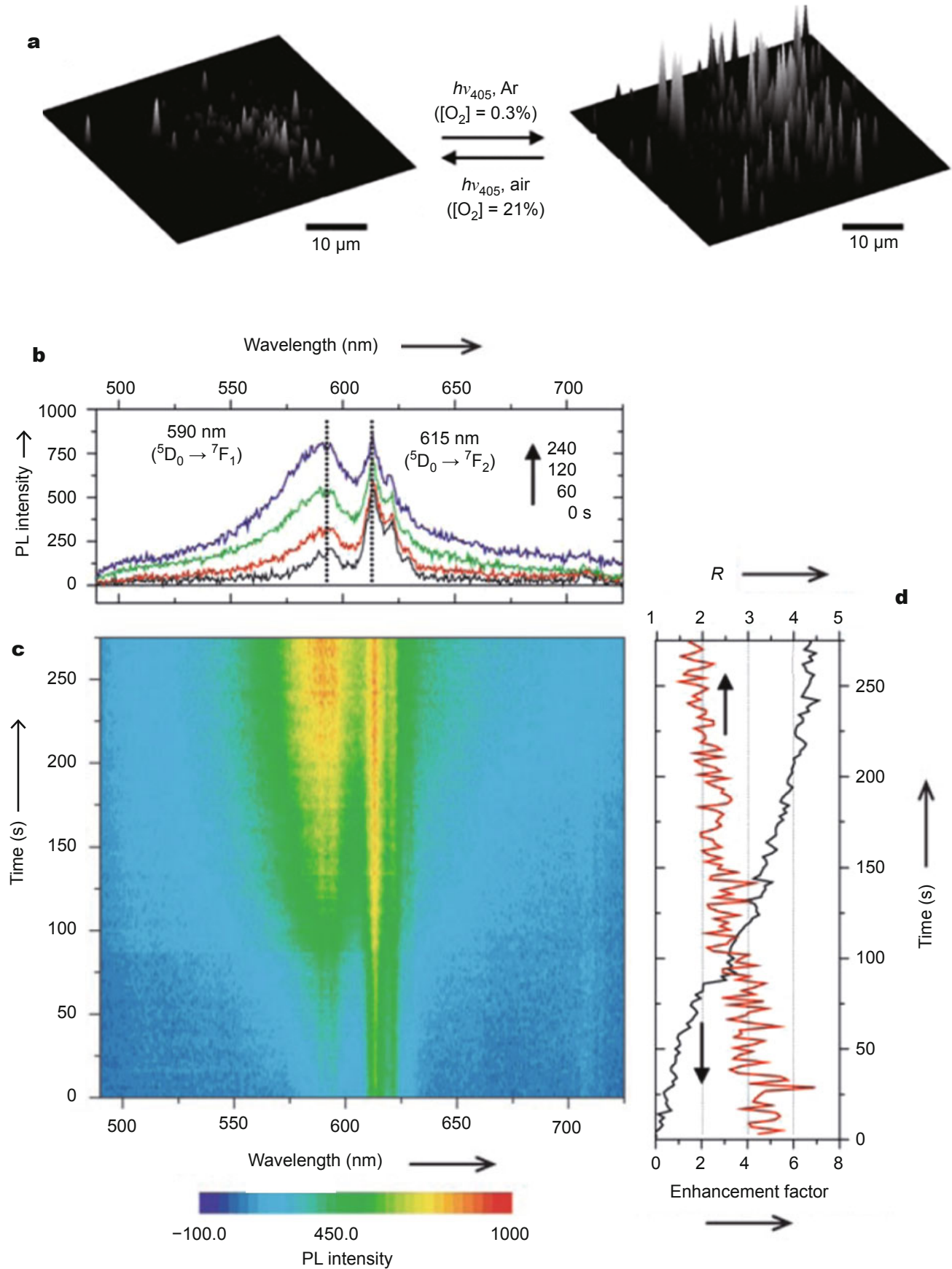

Figure 18 (a) Typical emission spots of $\mathrm{TiO}_{2}: \mathrm{Eu}^{3+}$ nanoparticles (or aggregates) upon 405-nm laser excitation in air (left) or Ar (right) atmospheres. Time evolutions of the PL spectra (b) and image (c) upon excitation for a single $\mathrm{TiO}_{2}$ : Eu ${ }^{3+}$ nanoparticle (or aggregate) in Ar atmosphere. $\mathrm{d}$ ) The dependence of the PL intensity enhancement factor at $550 \mathrm{~nm}$ (the ratio of the differential PL intensity to the original intensity) and $R$ value (PL intensity ratio of ${ }^{5} \mathrm{D}_{0} \rightarrow{ }^{7} \mathrm{~F}_{2}$ to ${ }^{5} \mathrm{D}_{0} \rightarrow \mathrm{F}_{1}$ ) on the 405-nm laser irradiation times. Adapted with permission from Ref. [166]. Copyright 2008, Wiley-VCH Verlag GmbH \& Co. KGaA.

PL intensity of ${ }^{5} \mathrm{D}_{0} \rightarrow{ }^{7} \mathrm{~F}_{2}(615 \mathrm{~nm})$ followed opposite trend. The ${ }^{5} \mathrm{D}_{0} \rightarrow{ }^{7} \mathrm{~F}_{2}$ transition is of forced ED nature and ultrasensitive to the local environment of $\mathrm{Eu}^{3+}$ ions, while the magnetic-dipole (MD) allowed ${ }^{5} \mathrm{D}_{0} \rightarrow{ }^{7} \mathrm{~F}_{1}$ is essentially not influenced. The relative PL intensity ratio $(R)$ of ${ }^{5} \mathrm{D}_{0} \rightarrow{ }^{7} \mathrm{~F}_{2}$ $(615 \mathrm{~nm})$ to ${ }^{5} \mathrm{D}_{0} \rightarrow{ }^{7} \mathrm{~F}_{1}(590 \mathrm{~nm})$ provides information about the site symmetry around $\mathrm{Eu}^{3+}$ ions. It turned out that the $R$ value for $\mathrm{Eu}^{3+}$ at the surface site was smaller than that in the 
interior region of $\mathrm{TiO}_{2}$ [166]. Consequently, the decrease of $R$ value together with the overall augment of PL emission intensity suggested that the emission of $\mathrm{Eu}^{3+}$ at the surface site of $\mathrm{TiO}_{2} \mathrm{NCs}$ was greatly improved with the increase of light induced surface defects, which undoubtedly indicated that the surface defect participated in and promoted the energy transfer process from $\mathrm{TiO}_{2}$ host to $\mathrm{Eu}^{3+}$ ions.

In addition to acting as intermediate states to enhance the host-to- $\mathrm{Ln}^{3+}$ energy transfer, the defect may also play the role of the exciton traps in case of deep defects. The trapped excitons should be thermally released from the defect state prior to the energy transfer from the host to $\mathrm{Ln}^{3+}$ ions. When this defect trap of excitons becomes prominent, the de-trapping process will determine the de-excitation process of excitons, i.e., the PL lifetime of $\mathrm{Ln}^{3+}$ emitters will be significantly lengthened. In our recent work, host sensitized afterglow luminescence of $\mathrm{Eu}^{3+}$ in $\mathrm{SnO}_{2} \mathrm{NCs}$ was observed at the temperature below $250 \mathrm{~K}$ due to the capture of excitons in the deep defects during the energy transfer process [211]. Fig. 19a shows room-temperature PL excitation and emission spectra of $\mathrm{Eu}^{3+}$ in $\mathrm{SnO}_{2}$ NCs. The bandgap absorption of $\mathrm{SnO}_{2} \mathrm{NCs}$ at $300 \mathrm{~nm}$ was found to dominate the excitation spectrum when monitoring the $\mathrm{Eu}^{3+}$ emission at $588 \mathrm{~nm}$ (Fig. 19a, left), indicating an efficient energy transfer process from host to $\mathrm{Eu}^{3+}$. Sharp and well resolved emission lines of $\mathrm{Eu}^{3+}$ with the dominant ${ }^{5} \mathrm{D}_{0} \rightarrow{ }^{7} \mathrm{~F}_{1}$ transition lines at 588.0, 592.8 and $599.0 \mathrm{~nm}$ were observed in the emission spectrum, which obeyed the selection rule for the $4 \mathrm{f}-4 \mathrm{f}$ transitions of $\mathrm{Eu}^{3+}$ in centrosymmetric site (most likely to replace $\mathrm{Sn}^{4+}$ at $D_{2 h}$ ), thereby confirming the incorporation of $\mathrm{Eu}^{3+}$ into the $\mathrm{SnO}_{2}$ lattice sites. Fig. 19b illustrates the PL decays by monitoring the ${ }^{5} \mathrm{D}_{0} \rightarrow{ }^{7} \mathrm{~F}_{1}$ transition at 588 $\mathrm{nm}$ of $\mathrm{Eu}^{3+}$ in $\mathrm{SnO}_{2}: \mathrm{Eu}^{3+} \mathrm{NCs}$ at $100-300 \mathrm{~K}$ upon excitation above the bandgap energy at $300 \mathrm{~nm}$. The PL decay at 300 $\mathrm{K}$ exhibited single exponential nature and PL lifetime of ${ }^{5} \mathrm{D}_{0}$ was fitted to be $15.9 \mathrm{~ms}$. With the decrease of experimental temperature, the decay curves of $\mathrm{Eu}^{3+}$ were found to deviate from the single exponential, regardless of the low doping concentration (0.01 at.\%). Moreover, an unusually long decay of $\mathrm{Eu}^{3+}$ even up to several tens of seconds was observed in the tail at temperature below $250 \mathrm{~K}$, indicating the occurrence of long afterglow luminescence from the sample. The origin of long afterglow luminescence was verified from $\mathrm{Eu}^{3+}$ ions by the persistent emission spectra
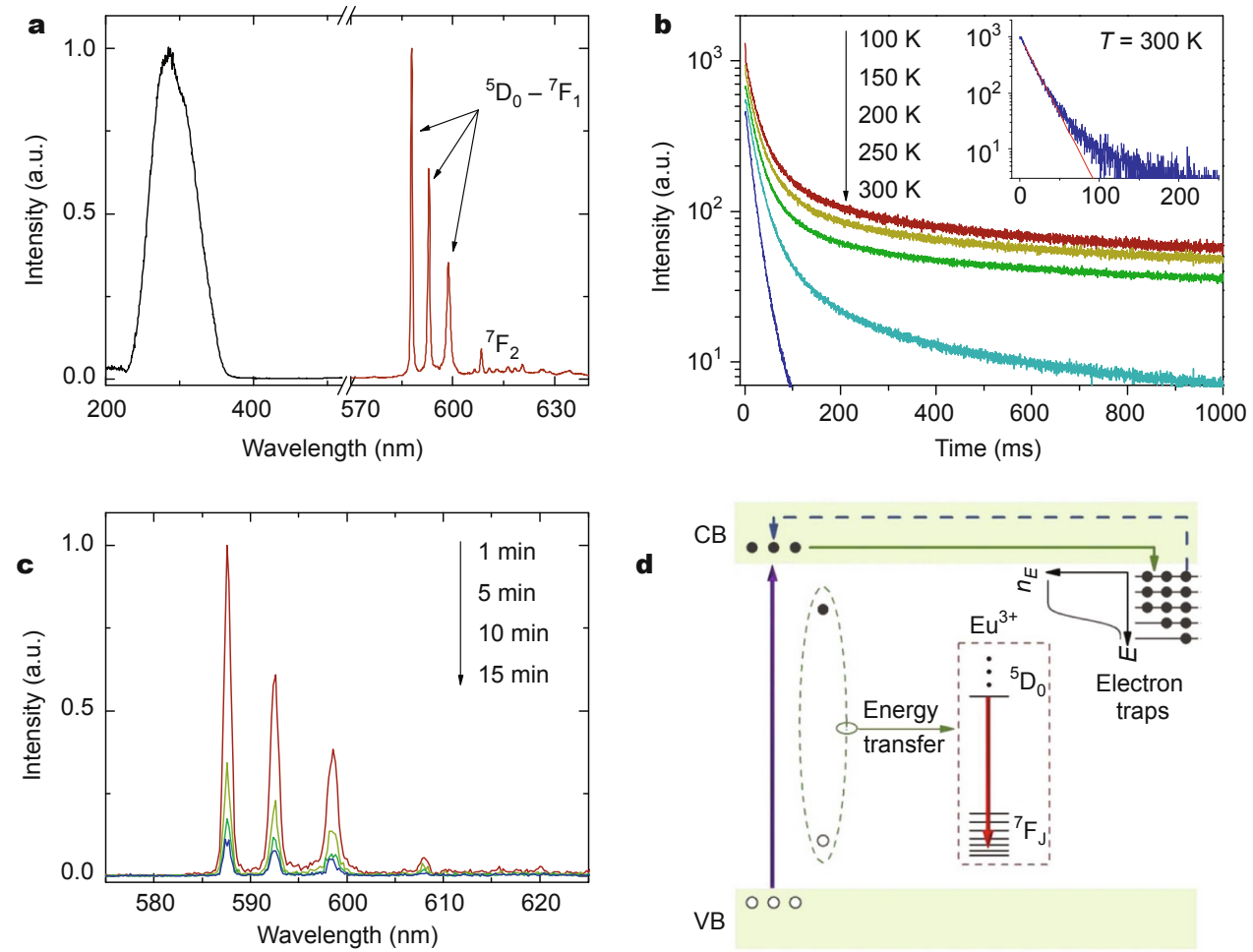

Figure 19 (a) Normalized PL excitation $\left(\lambda_{\mathrm{em}}=588 \mathrm{~nm}\right)$ and emission $\left(\lambda_{\mathrm{ex}}=300 \mathrm{~nm}\right.$ ) spectra of the $\mathrm{SnO}_{2}: \mathrm{Eu}^{3+} \mathrm{NCs}$ at $300 \mathrm{~K}$. (b) Temperature-dependent PL decays of $\mathrm{Eu}^{3+}$ in the temperature range of 100-300 K. The inset shows the decay at $300 \mathrm{~K}$ and the fitting curve using single-exponential function (red line). (c) Persistent emission spectra of $\mathrm{SnO}_{2}: \mathrm{Eu}^{3+} \mathrm{NPs}$ acquired at $200 \mathrm{~K}$ and at different time intervals after the stoppage of excitation. (d) A schematic illustrtion of the persistent luminescence mechanism in $\mathrm{SnO}_{2}$ : Eu ${ }^{3+} \mathrm{NCs}$. Adapted with permission from Ref. [211]. Copyright 2015, the Royal Society of Chemistry. 
in Fig. 19c, which exhibited essentially the same profile as that of the steady-state emission spectrum at different time intervals after the stoppage of excitation. The persistent luminescence of $\mathrm{Eu}^{3+}$ was further revealed to arise from the trap of electron in the $\mathrm{CB}$ by the deep defects below the $\mathrm{CB}$ prior to nonradiative transferring its energy to $\mathrm{Eu}^{3+}$ ions (Fig. 19d).

To overcome the concern of low solubility of $\mathrm{Ln}^{3+}$ in SNCs, more efforts have recently been devoted to designing new heterostructures such as isolator/semiconductor core-shell structure to spatially isolate the activators $\left(\mathrm{Ln}^{3+}\right)$ and sensitizers (SNCs) and thus to enhance the dopant concentration in the materials [212-214]. Generally, the $\mathrm{Ln}^{3+}$ ions are doped into the isolator layer in which the $\mathrm{Ln}^{3+}$ ions have high solubility due to the similar ionic radius and the same charge between dopants and host cations, and the semiconductor layer acts as sensitizers. For example, in $\mathrm{Y}_{2} \mathrm{O}_{3}: \mathrm{Tb}^{3+}, \mathrm{Yb}^{3+}, \mathrm{Li}^{+} / \mathrm{CdZnS}$ core-shell heterostructures, the energy absorbed by $\mathrm{CdZnS}$ bandgap can be nonradiatively transferred to $\mathrm{Tb}^{3+}$ excited states in $\mathrm{Y}_{2} \mathrm{O}_{3}$ core, and the subsequent quantum cutting downconversion between $\mathrm{Tb}^{3+}$ $\mathrm{Yb}^{3+}$ couples resulted in NIR emission of $\mathrm{Yb}^{3+}$. Herein, $\mathrm{Tb}^{3+}$ acted as an energy bridge to mediate the energy transfer from $\mathrm{CdZnS}$ to $\mathrm{Yb}^{3+}$ ions (Fig. 20a). To verify this energy transfer, PL excitation, emission and excited state dynamics were investigated in detail (Figs 20b-e). Fig. 20b shows the NIR emission spectra under the excitation directly from the $4 \mathrm{f}-5 \mathrm{~d}$ transition at $300 \mathrm{~nm}$ of $\mathrm{Tb}^{3+}$ or from band edge absorption at $472 \mathrm{~nm}$ of $\mathrm{CdZnS}$. The PL intensity upon excitation above CdZnS bandgap was observed to be much stronger than that upon direct excitation, indicative of a more efficient excitation via host sensitization than via direct excitation. The energy transfer between the core and the shell was further confirmed by the excitation spectra in Fig. 20c. For core-only phosphors, a broad band at around $300 \mathrm{~nm}$ ascribed to the $4 \mathrm{f}-5 \mathrm{~d}$ absorption of $\mathrm{Tb}^{3+}$ dominated the excitation spectrum by monitoring the $977 \mathrm{~nm}$ emission of $\mathrm{Yb}^{3+}$. By contrast, after the growth of $\mathrm{CdZnS}$ shell, an intense excitation peak at $472 \mathrm{~nm}$ appeared in addition to the 300-nm excitation band (Fig. 20c). The main excitation peak at $472 \mathrm{~nm}$ proved to originate from the CdZnS bandgap absorption, suggesting that efficient energy transfer from CdZnS to $\mathrm{Yb}^{3+}$ ions occurred. In this case, $\mathrm{Tb}^{3+}$ ions were found to play the key role for the sensitized emission of $\mathrm{Yb}^{3+}$, based on the fact that the $\mathrm{Yb}^{3+}$ emission decreased dramatically in the absence of $\mathrm{Tb}^{3+}$ (Fig. 20d). The energy transfer efficiency of $\mathrm{Tb}^{3+} \rightarrow \mathrm{Yb}^{3+}$ was determined by means of the excitation dynamic experiments, which was found to increase with the increasing concentration of $\mathrm{Yb}^{3+}$ and was estimated to be $56.4 \%$ when the $\mathrm{Yb}^{3+}$ concentra- tion reached 10 mol.\%. It should be noted that, in such core-shell heterostructures, only small part of activators located at the interface and adjacent to the energy donors participated in the light emission, which may greatly reduce the overall luminescent efficiency of materials.

\section{CONCLUSIONS AND PERSPECTIVES}

$\mathrm{Ln}^{3+}$ ions doped SNCs have been regarded as promising new-generation luminescent materials in view of the potential efficient energy transfer from SNCs host to $\mathrm{Ln}^{3+}$ ions. For the past decades, many efforts have been devoted to the material synthesis and optical property tuning of this kind of materials. It was found that by carefully controlling the synthesis strategies, $\mathrm{Ln}^{3+}$ can be effectively incorporated into the SNC host lattice via some wet chemical methods, e.g., sol-gel or hydro- (solvo-) thermal routes. Because of the large mismatch in ionic radius and charge imbalance between $\mathrm{Ln}^{3+}$ and the host cations, multiple sites possessing various CF surroundings were usually formed after the introduction of $\mathrm{Ln}^{3+}$ ions into the lattices of SNCs. These different luminescence centers of $\mathrm{Ln}^{3+}$ ions can be well identified with the aid of site-selective and time-resolved optical spectroscopy. The host-to- $\mathrm{Ln}^{3+}$ energy transfer could be readily achieved in the case that the energy levels of $\mathrm{Ln}^{3+}$ excited states match well with the bandgap energy of SNCs. The defect states or the co-doped guest ions were found to be effective in bridging the energy gap between the CB of SNCs and the excited states of $\mathrm{Ln}^{3+}$ ions, which might eventually enhance the host-to- $\mathrm{Ln}^{3+}$ energy transfer efficiency.

Although these findings are encouraging, some key challenges are still needed to be resolved for SNCs: $\mathrm{Ln}^{3+}$ in order to advance their potential applications in lighting, displays and biomedical fields. First, the luminescent efficiency or absolute quantum yield of SNCs: $\operatorname{Ln}^{3+}$ is still low, not ideal for practical applications. The improvement of the material crystallization and the introduction of proper charge compensators to reduce the defects in the SNCs system might be two effective strategies to improve the optical performance of SNCs: $\mathrm{Ln}^{3+}$. Second, although a variety of approaches or techniques have been proposed to prepare $\mathrm{Ln}^{3+}$ ions doped SNCs, synthesizing monodisperse and size-controllable SNCs remains a challenge so far. More efforts are required to develop simple but feasible synthetic protocols for fabricating monodisperse $\mathrm{Ln}^{3+}$ ions doped SNCs with desired physicochemical properties, which is currently of particular interest for their further technological applications as versatile nano-bioprobes. Last but not the least, an important and unique merit of SNCs: $\mathrm{Ln}^{3+}$, different from the other luminescent materials, is their potential ability to tune the optical properties of $\mathrm{Ln}^{3+}$ via 

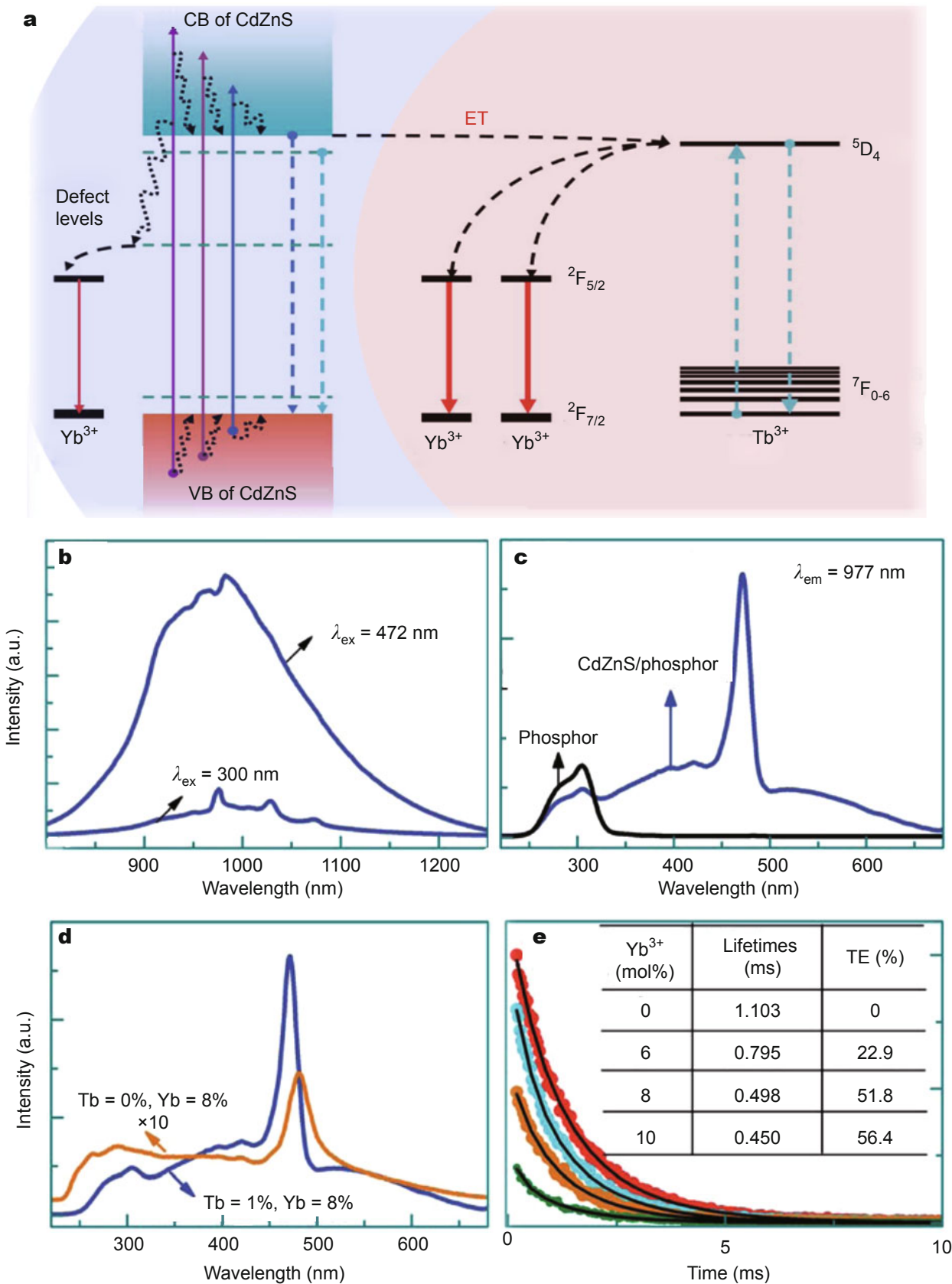

Figure 20 (a) A schematic illustration of energy transfer process from the CdZnS shell to $\mathrm{Y}_{2} \mathrm{O}_{3}: \mathrm{Tb}^{3+}$, $\mathrm{Yb}^{3+}$ core particles; (b) emission spectra of $\mathrm{Y}_{2} \mathrm{O}_{3}: \mathrm{Tb}^{3+}, \mathrm{Yb}^{3+} / \mathrm{CdZnS}$ under the excitation at 300 and $472 \mathrm{~nm}$, respectively; (c) excitation spectra of the core-shell heterostructures and the core-only phosphor; (d) comparison of excitation spectra between the samples with and without Tb doping; (e) PL decays of Tb ${ }^{3+}$ by monitoring the 544-nm emission in the core-shell sample with various $\mathrm{Yb}^{3+}$ contents. Adapted with permission from Ref. [213]. Copyright 2015, the Royal Society of Chemistry.

the bandgap engineering of SNCs, which is a facile and effective approach to further optimizing the optical performance of the materials. Nevertheless, such kind of work remains nearly untouched hitherto.

Received 6 September, 2015; accepted 21 September, 2015; published online 23 October 2015
1 Deng ML, Wang LY. Unexpected luminescence enhancement of upconverting nanocrystals by cation exchange with well retained small particle size. Nano Res, 2014, 7: 782-793

2 Deng ML, Ma YX, Huang S, Hu GF, Wang LY. Monodisperse upconversion $\mathrm{NaYF}_{4}$ nanocrystals: syntheses and bioapplications. Nano Res, 2011, 4: 685-694

3 Dong H, Sun LD, Yan CH. Energy transfer in lanthanide upconver- 
sion studies for extended optical applications. Chem Soc Rev, 2015, 44: 1608-1634

4 Dong H, Du SR, Zheng XY, et al. Lanthanide nanoparticles: from design toward bioimaging and therapy. Chem Rev, 2015, 115: 10725-10815

5 Shang MM, Li CX, Lin J. How to produce white light in a singlephase host? Chem Soc Rev, 2014, 43: 1372-1386

6 Hou ZY, Zhang YX, Deng KR, et al. UV-emitting upconversionbased $\mathrm{TiO}_{2}$ photosensitizing nanoplatform: near-infrared light mediated in vivo photodynamic therapy via mitochondria-involved apoptosis pathway. ACS nano, 2015, 9: 2584-2599

7 Deng RR, Qin F, Chen RF, et al. Temporal full-colour tuning through non-steady-state upconversion. Nat Nanotechnol, 2015, 10: 237-242

8 Liu XG, Yan CH, Capobianco JA. Photon upconversion nanomaterials. Chem Soc Rev, 2015, 44: 1299-1301

9 Huang P, Tu DT, Zheng W, et al. Inorganic lanthanide nanoprobes for background-free luminescent bioassays. Sci China Mater, 2015, 58: 156-177

10 Yu XF, Li M, Xie MY, et al. Dopant-controlled synthesis of water-soluble hexagonal $\mathrm{NaYF}_{4}$ nanorods with efficient upconversion fluorescence for multicolor bioimaging. Nano Res, 2010, 3: 51-60

11 Wang L, Zhang Y, Zhu Y. One-pot synthesis and strong near-infrared upconversion luminescence of poly(acrylic acid)-functionalized $\mathrm{YF}^{3}: \mathrm{Yb}^{3+} / \mathrm{Er}^{3+}$ nanocrystals. Nano Res, 2010, 3: 317-325

12 Cheng L, Yang K, Zhang S, et al. Highly-sensitive multiplexed in vivo imaging using PEGylated upconversion nanoparticles. Nano Res, 2010, 3: 722-732

13 Prasad PN. Nanophotonics. New York: John Wiley \& Sons, 2004

14 Bol AA, van Beek R, Meijerink A. On the incorporation of trivalent rare earth ions in II-VI semiconductor nanocrystals. Chem Mater, 2002, 14: 1121-1126

15 Pandey P, Kurchania R, Haque FZ. Optical studies of europiumdoped $\mathrm{ZnO}$ nanoparticles prepared by sol-gel technique. J Adv Phys, 2014, 3: 104-110

16 Tanner PA, Yu LX. Photoluminescence of $\mathrm{ZnO}: \mathrm{Eu}^{3+}$ nanoflowers. J Nanosci Nanotechnol, 2008, 8: 1307-1311

17 Armelao L, Bottaro G, Pascolini M, et al. Structure-luminescence correlations in europium-doped sol-gel $\mathrm{ZnO}$ nanopowders. J Phys Chem C, 2008, 112: 4049-4054

18 Wang N, Lin H, Li JB, Yang XZ, Zhang LZ. Photoluminescence of $\mathrm{TiO}_{2}$ :Eu nanotubes prepared by a two-step approach. J Lumin, 2007, 122: 889-891

19 Wang J, Zhou MJ, Hark SK, et al. Local electronic structure and luminescence properties of Er doped $\mathrm{ZnO}$ nanowires. Appl Phys Lett, 2006, 89: 221917

20 Liu YS, Li RF, Luo WQ, Zhu HM, Chen XY. Optical spectroscopy of $\mathrm{Sm}^{3+}$ and $\mathrm{Dy}^{3+}$ doped $\mathrm{ZnO}$ nanocrystals. Spectrosc Lett, 2010, 43: 343-349

21 Kar A, Patra A. Optical and electrical properties of $\mathrm{Eu}^{3+}$-doped $\mathrm{SnO}_{2}$ nanocrystals. J Phys Chem C, 2009, 113: 4375-4380

22 Sun YJ, Chen Y, Tian LJ, et al. Morphology-dependent upconversion luminescence of $\mathrm{ZnO}: \mathrm{Er}^{3+}$ nanocrystals. J Lumin, 2008, 128: 15-21

23 Li JG, Wang XH, Watanabe K, Ishigaki T. Phase structure and luminescence properties of $\mathrm{Eu}^{3+}$-doped $\mathrm{TiO}_{2}$ nanocrystals synthesized by $\mathrm{Ar} / \mathrm{O}_{2}$ radio frequency thermal plasma oxidation of liquid precursor mists. J Phys Chem B, 2006, 110: 1121-1127

24 Liu YS, Luo WQ, Li RF, Chen XY. Optical properties of $\mathrm{Nd}^{3+}$ ion-doped ZnO nanocrystals. J Nanosci Nanotechnol, 2010, 10: 1871-1876

25 Mukherjee P, Shade CM, Yingling AM, et al. Lanthanide sensitization in II-VI semiconductor materials: a case study with terbi-
um(III) and europium(III) in zinc sulfide nanoparticles. J Phys Chem A, 2011, 115: 4031-4041

26 Liang ZG, Mu J, Han L, Yu HQ. Microbe-assisted synthesis and luminescence properties of monodispersed $\mathrm{Tb}^{3+}$-doped $\mathrm{ZnS}$ nanocrystals. J Nanomater, 2015, 2015: 519303

27 Mukherjee P, Sloan RF, Shade CM, Waldeck DH, Petoud S. A postsynthetic modification of II-VI semiconductor nanoparticles to create $\mathrm{Tb}^{3+}$ and $\mathrm{Eu}^{3+}$ luminophores. J Phys Chem C, 2013, 117: 14451-14460

28 Liu YS, Zhou SY, Tu DT, et al. Amine-functionalized lanthanide-doped zirconia nanoparticles: optical spectroscopy, time-resolved fluorescence resonance energy transfer biodetection, and targeted imaging. J Am Chem Soc, 2012, 134: 15083-15090

29 Vela J, Prall BS, Rastogi P, et al. Sensitization and protection of lanthanide ion emission in $\operatorname{In}_{2} \mathrm{O}_{3}$ :Eu nanocrystal quantum dots. J Phys Chem C, 2008, 112: 20246-20250

30 Ghatak A, Debnath GH, Mandal M, Mukherjee P. Lanthanide cation-induced tuning of surface capping properties in zinc sulfide nanoparticles: an infrared absorption study. RSC Adv, 2015, 5: 32920-32932

31 Bishnoi S, Das R, Chawla S. Gold nanosphere enhanced green and red fluorescence in $\mathrm{ZnO}: \mathrm{Al}, \mathrm{Eu}^{3+}$. Appl Phys Lett, 2014, 105: 233108

32 Geburt S, Lorke M, da Rosa AL, et al. Intense intrashell luminescence of Eu-doped single $\mathrm{ZnO}$ nanowires at room temperature by implantation created Eu-Oi complexes. Nano Lett, 2014, 14: 4523-4528

33 Yang S, Han DL, Gao M, Yang JH, Bayanheshig. Controllable morphology and tunable colors of $\mathrm{Mg}$ and $\mathrm{Eu}$ ion co-doped $\mathrm{ZnO}$ by thermal annealing. CrystEngComm, 2014, 16: 6896-6900

34 Schäfer $H$, Hess C, Tobergte $H$, et al. Ultrafine sanding paper: a simple tool for creating small particles. Small, 2015, 11: 931-935

35 Yin JB, Xiang LQ, Zhao XP. Monodisperse spherical mesoporous Eu-doped $\mathrm{TiO}_{2}$ phosphor particles and the luminescence properties. Appl Phys Lett, 2007, 90: 113112

36 Pereira AS, Peres M, Soares MJ, et al. Synthesis, surface modification and optical properties of $\mathrm{Tb}^{3+}$-doped $\mathrm{ZnO}$ nanocrystals. Nanotechnology, 2006, 17: 834-839

37 Li L, Tsung CK, Yang Z, et al. Rare-earth-doped nanocrystalline titania microspheres emitting luminescence via energy transfer. Adv Mater, 2008, 20: 903-908

38 Du YP, Zhang YW, Sun LD, Yan CH. Efficient energy transfer in monodisperse Eu-doped $\mathrm{ZnO}$ nanocrystals synthesized from metal acetylacetonates in high-boiling solvents. J Phys Chem C, 2008, 112: 12234-12241

39 Das S, Mandal KC. Optical down-conversion in doped ZnSe:Tb ${ }^{3+}$ nanocrystals. Nanoscale, 2013, 5: 913-915

40 Chen W, Zhang JZ, Joly AG. Optical properties and potential applications of doped semiconductor nanoparticles. J Nanosci Nanotechnol, 2004, 4: 919-947

41 Liu YS, Luo WQ, Zhu HM, Chen XY. Optical spectroscopy of lanthanides doped in wide band-gap semiconductor nanocrystals. J Lumin, 2011, 131: 415-422

42 Chen XY, Luo WQ, Liu YS, Liu GK. Recent progress on spectroscopy of santhanide ions incorporated in semiconductor nanocrystals. J Rare Earths, 2007, 25: 515-525

43 O'Donnell KP. The temperature dependence of the luminescence of rare-earth-doped semiconductors: 25 years after Favennec. Phys Status Solidi C, 2015, 12: 466-468

44 Xiao QB, Zhu HM, Tu DT, Ma E, Chen XY. Near-infrared-to-near-infrared downshifting and near-infrared-to-visible upconverting luminescence of $\mathrm{Er}^{3+}$-doped $\mathrm{In}_{2} \mathrm{O}_{3}$ nanocrystals. J Phys Chem C, 2013, 117: 10834-10841

45 Lide DR. CRC Handbook of Chemistry and Physics (74th eds.). 
Boca Raton: CRC, 1993-1994

46 Yang L, Dong JZ, She YJ, et al. Self-purification construction of interstitial $\mathrm{O}$ in the neighbor of $\mathrm{Eu}^{3+}$ ions to act as energy transfer bridge. Appl Phys Lett, 2014, 104: 033109

47 Chen GY, Zhang YG, Somesfalean G, et al. Two-color upconversion in rare-earth-ion-doped $\mathrm{ZrO}_{2}$ nanocrystals. Appl Phys Lett, 2006, 89: 163105

48 Aneesh PM, Jayaraj MK. Red luminescence from hydrothermally synthesized Eu-doped $\mathrm{ZnO}$ nanoparticles under visible excitation. Bull Mater Sci, 2010, 33: 227-231

49 Zeng XY, Yuan JL, Wang ZY, Zhang L. Nanosheet-based microspheres of $\mathrm{Eu}^{3+}$-doped $\mathrm{ZnO}$ with efficient energy transfer from $\mathrm{ZnO}$ to $\mathrm{Eu}^{3+}$ at room temperature. Adv Mater, 2007, 19: 4510-4514

50 Tamm A, Kemell M, Kozlova J, et al. Atomic layer deposition and characterization of erbium oxide-doped zirconium oxide thin films. J Electrochem Soc, 2010, 157: G193-G201

51 Ji SL, Yin LL, Liu GD, Zhang LD, Ye CH. Synthesis of rare earth ions-doped $\mathrm{ZnO}$ nanostructures with efficient host-guest energy transfer. J Phys Chem C, 2009, 113: 16439-16444

52 Chen XB, Li LP, Su YG, Li GS. Phase evolution and photoluminescence of $\mathrm{Eu}^{3+}$-doped $\mathrm{ZrO}_{2}$. J Nanosci Nanotechnol, 2010, 10: 1800-1807

53 Fidelus JD, Yatsunenko S, Godlewski M, et al. Relation between structural properties of $\mathrm{Pr}^{3+}$-doped yttria-stabilized zirconia nanopowders and their luminescence efficiency. Scripta Mater, 2009, 61: 415-418

54 Chen LM, Liu YN, Li YD. Preparation and characterization of $\mathrm{ZrO}_{2}$ : $\mathrm{Eu}^{3+}$ phosphors. J Alloy Compd, 2004, 381: 266-271

55 Li GR, Dawa CR, Lu XH, Yu XL, Tong YX. Use of additives in the electrodeposition of nanostructured $\mathrm{Eu}^{3+} / \mathrm{ZnO}$ films for photoluminescent devices. Langmuir, 2009, 25: 2378-2384

56 Lue Q, Guo FY, Sun L, Li AH, Zhao LC. Surface modification of $\mathrm{ZrO}_{2}: \mathrm{Er}^{3+}$ nanoparticles to attenuate aggregation and enhance upconversion fluorescence. J Phys Chem C, 2008, 112: 2836-2844

57 Zeng XY, Yuan JL, Zhang L. Synthesis and photoluminescent properties of rare earth doped $\mathrm{ZnO}$ hierarchical microspheres. J Phys Chem C, 2008, 112: 3503-3508

58 Xue DQ, Zhang JY, Yang C, Wang TM. PL and EL characterizations of $\mathrm{ZnO}: \mathrm{Eu}^{3+} \mathrm{Li}^{+}$films derived by sol-gel process. J Lumin, 2008, 128: 685-689

59 Liu YS, Luo WQ, Li RF, et al. Optical spectroscopy of $\mathrm{Eu}^{3+}$ doped ZnO nanocrystals. J Phys Chem C, 2008, 112: 686-694

60 Liu L, Wang YX, Bai YF, et al. Single band upconversion mechanisms of $\mathrm{Er}^{3+} / \mathrm{Yb}^{3+}: \mathrm{ZrO}_{2}$ nanocrystals. Opt Commun, 2012, 285: 1528-1532

61 Gomez LA, Menezes LD, de Araujo CB, et al. Upconversion luminescence in $\mathrm{Er}^{3+}$ doped and $\mathrm{Er}^{3+} / \mathrm{Yb}^{3+}$ codoped zirconia and hafnia nanocrystals excited at $980 \mathrm{~nm}$. J Appl Phys, 2010, 107: 113508

62 Diaz-Torres LA, De la Rosa E, Salas P, Romero VH, Angeles-Chavez C. Efficient photo luminescence of $\mathrm{Dy}^{3+}$ at low concentrations in nanocrystalline $\mathrm{ZrO}_{2}$. J Solid State Chem, 2008, 181: 75-80

63 De la Rosa E, Diaz-Torres LA, Salas P, Rodriguez RA. Visible light emission under UV and IR excitation of rare earth doped $\mathrm{ZrO}_{2}$ nanophosphor. Opt Mater, 2005, 27: 1320-1325

64 Han HL, Yang LW, Liu YX, Zhang YY, Yang QB. Up-conversion luminescence switching in $\mathrm{Er}^{3+}$-containing $\mathrm{ZnO}$ nanoparticles through $\mathrm{Li}^{+}$co-doping. Opt Mater, 2008, 31: 338-341

65 Cheng BM, Yu LX, Duan CK, Wang HS, Tanner PA. Vacuum ultraviolet and visible spectra of $\mathrm{ZnO}: \mathrm{Eu}^{3+}$ prepared by combustion synthesis. J Phys-Condens Mat, 2008, 20: 345231-345234

66 Rinnert H, Miska P, Vergnat M, et al. Photoluminescence of Nddoped $\mathrm{SnO}_{2}$ thin films. Appl Phys Lett, 2012, 100: 101908

67 Strauss M, Destefani TA, Sigoli FA, Mazali IO. Crystalline $\mathrm{SnO}_{2}$ nanoparticles size probed by $\mathrm{Eu}^{3+}$ luminescence. Cryst Growth Des, 2011, 11: 4511-4516

68 Armelao L, Heigl F, Jurgensen A, et al. X-ray excited optical luminescence studies of $\mathrm{ZnO}$ and $\mathrm{Eu}$-doped $\mathrm{ZnO}$ nanostructures. J Phys Chem C, 2007, 111: 10194-10200

69 Kong JT, Zhu HM, Li RF, Luo WQ, Chen XY. Carrier-mediated 1.55 $\mu \mathrm{m}$ photoluminescence from single $\mathrm{Er}^{3+}$ center in $\mathrm{SnO}_{2}$ nanocrystals. Opt Lett, 2009, 34: 1873-1875

70 Moon T, Hwang ST, Jung DR, et al. Hydroxyl-quenching effects on the photoluminescence properties of $\mathrm{SnO}_{2}: \mathrm{Eu}^{3+}$ nanoparticles. J Phys Chem C, 2007, 111: 4164-4167

71 Wang $\mathrm{H}$, Wang Y, Kershaw SV, et al. Fluorinated Eu-doped $\mathrm{SnO}_{2}$ nanostructures with simultaneous phase and shape control and improved photoluminescence. Part Part Syst Char, 2013, 30: 332-337

72 Monteiro T, Neves AJ, Soares MJ, et al. Up conversion from visible to ultraviolet in bulk $\mathrm{ZnO}$ implanted with Tm ions. Appl Phys Lett, 2005, 87: 192108

73 Jia WY, Monge K, Fernandez F. Energy transfer from the host to $\mathrm{Eu}^{3+}$ in ZnO. Opt Mater, 2003, 23: 27-32

74 Brovelli S, Chiodini A, Lauria A, Meinardi F, Paleari A. Energy transfer to erbium ions from wide-band-gap $\mathrm{SnO}_{2}$ nanocrystals in silica. Phys Rev B, 2006, 73: 073406

75 Del Castillo J, Rodriguez VD, Yanes AC, Mendez-Ramos J, Torres ME. Luminescent properties of transparent nanostructured $\mathrm{Eu}^{3+}$ doped $\mathrm{SnO}_{2}-\mathrm{SiO}_{2}$ glass-ceramics prepared by the sol-gel method. Nanotechnology, 2005, 16: S300-S303

76 Nogami M, Ohno A, You HP. Laser-induced $\mathrm{SnO}_{2}$ crystallization and fluorescence properties in $\mathrm{Eu}^{3+}$-doped $\mathrm{SnO}_{2}-\mathrm{SiO}_{2}$ glasses. Phys Rev B, 2003, 68: 104204

77 Kiisk V, Kangur T, Paalo M, et al. Structural and luminescence characteristics of $\mathrm{SnO}_{2}$ :Eu and $\mathrm{SnO}_{2}$ :Eu,Sb nanophosphors upon annealing at high temperatures. Mater Chem Phys, 2011, 130: 293-298

78 Sambasivam S, Kim SB, Jeong JH, et al. Effect of $\mathrm{Er}^{3+}$ doping in $\mathrm{SnO}_{2}$ semiconductor nanoparticles synthesized by sol-gel technique. Curr Appl Phys, 2010, 10: 1383-1386

79 Bouzidi C, Elhouichet H, Moadhen A. $\mathrm{Yb}^{3+}$ effect on the spectroscopic properties of Er- $\mathrm{Yb}$ codoped $\mathrm{SnO}_{2}$ thin films. J Lumin, 2011, 131: 2630-2635

80 Ishizumi A, Kanemitsu Y. Structural and luminescence properties of Eu-doped $\mathrm{ZnO}$ nanorods fabricated by a microemulsion method. Appl Phys Lett, 2005, 86: 253106

81 Wei XJ, Wang W, Chen KZ. ZnO:Er,Yb,Gd particles designed for magnetic-fluorescent imaging and near-infrared light triggered photodynamic therapy. J Phys Chem C, 2013, 117: 23716-23729

82 Pal P, Manam J. Color tunable $\mathrm{ZnO}$ nanorods by $\mathrm{Eu}^{3+}$ and $\mathrm{Tb}^{3+}$ co-doping for optoelectronic applications. Appl Phys A, 2014, 116: 213-223

83 Zhu HM, Li RF, Luo WQ, Chen XY. Eu ${ }^{3+}$-doped beta- $\mathrm{Ga}_{2} \mathrm{O}_{3}$ nanophosphors: annealing effect, electronic structure and optical spectroscopy. Phys Chem Chem Phys, 2011, 13: 4411-4419

84 Biljan T, Gajovic A, Meic Z. Visible and NIR luminescence of nanocrystalline beta- $\mathrm{Ga}_{2} \mathrm{O}_{3}: \mathrm{Er}^{3+}$ prepared by solution combustion synthesis. J Lumin, 2008, 128: 377-382

85 Hirata GA, Ramos F, Garcia R, et al. A new combustion synthesis method for $\mathrm{GaN}: \mathrm{Eu}^{3+}$ and $\mathrm{Ga}_{2} \mathrm{O}_{3}: \mathrm{Eu}^{3+}$ luminescent powders. Phys Status Solidi A, 2001, 188: 179-182

86 Yue D, Lu W, Jin L, et al. Controlled synthesis, asymmetrical transport behavior and luminescence properties of lanthanide doped $\mathrm{ZnO}$ mushroom-like 3D hierarchical structures. Nanoscale, 2014, 6: 13795-13802

87 Zhao JG, Zhang WY, Xie EQ, et al. Structure and photoluminescence of beta- $\mathrm{Ga}_{2} \mathrm{O}_{3}: \mathrm{Eu}^{3+}$ nanofibers prepared by electrospinning. Appl Surf Sci, 2011, 257: 4968-4972 
88 Kumar V, Kumar V, Som S, et al. Effect of Eu doping on the photoluminescence properties of $\mathrm{ZnO}$ nanophosphors for red emission applications. Appl Surf Sci, 2014, 308: 419-430

89 Gu F, Wang SF, Lu MK, et al. Structure evaluation and highly enhanced luminescence of $\mathrm{Dy}^{3+}$-doped $\mathrm{ZnO}$ nanocrystals by $\mathrm{Li}^{+}$doping via combustion method. Langmuir, 2004, 20: 3528-3531

90 Li GG, Peng C, Li CX, et al. Shape-controllable synthesis and morphology-dependent luminescence properties of $\mathrm{GaOOH}: \mathrm{Dy}^{3+}$ and beta- $\mathrm{Ga}_{2} \mathrm{O}_{3}: \mathrm{Dy}^{3+}$. Inorg Chem, 2010, 49: 1449-1457

91 Niu JH, Hua RN, Li WL, Li MT, Yu TZ. Electroluminescent properties of a device based on terbium-doped $\mathrm{ZnS}$ nanocrystals. J Phys D Appl Phys, 2006, 39: 2357-2360

92 Chen W, Joly AG, Malm JO, Bovin JO. Upconversion luminescence of $\mathrm{Eu}^{3+}$ and $\mathrm{Mn}^{2+}$ in $\mathrm{ZnS}: \mathrm{Mn}^{2+}, \mathrm{Eu}^{3+}$ codoped nanoparticles. J Appl Phys, 2004, 95: 667-672

93 Ahemen I, Amah A, AttahDaniel B, Fasasi A. Spherical nanoparticles of $\mathrm{Eu}^{3+}$-doped $\mathrm{ZnS}$ semiconductor synthesized from $\mathrm{ZnO}$ nanorods precursor. Nanosci Nanotechno, 2014, 4: 7-15

94 Wei XJ, Wang W, Chen KZ. Preparation and characterization of $\mathrm{ZnS}: \mathrm{Tb}, \mathrm{Gd}$ and $\mathrm{ZnS}: \mathrm{Er}, \mathrm{Yb}, \mathrm{Gd}$ nanoparticles for bimodal magneticfluorescent imaging. Dalton T, 2013, 42: 1752-1759

95 Sinha G, Patra A. Generation of green, red and white light from rare-earth doped $\mathrm{Ga}_{2} \mathrm{O}_{3}$ nanoparticles. Chem Phys Lett, 2009, 473: $151-154$

96 Liu GC, Duan XC, Li HB, Liang D. Preparation and photoluminescence properties of Eu-doped $\mathrm{Ga}_{2} \mathrm{O}_{3}$ nanorods. Mater Chem Phys, 2008, 110: 206-211

97 Hou SL, Yuen YY, Mao HB, Wang JQ, Zhu ZQ. Photoluminescence properties of the $\mathrm{Eu}^{3+}$-doped $\mathrm{ZnS}$ nanocrystals and the crystal-field analysis. J Phys D-Appl Phys, 2009, 42: 215105

98 Nogales E, Mendez B, Piqueras J, Garcia JA. Europium doped gallium oxide nanostructures for room temperature luminescent photonic devices. Nanotechnology, 2009, 20: 115201

99 Nogales E, Garcia JA, Mendez B, Piqueras J. Doped gallium oxide nanowires with waveguiding behavior. Appl Phys Lett, 2007, 91: 133108

100 Liu XM, Yu CC, Li CX, Lin J. Comparative study of $\mathrm{Ga}_{2} \mathrm{O}_{3}: \mathrm{Dy}^{3+}$ phosphors prepared by three methods. J Electrochem Soc, 2007, 154: P86-P91

101 Wang YJ, Wu CX, Chen MZ, Huang MC. Dynamical analysis of relaxation luminescence in $\mathrm{ZnS}: \mathrm{Er}^{3+}$ thin film devices. J Appl Phys, 2003, 93: 9625-9629

102 Kim JS, Kim HE, Kwon AK, Park HL, Kim GC. Effect of initial pH on nanophosphor $\beta-\mathrm{Ga}_{2} \mathrm{O}_{3}: \mathrm{Eu}^{3+}$ prepared through sol-gel process. J Lumin, 2007, 122: 710-713

103 Shen WY, Pang ML, Lin J, Fang J. Host-sensitized luminescence of $\mathrm{Dy}^{3+}$ in nanocrystalline $\beta-\mathrm{Ga}_{2} \mathrm{O}_{3}$ prepared by a Pechini-type sol-gel process. J Electrochem Soc, 2005, 152: H25-H28

104 Pang ML, Shen WY, Lin J. Enhanced photoluminescence of $\mathrm{Ga}_{2} \mathrm{O}_{3}$ : $\mathrm{Dy}^{3+}$ phosphor films by $\mathrm{Li}^{+}$doping. J Appl Phys, 2005, 97: 033511

105 Kim JS, Kim HE, Park HL, Kim GC. Luminescence intensity and color purity enhancement in nanostructured $\beta-\mathrm{Ga}_{2} \mathrm{O}_{3}: \mathrm{Eu}^{3+}$ phosphors. Solid State Commun, 2004, 132: 459-463

106 Georgobiani AN, Kotljarevsky MB, Kidalov VV, Rogozin IV, Aminov UA. p-type II-VI compounds doped by rare-earth elements. J Cryst Growth, 2000, 214: 516-519

107 Hao JH, Lou ZD, Renaud I, Cocivera M. Electroluminescence of europium-doped gallium oxide thin films. Thin Solid Films, 2004, 467: $182-185$

$108 \mathrm{Hao} \mathrm{JH,} \mathrm{Cocivera} \mathrm{M.} \mathrm{Optical} \mathrm{and} \mathrm{luminescent} \mathrm{properties} \mathrm{of} \mathrm{un-}$ doped and rare-earth-doped $\mathrm{Ga}_{2} \mathrm{O}_{3}$ thin films deposited by spray pyrolysis. J Phys D-Appl Phys, 2002, 35: 433-438

109 Lin T, Ding XY, Xu J, et al. Influences of doping and annealing con- ditions on the photoluminescence from $\operatorname{In}_{2} \mathrm{O}_{3}$ nanocrystals and $\mathrm{Eu}^{3+}$ ions co-doped sol-gel $\mathrm{SiO}_{2}$ films. J Appl Phys, 2011, 109: 083512

110 Jin BK, Kim JK, Yu SM, Choi YG. Electrical and optical properties of $\mathrm{Er}^{3+}$-doped indium tin oxide thin films fabricated via a sol-gel technique. J Ceram Process Res, 2009, 10: S26-S31

111 Podhorodecki A, Kudrawiec R, Misiewicz J, Gaponenko NV, Tsyrkunov DA. $1.54 \mu \mathrm{m}$ photoluminescence from Er-doped sol-gel derived $\mathrm{In}_{2} \mathrm{O}_{3}$ films embedded in porous anodic alumina. Opt Mater, 2006, 28: 685-687

112 Deng L, Shan Y, Xu JJ, Chen HY. Electrochemiluminescence behaviors of $\mathrm{Eu}^{3+}$-doped $\mathrm{CdS}$ nanocrystals film in aqueous solution. Nanoscale, 2012, 4: 831-836

113 Planelles-Arago J, Cordoncillo E, Ferreira RAS, Carlos LD, Escribano P. Synthesis, characterization and optical studies on lanthanide-doped CdS quantum dots: new insights on CdS $\rightarrow$ lanthanide energy transfer mechanisms. J Mater Chem, 2011, 21: 1162-1170

114 Chowdhury PS, Patra A. Role of dopant concentration and surface coating on photophysical properties of CdS:Eu ${ }^{3+}$ nanocrystals. Phys Chem Chem Phys, 2006, 8: 1329-1334

115 Xiao QB, Liu YS, Liu LQ, et al. $\mathrm{Eu}^{3+}$-doped $\operatorname{In}_{2} \mathrm{O}_{3}$ nanophosphors: electronic structure and optical characterization. J Phys Chem C, 2010, 114: 9314-9321

116 Zou SY, Meng JX. Synthesis and upconversion luminescence of $\mathrm{Er}^{3+} / \mathrm{Yb}^{3+}$ co-doped $\mathrm{In}_{2} \mathrm{O}_{3}$ nanocrystals. Chinese J Inorg Chem, 2011, 27: 1138-1142

117 Zhang KX, Yu YX, Sun SQ. Influence of Eu doping on the microstructure and photoluminescence of CdS nanocrystals. Appl Surf Sci, 2012, 258: 7658-7663

118 Yu YL, Chen DQ, Wang YS, et al. Enhanced photoluminescence of $\mathrm{Eu}^{3+}$ induced by energy transfer from $\mathrm{In}_{2} \mathrm{O}_{3}$ nano-crystals embedded in glassy matrix. Phys Chem Chem Phys, 2009, 11: 8774-8778

119 Rai S, Bokatial L, Dihingia PJ. Effect of CdS nanoparticles on fluorescence from $\mathrm{Sm}^{3+}$ doped $\mathrm{SiO}_{2}$ glass. J Lumin, 2011, 131: 978-983

120 Bokatial L, Rai S. Optical properties and up-conversion of $\operatorname{Pr}^{3+}$ doped CdS nanoparticles in sol-gel glasses. J Lumin, 2010, 130: 1857-1862

121 Planelles-Arago J, Julian-Lopez B, Cordoncillo E, et al. Lanthanide doped $\mathrm{ZnS}$ quantum dots dispersed in silica glasses: an easy one pot sol-gel synthesis for obtaining novel photonic materials. J Mater Chem, 2008, 18: 5193-5199

122 Julian B, Planelles J, Cordoncillo E, et al. $\mathrm{Eu}^{3+}$-doped CdS nanocrystals in $\mathrm{SiO}_{2}$ matrices: one-pot sol-gel synthesis and optical characterization. J Mater Chem, 2006, 16: 4612-4618

123 Lee DG, Nishikawa A, Terai Y, Fujiwara Y. Eu luminescence center created by Mg codoping in Eu-doped GaN. Appl Phys Lett, 2012, 100: 171904

124 Jia CW, Xie EQ, Zhao JG, Sun ZW, Peng AH. Visible and near-infrared photoluminescences of europium-doped titania film. J Appl Phys, 2006, 100: 023529

125 Bahtat A, Bouazaoui M, Bahtat M, et al. Up-conversion fluorescence spectroscopy in $\mathrm{Er}^{3+}: \mathrm{TiO}_{2}$ planar waveguides prepared by a sol-gel process. J Non-Cryst Solids, 1996, 202: 16-22

126 Setiawati E, Kawano K. Stabilization of anatase phase in the rare earth; $\mathrm{Eu}$ and $\mathrm{Sm}$ ion doped nanoparticle $\mathrm{TiO}_{2}$. J Alloy Compd, 2008, 451: 293-296

127 Frindell KL, Bartl MH, Popitsch A, Stucky GD. Sensitized luminescence of trivalent europium by three-dimensionally arranged anatase nanocrystals in mesostructured titania thin films. Angew Chem Int Edit, 2002, 41: 959-962

128 Zhao XP, Yin JB. Preparation and electrorheological characteristics of rare-earth-doped $\mathrm{TiO}_{2}$ suspensions. Chem Mater, 2002, 14 : 2258-2263

129 Conde-Gallardo A, Garcia-Rocha M, Hernandez-Calderon I, Palo- 
mino-Merino R. Photoluminescence properties of the $\mathrm{Eu}^{3+}$ activator ion in the $\mathrm{TiO}_{2}$ host matrix. Appl Phys Lett, 2001, 78: 3436-3438

130 Conde-Gallardo A, Garcia-Rocha M, Palomino-Merino R, Velasquez-Quesada MP, Hernandez-Calderon I. Photoluminescence properties of $\mathrm{Tb}^{3+}$ and $\mathrm{Eu}^{3+}$ ions hosted in $\mathrm{TiO}_{2}$ matrix. Appl Surf Sci, 2003, 212: 583-588

131 Palomino-Merino R, Conde-Gallardo A, Garcia-Rocha M, et al. Photoluminescence of $\mathrm{TiO}_{2}: \mathrm{Eu}^{3+}$ thin films obtained by sol-gel on $\mathrm{Si}$ and Corning glass substrates. Thin Solid Films, 2001, 401: 118-123

132 Gao CM, Song HW, Hu LY, et al. Luminescence enhancement in bromine and samarium co-doped $\mathrm{TiO}_{2}$ semiconductor nanocrystalline powders. J Lumin, 2008, 128: 559-564

133 Shang QK, Yu H, Kong XG, et al. Green and red up-conversion emissions of $\mathrm{Er}^{3+}-\mathrm{Yb}^{3+}$ co-doped $\mathrm{TiO}_{2}$ nanocrystals prepared by solgel method. J Lumin, 2008, 128: 1211-1216

134 Ting CC, Chen SY, Hsieh WF, Lee HY. Effects of yttrium codoping on photoluminescence of erbium-doped $\mathrm{TiO}_{2}$ films. J Appl Phys, 2001, 90: 5564-5569

135 Ghosh P, Patra A. Influence of surface coating on physical properties of $\mathrm{TiO}_{2} / \mathrm{Eu}^{3+}$ nanocrystals. J Phys Chem C, 2007, 111: 7004-7010

136 Fu CY, Liao JS, Luo WQ, Li RF, Chen XY. Emission of $1.53 \mu \mathrm{m}$ originating from the lattice site of $\mathrm{Er}^{3+}$ ions incorporated in $\mathrm{TiO}_{2}$ nanocrystals. Opt Lett, 2008, 33: 953-955

137 Takagi Y, Suwa T, Sekiguchi H, Okada H, Wakahara A. Effect of Mg codoping on $\mathrm{Eu}^{3+}$ luminescence in $\mathrm{GaN}$ grown by ammonia molecular beam epitaxy. Appl Phys Lett, 2011, 99: 171905

138 Wang R, Steckl AJ. Effect of growth conditions on $\mathrm{Eu}^{3+}$ luminescence in GaN. J Cryst Growth, 2010, 312: 680-684

139 Higuchi S, Ishizumi A, Sawahata J, Akimoto K, Kanemitsu Y. Luminescence and energy-transfer mechanisms in $\mathrm{Eu}^{3+}$-doped $\mathrm{GaN}$ epitaxial films. Phys Rev B, 2010, 81: 035207

140 Wang R, Steckl AJ, Brown EE, Hommerich U, Zavada JM. Effect of Si codoping on $\mathrm{Eu}^{3+}$ luminescence in GaN. J Appl Phys, 2009, 105: 043107

141 Peng H, Lee CW, Everitt HO, et al. Spectroscopic and energy transfer studies of $\mathrm{Eu}^{3+}$ centers in GaN. J Appl Phys, 2007, 102: 073520

142 Sawahata J, Seo J, Chen SQ, et al. Photoluminescence spectra of Eudoped GaN with various Eu concentrations. Appl Phys Lett, 2006, 89: 192104

143 Ishizumi A, Sawahata J, Akimoto K, Kanemitsu Y. Origin of efficient luminescence from $\mathrm{GaN}: \mathrm{Eu}^{3+}$ epitaxial films revealed by microscopic photoluminescence imaging spectroscopy. Appl Phys Lett, 2006, 89: 191908

144 Andreev T, Liem NQ, Hori Y, et al. Optical transitions in $\mathrm{Eu}^{3+}$ ions in GaN:Eu grown by molecular beam epitaxy. Phys Rev B, 2006, 73: 195203

145 Peng HY, Lee CW, Everitt HO, et al. Effect of optical excitation energy on the red luminescence of $\mathrm{Eu}^{3+}$ in GaN. Appl Phys Lett, 2005, 86: 051110

146 Andreev T, Monroy E, Gayral B, et al. Eu locations in Eu-doped in GaN/GaN quantum dots. Appl Phys Lett, 2005, 87: 021906

147 Nyein EE, Hommerich U, Heikenfeld J, et al. Spectral and timeresolved photoluminescence studies of Eu-doped GaN. Appl Phys Lett, 2003, 82: 1655-1657

148 Heikenfeld J, Garter M, Lee DS, Birkhahn R, Steckl AJ. Red light emission by photoluminescence and electroluminescence from Eudoped GaN. Appl Phys Lett, 1999, 75: 1189-1191

149 Gruber JB, Zandi B, Lozykowski HJ, Jadwisienczak WM. Spectroscopic properties of $\mathrm{Sm}^{3+}\left(4 \mathrm{f}^{5}\right)$ in GaN. J Appl Phys, 2002, 91: 2929-2935

150 Park JH, Steckl AJ. Site specific $\mathrm{Eu}^{3+}$ stimulated emission in GaN host. Appl Phys Lett, 2006, 88: 011111

151 Yu HK, Yi GR, Kang JH, et al. Surfactant-assisted synthesis of uni- form titania microspheres and their clusters. Chem Mater, 2008, 20: 2704-2710

152 Roqan IS, O'Donnell KP, Martin RW, et al. Identification of the prime optical center in GaN:Eu ${ }^{3+}$. Phys Rev B, 2010, 81: 085209

153 Stouwdam JW, van Veggel FCJM. Sensitized emission in $\mathrm{Ln}^{3+}$ doped $\mathrm{TiO}_{2}$ semiconductor nanoparticles. Chem Phys Chem, 2004, 5: 743-746

154 Nyk M, Kudrawiec R, Strek W, Misiewicz J. Synthesis and optical properties of $\mathrm{Eu}^{3+}$ and $\mathrm{Tb}^{3+}$ doped $\mathrm{GaN}$ nanocrystallite powders. Opt Mater, 2006, 28: 767-770

155 Ji TH, Liu Y, Zhao H, et al. Preparation and up-conversion fluorescence of rare earth $\left(\mathrm{Er}^{3+}\right.$ or $\left.\mathrm{Yb}^{3+} / \mathrm{Er}^{3+}\right)$-doped $\mathrm{TiO}_{2}$ nanobelts. J Solid State Chem, 2010, 183: 584-589

156 Jeon S, Braun PV. Hydrothermal synthesis of Er-doped luminescent $\mathrm{TiO}_{2}$ nanoparticles. Chem Mater, 2003, 15: 1256-1263

157 Qi XF, Song YH, Sheng Y, et al. Controllable synthesis and luminescence properties of $\mathrm{TiO}_{2}: \mathrm{Eu}^{3+}$ nanorods, nanoparticles and submicrospheres by hydrothermal method. Opt Mater, 2014, 38: 193-197

158 Vranješ M, Kuljanin-Jakovljević J, Ahrenkiel S, et al. $\mathrm{Sm}^{3+}$ doped $\mathrm{TiO}_{2}$ nanoparticles synthesized from nanotubular precursors-luminescent and structural properties. J Lumin, 2013, 143: 453-458

159 Kudrawiec R, Nyk M, Podhorodecki A, et al. Change in photoluminescence spectra of Eu-doped GaN powders due to the aggregation of nanosized grains into micrometer-sized conglomerations. Appl Phys Lett, 2006, 88: 061916

160 Park DJ, Sekino T, Tsukuda S, et al. Photoluminescence of samarium-doped $\mathrm{TiO}_{2}$ nanotubes. J Solid State Chem, 2011, 184: 2695-2700

161 Liu FS, Liu QL, Liang JK, et al. Structure and visible photoluminescence of $\mathrm{Sm}^{3+}$, $\mathrm{Dy}^{3+}$ and $\mathrm{Tm}^{3+}$ doped $c$-axis oriented AlN films. Chinese Phys, 2006, 15: 2445-2449

162 Zhao X, Ikegami K, Ishiwata S, et al. Photoluminescence and local structure analysis of $\mathrm{Sm}^{3+}$ ions in single phase $\mathrm{TiO}_{2}$ thin films. AIP Conf Proc, 2011, 1399: 485-486

163 Vetter U, Gruber JB, Nijjar AS, et al. Crystal field analysis of $\mathrm{Pm}^{3+}$ $\left(4 \mathrm{f}^{4}\right)$ and $\mathrm{Sm}^{3+}\left(4 \mathrm{f}^{5}\right)$ and lattice location studies of Nd-147 and Pm147 in w-AlN. Phys Rev B, 2006, 74: 205201

164 Ikeda M, Li JG, Kobayashi N, et al. Phase formation and luminescence properties in $\mathrm{Eu}^{3+}$-doped $\mathrm{TiO}_{2}$ nanoparticles prepared by thermal plasma pyrolysis of aqueous solutions. Thin Solid Films, 2008, 516: 6640-6644

165 Zhang CN, Uchikoshi T, Li JG, Watanabe T, Ishigaki T. Influence of niobium doping on phase composition and defect-mediated photoluminescence properties of $\mathrm{Eu}^{3+}$-doped $\mathrm{TiO}_{2}$ nanopowders synthesized in $\mathrm{Ar} / \mathrm{O}_{2}$ thermal plasma. J Alloy Compd, 2011, 509: 8944-8951

166 Tachikawa T, Ishigaki T, Li JG, Fujitsuka M, Majima T. DefectMediated photoluminescence dynamics of $\mathrm{Eu}^{3+}$ doped $\mathrm{TiO}_{2}$ nanocrystals revealed at the single-particle or single-aggregate level. Angew Chem Int Edit, 2008, 47: 5348-5352

167 Kaczmarek D, Domaradzki J, Borkowska A, et al. Optical emission from $\mathrm{Eu}, \mathrm{Tb}$, Nd luminescence centers in $\mathrm{TiO}_{2}$ prepared by magnetron sputtering. Opt Appl, 2007, 37: 433-438

168 Zhao YM, Rabouw FT, Puffelen Tv, et al. Lanthanide-doped CaS and SrS luminescent nanocrystals: a single-source precursor approach for doping. J Am Chem Soc, 2014, 136: 16533-16543

169 Dethlefsen JR, Mikhailovsky AA, Burks PT, Døssing A, Ford PC. Lanthanide modification of $\mathrm{CdSe} / \mathrm{ZnS}$ core/shell quantum dots. J Phys Chem C, 2012, 116: 23713-23720

170 Liu N, Xu L, Wang H, et al. Sensitization enhancement of europium in $\mathrm{ZnSe} / \mathrm{ZnS}$ core/shell quantum dots induced by efficient energy transfer. Luminescence, 2014, 29: 1095-1101

171 Martín-Rodríguez R, Geitenbeek R, Meijerink A. Incorporation 
and luminescence of $\mathrm{Yb}^{3+}$ in CdSe nanocrystals. J Am Chem Soc, 2013, 135: 13668-13671

172 Liu GK, Chen XY. Spectroscopic properties of lanthanides in nanomaterials. In: Gschneidner KA, Bunzli JCG, Pecharsky VK (eds.). Handbook on the Physics and Chemistry of Rare Earths. Amsterdam: Elsevier, 2007, 37: 99-170

173 Crosswhite HM, Crosswhite H. Parametric model for $f$-shell configurations. I. The effective-operator Hamiltonian. J Opt Soc Am B: Opt Phys, 1984, 1: 246-254

174 Carnall WT, Goodman GL, Rajnak K, Rana RS. A systematic analysis of the spectra of the lanthanides doped into single crystal lanthanum fluoride $\left(\mathrm{LaF}_{3}\right)$. J Chem Phys, 1989, 90: 3443-3457

175 Wybourne BG. Spectroscopic Properties of Rare Earths. New York: Interscience, 1965

176 Morrison CA, Leavitt RP. Spectroscopic properties of triply ionized lanthanides in transparent host crystals. In: Gschneidner KA, Eyring L (eds.). Handbook on the Physics and Chemistry of Rare Earths. Amsterdam: North-Holland, 1981, 5: 461-692

177 Chang NC, Gruber JB, Leavitt RP, Morrison CA. Optical spectra, energy levels, and crystal-field analysis of tripositive rare earth ions in $\mathrm{Y}_{2} \mathrm{O}_{3}$. I. Kramers ions in $C_{2}$ sites. J Chem Phys, 1982, 76 : 3877-3899

178 Luo WQ, Li RF, Liu GK, Antonio MR, Chen XY. Evidence of trivalent europium incorporated in anatase $\mathrm{TiO}_{2}$ nanocrystals with multiple sites. J Phys Chem C, 2008, 112: 10370-10377

179 Ma CG, Brik MG, Kiisk V, Kangur T, Sildos I. Spectroscopic and crystal-field analysis of energy levels of $\mathrm{Eu}^{3+}$ in $\mathrm{SnO}_{2}$ in comparison with $\mathrm{ZrO}_{2}$ and $\mathrm{TiO}_{2}$. J Alloy Compd, 2011, 509: 3441-3451

180 Luo WQ, Fu CY, Li Rf, et al. $\mathrm{Er}^{3+}$-doped anatase $\mathrm{TiO}_{2}$ nanocrystals: crystal-field levels, excited-state dynamics, upconversion, and defect luminescence. Small, 2011, 7: 3046-3056

181 Kiisk V, Reedo V, Karbowiak M, Brik MG, Sildos I. Spectroscopic and crystal field study of $\mathrm{Sm}^{3+}$ in different phases of $\mathrm{TiO}_{2}$. J Phys D Appl Phys, 2009, 42: 125107

182 Liu LQ, Chen XY. Energy levels, fluorescence lifetime and JuddOfelt parameters of $\mathrm{Eu}^{3+}$ in $\mathrm{Gd}_{2} \mathrm{O}_{3}$ nanocrystals. Nanotechnology, 2007, 18: 255704

183 Chen XY, Ma E, Liu GK. Energy levels and optical spectroscopy of $\mathrm{Er}^{3+}$ in $\mathrm{Gd}_{2} \mathrm{O}_{3}$ nanocrystals. J Phys Chem C, 2007, 111: 10404-10411

184 Chen XY, Luo ZD. Group-chain scheme analysis of the energy levels and magnetic properties of $\mathrm{Er}^{3+}$ in the $\mathrm{LiYF}_{4}$ crystal. J Phys-Condens Mat, 1996, 8: 2571-2583

185 Reid MF. $f$-Shell empirical programs and examples. Private Communication.

186 Capobianco JA, Kabro P, Ermeneux FS, et al. Optical spectroscopy, fluorescence dynamics and crystal-field analysis of $\mathrm{Er}^{3+}$ in $\mathrm{YVO}_{4}$. Chem Phys, 1997, 214: 329-340

187 Luo WQ, Li RF, Chen XY. Host-sensitized luminescence of $\mathrm{Nd}^{3+}$ and $\mathrm{Sm}^{3+}$ ions incorporated in anatase titania nanocrystals. J Phys Chem C, 2009, 113: 8772-8777

188 Walsh A, Da Silva JLF, Wei SH, et al. Nature of the band gap of $\mathrm{In}_{2} \mathrm{O}_{3}$ revealed by first-principles calculations and X-ray spectroscopy. Phys Rev Lett, 2008, 100: 167402

189 Fuchs F, Bechstedt F. Indium-oxide polymorphs from first principles: quasiparticle electronic states. Phys Rev B, 2008, 77: 155107

190 Bourlange A, Payne DJ, Egdell RG, et al. Growth of $\operatorname{In}_{2} \mathrm{O}_{3}(100)$ on Y-stabilized $\mathrm{ZrO}_{2}(100)$ by O-plasma assisted molecular beam epitaxy. Appl Phys Lett, 2008, 92: 092117

191 Liang CH, Meng GW, Lei Y, Phillipp F, Zhang LD. Catalytic growth of semiconducting $\operatorname{In}_{2} \mathrm{O}_{3}$ nanofibers. Adv Mater, 2001, 13: 1330-1333

192 Dutta DP, Sudarsan V, Srinivasu P, Vinu A, Tyagi AK. Indium oxide and europium/dysprosium doped indium oxide nanoparticles: sonochemical synthesis, characterization, and photoluminescence studies. J Phys Chem C, 2008, 112: 6781-6785

193 Kim HK, Li CC, Barrios PJ. Erbium-doped indium oxide-films prepared by radio-frequency sputtering. J Vac Sci Technol A, 1994, 12: 3152-3156

194 Choi YG, Yu SM, Chung WJ. Local structural environment and photoluminescence of $\mathrm{Er}^{3+}$ ions doped in indium tin oxide nanopowder. Chem Phys Lett, 2008, 461: 290-293

195 Anticfidancev E, Aride J, Lemaitreblaise M, Porcher P, Taibi M. Emission-spectra and crystal-field calculation of europium-doped C-type $\mathrm{In}_{2} \mathrm{O}_{3}$ oxide. J Alloy Compd, 1992, 188: 242-245

196 Faucher MD, Dexpert-Ghys J. Crystal-field analysis of $\mathrm{Eu}^{3+}$ doped in cubic yttrium sesquioxide. Application of the electrostatic and angular overlap models. Phys Rev B, 1981, 24: 3138-3144

197 Tippins HH. Optical absorption and photoconductivity in band edge of beta- $\mathrm{Ga}_{2} \mathrm{O}_{3}$. Phys Rev, 1965, 140: A316-A319

198 Ueda N, Hosono H, Waseda R, Kawazoe H. Anisotropy of electrical and optical properties in beta- $\mathrm{Ga}_{2} \mathrm{O}_{3}$ single crystals. Appl Phys Lett, 1997, 71: 933-935

199 Geller S. Crystal structure of beta- $\mathrm{Ga}_{2} \mathrm{O}_{3}$. J Chem Phys, 1960, 33: 676-684

200 Nogales E, Mendez B, Piqueras J. Visible cathodoluminescence of Er ions in beta- $\mathrm{Ga}_{2} \mathrm{O}_{3}$ nanowires and microwires. Nanotechnology, 2008, 19: 035713

201 Vincent J, Guillot-Noel O, Binet L, et al. Electron paramagnetic resonance and optical spectroscopy of Er-doped beta- $\mathrm{Ga}_{2} \mathrm{O}_{3}$. J Appl Phys, 2008, 104: 033519

202 Xie HB, Chen LM, Liu YN, Huang KL. Preparation and photoluminescence properties of Eu-doped alpha- and, $\beta-\mathrm{Ga}_{2} \mathrm{O}_{3}$ phosphors. Solid State Commun, 2007, 141: 12-16

203 Wu ZP, Bai GX, Hu QR, et al. Effects of dopant concentration on structural and near-infrared luminescence of $\mathrm{Nd}^{3+}$-doped beta$\mathrm{Ga}_{2} \mathrm{O}_{3}$ thin films. Appl Phys Lett, 2015, 106: 171910

204 Wawrzynczyk D, Nyk M, Samoc M. Synthesis and optical characterization of lanthanide-doped colloidal $\mathrm{Ga}_{2} \mathrm{O}_{3}$ nanoparticles. Chem Phys, 2015, 456: 73-78

205 Layek A, Yildirim B, Ghodsi V, et al. Dual europium luminescence centers in colloidal $\mathrm{Ga}_{2} \mathrm{O}_{3}$ nanocrystals: controlled in situ reduction of Eu (III) and stabilization of Eu (II). Chem Mater, 2015, 27: 6030-6037

206 Liu YS, Luo WQ, Li RF, Chen XY. Spectroscopic evidence of the multiple-site structure of $\mathrm{Eu}^{3+}$ ions incorporated in $\mathrm{ZnO}$ nanocrystals. Opt Lett, 2007, 32: 566-568

207 Liu YS, Luo WQ, Li RF, Zhu HM, Chen XY. Near-infrared luminescence of $\mathrm{Nd}^{3+}$ and $\mathrm{Tm}^{3+}$ ions doped $\mathrm{ZnO}$ nanocrystals. Opt Express, 2009, 17: 9748-9753

208 Luo WQ, Li RF, Liu YS, Chen XY. Sensitized luminescence of $\mathrm{Sm}^{3+}$, $\mathrm{Eu}^{3+}$-codoped $\mathrm{TiO}_{2}$ nanoparticles. J Nanosci Nanotechnol, 2010, 10: 1693-1698

209 Wang DD, Xing GZ, Gao M, et al. Defects-mediated energy transfer in red-light-emitting Eu-doped $\mathrm{ZnO}$ nanowire arrays. J Phys Chem C, 2011, 115: 22729-22735

210 Jin Y, Zhang JH, Lu SZ, et al. Fabrication of $\mathrm{Eu}^{3+}$ and $\mathrm{Sm}^{3+}$ codoped micro/nanosized $\mathrm{MMoO}_{4}(\mathrm{M}=\mathrm{Ca}, \mathrm{Ba}$, and $\mathrm{Sr})$ via facile hydrothermal method and their photoluminescence properties through energy transfer. J Phys Chem C, 2008, 112: 5860-5864

211 Kong JT, Zheng W, Liu YS, et al. Persistent luminescence from $\mathrm{Eu}^{3+}$ in $\mathrm{SnO}_{2}$ nanoparticles. Nanoscale, 2015, 7: 11048-11054

212 Wu XJ, Meng FZ, Zhang ZZ, et al. Broadband down-conversion for silicon solar cell by ZnSe/phosphor heterostructure. Opt Express, 2014, 22: A735-A741

213 Wu XJ, Zhang ZZ, Meng FZ, et al. Core-shell-like $\mathrm{Y}_{2} \mathrm{O}_{3}:\left[\left(\mathrm{Tb}^{3+}-\mathrm{Yb}^{3+}\right)\right.$, $\left.\mathrm{Li}^{+}\right] / \mathrm{CdZnS}$ heterostructure synthesized by super-close-space sub- 
limation for broadband down-conversion. Nanoscale, 2014, 6: 4745-4749

214 Zhu YS, Cui SB, Chen X, et al. Efficient energy transfer from inserted CdTe quantum dots to $\mathrm{YVO}_{4}: \mathrm{Eu}^{3+}$ inverse opals: a novel strategy to improve and expand visible excitation of rare earth ions. $\mathrm{Na}$ noscale, 2014, 6: 8075-8083

Acknowledgements This work was supported by the National Basic Research Program of China (2014CB845605), the Special Project of National Major Scientific Equipment Development of China (2012YQ120060), the National Natural Science Foundation of China (NSFC) (U1305244 and 21325104), the Chinese Academy of Sciences (CAS)/ State Administration of Foreign Experts Affairs International
Partnership Program for Creative Research Teams, the CAS CrossDisciplinary \& Collaborative Research Team Program, and the Scientific Equipment Development Project of the CAS (YZ201210), the Key Project of Science and Technology of Fujian Province (2013H0060) and the NSF of Fujian Province for Young Scientists (2014J05070).

Author contributions Luo W and Chen X surveyed the literature and discussed the contents. Luo W, Liu Y and Chen X wrote the manuscript and designed the figures. All authors contributed to the general discussion and revision of the manuscript.

Conflict of interest The authors declare that they have no conflict of interest.

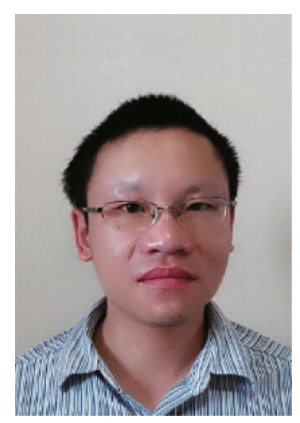

Wenqin Luo earned his BSc degree in chemistry from Xiamen University in China (2002). He received his PhD (2010) in materials physics and chemistry from Fujian Institute of Research on the Structure of Matter (FJIRSM), CAS. He joined the faculty at Huzhou University in 2014. His research interest focuses on the chemical synthesis and optical spectroscopy of lanthanide-doped nanoparticles.

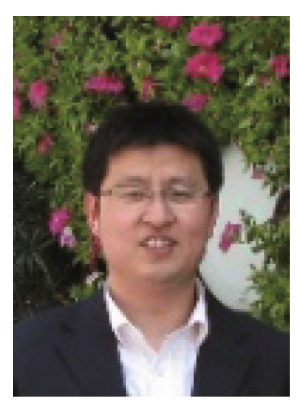

Yongsheng Liu was born in Shandong, China. He earned his BSc degree (2001) in chemistry from Shandong Normal University. He received his MSc (2007) and PhD (2010) degrees in physical chemistry from FJIRSM, CAS. He joined Prof. Xueyuan Chen's group as an assistant professor in 2010 and was promoted to associate professor in 2012. Currently, his research interest focuses on the optical spectroscopy and bioapplications of lanthanide-doped nanomaterials.

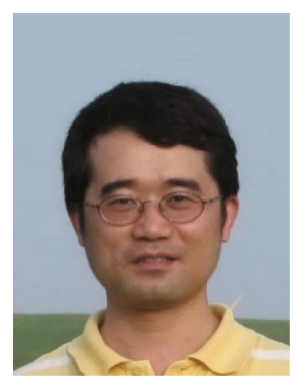

Xueyuan Chen earned his BSc degree from the University of Science and Technology of China (1993) and his PhD degree from FJIRSM, CAS (1998). From 2001 to 2005, he was a postdoctoral research associate at the Chemistry Division of Argonne National Laboratory, US Department of Energy, where he studied the photophysics and photochemistry of heavy elements. In 2005, he joined the faculty at FJIRSM, where he is currently professor and group leader in material chemistry and physics. His research focuses on the chemistry, optical spectroscopy and bioapplications of lanthanide-doped luminescent nanomaterials.

中文摘要 三价稀土离子掺杂半导体纳米晶具有独特的光学性能, 其在光电子器件、平板显示和苂光生物标记等方面的潜在应用前景, 获得了人们的普遍关注. 本文从材料制备、光谱性能、电子能级结构及能量传递机理等几个方面系统总结了近年来稀土掺杂半导体纳 米晶的最新研究进展. 本文重点综述了通过湿化学方法把稀土离子掺杂进入半导体纳米晶晶格位置的合成策略、稀土离子在半导体纳 米晶中的格位分布及半导体纳米晶到稀土离子能量传递机理. 同时, 还总结了近年来通过能级拟合计算来探索稀土在半导体纳米晶中的 能级结构和晶体场参数的工作. 这些方面的研究对于深入理解稀土掺杂半导体纳米晶的光物理具有重要意义. 最后, 针对稀土掺杂半导 体纳米晶未来的发展趋势与努力的方向作了进一步的前景展望. 